\title{
Infrared Spectra of the Crystalline Inorganic Borates
}

\author{
C. E. Weir and R. A. Schroeder
}

(April 8, 1964)

\begin{abstract}
Infrared absorption spectra of anhydrous, crystalline, inorganic borates were obtained in the $2000 \mathrm{~cm}^{-1}$ to $300 \mathrm{~cm}^{-1}$ range. Compounds with $\mathrm{B}^{10}$ and $\mathrm{B}^{11}$ isotopes were prepared to assist interpretation. Spectral bands for all orthoborates and pyroborates and some metaborates could be assigned satisfactorily. Borates with complex ring-type anions generally exhibited spectra of such complexity that only superficial interpretation was attempted. From correlations between spectra and structure it appears that boron in 3-fold or in 4-fold coordination can be identified with reasonable assurance on the basis of the infrared spectrum alone. Absorption bands are tabulated for about 80 borates and typical spectra are shown.
\end{abstract}

\section{Introduction}

The chemistry of systems containing boron oxide and the structures of glassy and crystalline inorganic borates are of considerable interest in this laboratory. In such work it is evident that the information available from infrared spectroscopy should be of considerable value. Such spectra are easily and rapidly obtained on very small quantities of material and contain direct information on the nature of the borate anion, the coordination of the boron, the strength of the $\mathrm{B}-\mathrm{O}$ bonds, etc. Although this information is implicit in the absorption spectrum, an explicit derivation of the desired data requires a thorough understanding of the spectrum which is rarely available for any crystalline solid. This work is designed to advance the understanding of the spectra of the crystalline anhydrous borates by recording and correlating the spectrum with the structure of the crystal where this is known. Most structures are unknown so that the data obtained must be interpreted by comparisons, wherever possible, with spectra of crystals whose structure is known.

In addition to the general interest in borates, there is a specific interest here in crystals containing planar trigonal ions. Previous studies on the infrared spectra of carbonates, nitrates, and borates [57 ${ }^{1}$ showed many close similarities, but demonstrated a striking difference in the spectra of the borates and the carbonate having the vaterite structure. The reason for the difference was left unresolved. Numerous absorption bands were found in low temperature spectra [48] of single crystals of carbonates and nitrates. These were attributed to combinations of fundamentals and lattice modes. The present survey was considered to be a preliminary requirement to a proposed study of crystals of the borates at low temperatures.

Previous work on the spectra of the borates will not be reviewed in detail here because the majority of such work consists of reports on only one or two

\footnotetext{
${ }^{1}$ Figures in brackets indicate the literature references at the end of this paper.
}

materials. Such references will be discussed in connection with specific spectra. The only comprehensive study of the infrared spectra of anhydrous borates appears to be the recent work of Hart and Smallwood [18]. They studied a large number of borates, but the frequency range used did not extend to sufficiently low frequencies to observe all the fundamental vibrations of interest here. Hart and Smallwood concluded that assignment and interpretation of the more complex spectra was rather difficult. They did not examine several borates for which detailed crystal structures have been reported recently.

In this report, data are tabulated for infrared absorption bands of a number of inorganic borates. In many instances isotopic substitution was employed to assist in the interpretation of the spectra. The data are interpreted in terms of the structure of the anion wherever this is possible.

\section{Experimental Method}

Infrared spectra were obtained with a doublebeam dual-grating spectrometer covering the range $2000 \mathrm{~cm}^{-1}$ to $200 \mathrm{~cm}^{-1}$. Higher frequencies were not employed because it was known [18] that fundamentals and most strong overtones and combination bands did not fall above $2000 \mathrm{~cm}^{-1}$ in the crystalline compounds. Dry air was circulated through the spectrometer to eliminate interference from atmospheric moisture in the $400 \mathrm{~cm}^{-1}$ region. Although the range of the spectrometer extended to $200 \mathrm{~cm}^{-1}$ a practical limit of $300 \mathrm{~cm}^{-1}$ appeared to be imposed by the available energy.

Spectra were obtained under two conditions, first as a suspension in light petroleum oil, and second as a film produced by evaporation of a $\mathrm{CCl}_{4}$ suspension. Both $\mathrm{KBr}$ and $\mathrm{CsBr}$ windows were used with a similar window being placed in the reference beam in all experiments. Mull spectra were used principally in the $1100 \mathrm{~cm}^{-1}$ to $300 \mathrm{~cm}^{-1}$ region while film spectra were found useful in the region above $1000 \mathrm{~cm}^{-1}$ where some interference by absorption in the mineral oil occurred. In the case of film spectra it was fre- 
quently found useful to expand the absorption peaks along the intensity axis, a similar expansion for the suspension was not possible because of the undesirable magnification of weak absorption bands in the oil. In the region where the two spectra overlapped the positions of absorption bands frequently showed discrepancies of at most $2 \mathrm{~cm}^{-1}$. Under these circumstances the mull spectra were assumed to be correct and a linear correction applied to the absorption bands of the film spectra. The correction is probably not linear if it arises from solubility effects in the alkali halide. However, the corrections are quite small and are not expected to affect the tabulated data appreciably.

\section{Preparation of Borates}

Borates were prepared using orthoboric acid and the metal carbonate or the metal oxide if the carbonate was unavailable. To reduce the loss of boric acid on ignition most reactions were initiated in aqueous suspensions. The residue on evaporation was subjected to several cycles of heating and grinding until reaction was judged to be complete. For most materials the maximum temperature employed was below the solidus temperature reported in the corresponding phase diagram. However, in the preparation of the alkali borates which crystallized as hydrates from solution, those specimens which melted congruently were melted prior to use. The resulting glasses were crystallized at temperatures below the melting points. The alkali borates that melted incongruently were dehydrated for $24 \mathrm{hr}$ at temperatures $10-20$ deg $\mathrm{C}$ below the reported incongruent melting points.

For isotope enrichment studies, specimens were prepared using $\mathrm{H}_{3} \mathrm{~B}^{11} \mathrm{O}_{3}\left(98.3 \% \mathrm{~B}^{11}\right)$ and $\mathrm{H}_{3} \mathrm{~B}^{10} \mathrm{O}_{3}$ $\left(96.5 \% \mathrm{~B}^{10}\right)$ which were obtained from the Oak Ridge National Laboratory. Such pairs of specimens were synthesized in a limited number of cases, usually one for each major structure type expected except in the alkaline earth borates where more were prepared.

Powder x-ray diffraction patterns were obtained on all preparations. The diffraction patterns were checked against reported results where these were available. In many instances powder diffraction data were not available but the x-ray data served to check for contamination by metal oxide or related borates. In many instances the purity of the preparation was checked by means of a polarizing microscope.

In describing the composition of the borates prepared, the following system will be used here and to some extent throughout the paper: The molar ratios will be given with the metal oxide first and the borate as $\mathrm{B}_{2} \mathrm{O}_{3}$ last. Thus a $4: 1$ compound will contain 4 moles of metal oxide and 1 mole of boric oxide. Using this convention the following borates were prepared:

1. Lithium borates $1: 1,1: 2,1: 3,1: 4$, and $1: 5$ were prepared using the data of Mazzetti and Carli [38] as modified by Sastry and Hummel [46]. The recent data of Rollet and Bouaziz [45] which Tshow additional $3: 1$ and $3: 2$ compounds could not be v erified.

2. Sodium borates $2: 1,1: 1,1: 2,1: 3$, and $1: 4$ were synthesized in accordance with the phase diagram given by Morey and Merwin [40]. It should be noted that these authors report a $2: 1$ compound although it is not shown on the phase diagram.

3. Potassium borates $1: 1,1: 2,1: 3,1: 4$, and $1: 5$ were prepared using the data of Rollet [44].

4. Calcium borates $3: 1,2: 1,1: 1$, and $1: 2$ were prepared in accordance with the diagram given by Carlson [9].

5. Strontium borates $3: 1,2: 1,1: 1$, and $1: 2$ were prepared. A phase diagram for the system does not appear to be available to date although Hart and Smallwood [18] apparently have phase equilibrium data. The $1: 4$ compound corresponding to a known barium borate does not appear to exist.

6. Barium borates $3: 1,1: 1,1: 2$, and $1: 4$ were prepared in accordance with the results of Levin and McMurdie [34].

7. Magnesium borates $3: 1,2: 1$, and $1: 1$ were prepared using the diagram reported by Davis and Knight [10].

It should be noted that there is some confusion concerning the $1: 1$ compound which, according to Davis and Knight, decomposes at temperatures above $988{ }^{\circ} \mathrm{C}$ into $\mathrm{B}_{2} \mathrm{O}_{3}$ and the $2: 1$ compound. The powder diffraction pattern in the ASTM file is incorrectly labeled, a point which has been discussed in detail by Block, Burley, Perloff, and Mason [6]. A 1:1 mixture heated at $900{ }^{\circ} \mathrm{C}$ forms a product which yields a very complex powder diffraction pattern. It cannot be safely concluded that this pattern is free from the 2:1 borate. However, microscopic examination showed that the $1: 1 \mathrm{com}-$ pound prepared in this manner was a single phase differing from the $2: 1$ compound.

8. Cadmium borates $3: 1,2: 1$, and $1: 2$ were prepared. The phase diagram given by Subbarao and Hummel [53] reported $3: 2$ and $2: 3$ compounds but no $1: 2$ compound. The existence of the $3: 2$ compound was questioned by Hart and Smallwood [18] on the basis of $x$-ray and infrared data and later by Hand and Krogh-Moe [16]. Results here confirm the absence of the $3: 2$ compound. Hand and Krogh-Moe [16] have shown that the $2: 3$ compound is in fact a $1: 2$ compound.

9. Zinc borates $5: 2,4: 3$, and $1: 2$ were prepared. The original work of Ingerson, Morey, and 'Tuttle on the $\mathrm{ZnO}-\mathrm{B}_{2} \mathrm{O}_{3}$ system [22] reported the existence of $5: 2$ and $1: 1$ compounds. Harrison and Hummel [17] later confirmed these findings and reported polymorphic forms of both compounds. However, Smith, Garcia-Blanco, and Rivoir [50, 51] showed from single crystal diffraction studies that the $1: 1 \mathrm{com}-$ pound of empirical formula $\mathrm{Zn}\left(\mathrm{BO}_{2}\right)_{2}$ had the structural formula $\mathrm{Zn}_{4} \mathrm{O}\left(\mathrm{BO}_{2}\right)_{6}$ and was therefore a $4: 3$ compound. Recently Bauer [2], who appeared to be unaware of the previous reports of Smith et al. [50, 51 , concluded that the compounds existing in the system were $3: 1$ (rather than $5: 2$ ), $1: 1$, and $1: 2$. 
Data obtained here by x-ray diffraction and infrared absorption confirm the existence of the $1: 2$ compound reported by Bauer [2] but are in agreement with the $5: 2$ ratio rather than the $3: 1$ value.

10. Lead borates $2: 1,5: 4,1: 1$, and $1: 2$ were prepared. The data of Geller and Bunting [13] did not show a $1: 1$ lead borate but on the basis of $x$-ray data here it appears probable that this compound exists.

11. Rare earth borates having the ratios $3: 1,1: 1$, and $1: 3$ were prepared. Levin, Roth, and Martin [31] have reported on the $1: 1$ compounds and the $3: 1,1: 1$, and $1: 3$ compounds in the $\mathrm{La}_{2} \mathrm{O}_{3}-\mathrm{B}_{2} \mathrm{O}_{3}$ system were described by Levin, Robbins, and Waring [33]. Further work on the system by Levin and McDaniel [35] shows the existence of some compounds having nominal ratios of $3: 1$ and $1: 3$ for many of the other rare earths. Although the exact compositions and properties are not established to date, the materials were prepared for study.

12. Bismuth borates $2: 1,3: 5,1: 3$, and $1: 4$ were formed in accordance with the phase diagram of Levin and McDaniel [32].

13. Cobalt borates $3: 1$ and $2: 1$ were prepared using the finding's of Konovalov [23].

14. Miscellaneous borates were prepared as follows: a. beryllium borate, presumably of composition $3: 1[56]$.

b. indium borate, $1: 1$ [31].

c. nickel borate $3: 1$. This product was formed using NiO. Attempts to prepare the $2: 1$ nickel borate analogous to the cobalt compound met with no success. The failure to form other compounds might be attributed to the high temperature required to induce reactivity in $\mathrm{NiO}$. The use of $\mathrm{NiCO}_{3}$ might facilitate formation of other borates.

d. rubidium borate 1:5 [27].

e. cesium borates $1: 3$ and $1: 9[26]$.

f. two copper borates which appear in the system $\mathrm{CuO}-\mathrm{B}_{2} \mathrm{O}_{3}$. One compound is apparently a $3: 1$ compound, forming large green crystals. The crystals are highly birefringent, biaxial, negative with $2 \mathrm{~V} \approx 15^{\circ}, \alpha=1.78, \beta>2.00, \gamma>2.00$. The other compound is probably a $1: 1$ compound and is azure blue. The properties of these crystals have not been determined with certainty. They may be uniaxial negative or biaxial negative.

g. $\mathrm{TaBO}_{4}$ reported by Zaslavskii and Zvinchuk [61] was prepared with some difficulty. The samples prepared here were not suitable for use because of impurities. The material actually used was supplied by Mrose [41] who has studied this compound in detail.

h. The two isostructural compounds $\mathrm{BPO}_{4}$ and $\mathrm{BAsO}_{4}$, were prepared according to the data of Schulze [49]. Attempts to prepare the antimony analog, $\mathrm{BSbO}_{4}$ were not successful.

14. Several borates previously reported could not be prepared, in particular, ferrous and manganous borates [6]. Oxidation proceeding in the normal preparation techniques was probably responsible for the failure to obtain these borates.

\section{Anion Structure and Vibrational Analysis}

\subsection{Structures}

The fact that a number of borates are formed with the same cation is due to the polymeric behavior of the borate ion. Complex anions can arise from polymerization of basic triangular $\mathrm{BO}_{3}$ or tetrahedral $\mathrm{BO}_{4}$ units alone or in combination. The anion structures known to exist have been reported as follows:

The isolated planar anion $\mathrm{BO}_{3}^{-3}$ is found in $\mathrm{LuBO}_{3}$, $\mathrm{InBO}_{3}$, and $\mathrm{ScBO}_{3}$ which have the calcite structure $[31,52]$, in $\mathrm{LaBO}_{3}$ with the aragonite structure [31], and in $3 \mathrm{MgO} \cdot \mathrm{B}_{2} \mathrm{O}_{3}[5]$. The borates isostructural with $3 \mathrm{MgO} \cdot \mathrm{B}_{2} \mathrm{O}_{3}-3 \mathrm{CoO} \cdot \mathrm{B}_{2} \mathrm{O}_{3}, \quad 3 \mathrm{NiO} \cdot \mathrm{B}_{2} \mathrm{O}_{3}$, and $3 \mathrm{CdO} \cdot \mathrm{B}_{2} \mathrm{O}_{3}$ - must also have this anion [42].

The tetrahedral anion $\mathrm{BO}_{4}^{-5}$ has been reported in $\mathrm{TaBO}_{4}[6]$ and in $\mathrm{BPO}_{4}$ and $\mathrm{BAsO}_{4}$ [49].

The pyroborate ion $\mathrm{B}_{2} \mathrm{O}_{5}^{-2}$ is formed by connecting two triangular $\mathrm{BO}_{3}$ groups at one corner. This ion occurs in $2 \mathrm{MgO} \cdot \mathrm{B}_{2} \mathrm{O}_{3}[54]$ and in $2 \mathrm{CoO} \cdot \mathrm{B}_{2} \mathrm{O}_{3}$, $2 \mathrm{MnO} \cdot \mathrm{B}_{2} \mathrm{O}_{3}, 2 \mathrm{FeO} \cdot \mathrm{B}_{2} \mathrm{O}_{3}$, and $2 \mathrm{CdO} \cdot \mathrm{B}_{2} \mathrm{O}_{3}\left[\begin{array}{ll}6, & 16]\end{array}\right.$ which are isostructural.

An infinite chain of $\mathrm{BO}_{3}$ triangles connected at one corner was shown to be present in $\mathrm{CaO} \cdot \mathrm{B}_{2} \mathrm{O}_{3}$ by Zachariasen [36, 58, 59] and in $\alpha-\mathrm{Li}_{2} \mathrm{O} \cdot \mathrm{B}_{2} \mathrm{O}_{3}[21]$.

The boroxol ring, a six-membered ring formed by $3 \mathrm{BO}_{3}$ groups, contains alternate boron and oxygen atoms and 3 oxygen atoms out of the ring, each connected to one of the boron atoms. This unit occurs in $\mathrm{K}_{2} \mathrm{O} \cdot \mathrm{B}_{2} \mathrm{O}_{3}[60]$ and $\mathrm{Na}_{2} \mathrm{O} \cdot \mathrm{B}_{2} \mathrm{O}_{3}[12,37]$. The rings are interconnected by means of the external oxygen atoms.

Two six-membered rings similar to the boroxol ring are coupled by means of a tetrahedral boron atom common to both rings to form the $\mathrm{B}_{5} \mathrm{O}_{8}$ anion. This ion is found in $\mathrm{K}_{2} \mathrm{O} \cdot 5 \mathrm{~B}_{2} \mathrm{O}_{3}$ and $\mathrm{Rb}_{2} \mathrm{O} \cdot 5 \mathrm{~B}_{2} \mathrm{O}_{3}$ [27]. Individual $\mathrm{B}_{5} \mathrm{O}_{8}$ units are interconnected by the external oxygen atoms.

A six-membered ring containing 2 triangular and 1 tetrahedral boron is known in $\mathrm{Cs}_{2} \mathrm{O} \cdot 3 \mathrm{~B}_{2} \mathrm{O}_{3}$. This unit is connected to similar units through the off-ring oxygen atoms [29].

The basic structural unit in $\mathrm{Li}_{2} \mathrm{O} \cdot 2 \mathrm{~B}_{2} \mathrm{O}_{3}$ is a $\mathrm{B}_{4} \mathrm{O}_{7}^{-2}$ group consisting of $2 \mathrm{BO}_{4}$ tetrahedra and $2 \mathrm{BO}_{3}$ triangles. The anion is an 8-membered ring in which the opposite tetrahedral $\mathrm{BO}_{4}$ groups provide an oxygen bridge. Similar units are interconnected to form a 3 dimensional network [28].

The structure of $\mathrm{BaO} \cdot 2 \mathrm{~B}_{2} \mathrm{O}_{3}$ has been reported to consist of a network containing rings similar to those found in $\mathrm{Cs}_{2} \mathrm{O} \cdot 3 \mathrm{~B}_{2} \mathrm{O}_{3}$ and $\mathrm{K}_{2} \mathrm{O} \cdot 5 \mathrm{~B}_{2} \mathrm{O}_{3}$. The two sets of rings are connected by means of the off-ring oxygen atoms and form a 3 dimensional network [7].

Lehmann and Teiss [30] have observed two additional forms of $\mathrm{Li}_{2} \mathrm{O} \cdot \mathrm{B}_{2} \mathrm{O}_{3}$ one of which denoted as the $\beta$ form has a structure similar to that of cristobalite, the other denoted as the $\gamma$ form appears to be similar to the cubic form of $\mathrm{HBO}_{2}$.

Finally, the compound $4 \mathrm{ZnO} \cdot 3 \mathrm{~B}_{2} \mathrm{O}_{3}$ contains only tetrahedral boron atoms. The tetrahedra are coupled at certain corners to form a complex 3 dimensional array $[50,51]$. 
The compounds $\mathrm{TaBO}_{4}[61]$ and $\mathrm{BPO}_{4}$ and $\mathrm{BAsO}_{4}$ [49] also contain only tetrahedral boron atoms. In the latter two compounds the borate tetrahedra share corners with $\mathrm{PO}_{4}$ and $\mathrm{AsO}_{4}$ tetrahedra, respectively, so that each oxygen atom is part of two different tetrahedra. The empirical formulas of these two compounds could be written $\mathrm{BO}_{2} \mathrm{PO}_{2}$ and $\mathrm{BO}_{2} \mathrm{AsO}_{2}$. $\mathrm{TaBO}_{4}$ is isostructural with zircon [61] and contains discrete $\mathrm{BO}_{4}$ tetrahedra.

\subsection{Vibrational Analysis}

Both the planar triangle and the tetrahedral unit have been discussed in detail many times and only the results will be indicated here [19]. For an isolated, planar, trigonal $\mathrm{BO}_{3}$ group of $\mathrm{D}_{3 h}$ symmetry there are four fundamental modes of vibration; $\nu_{1}$ - the symmetrical stretch, $\nu_{2}$ - the out-of-plane bend, $\nu_{3}$ the antisymmetric stretch, and $\nu_{4}$-the in-plane bend. Both $\nu_{3}$ and $\nu_{4}$ are doubly degenerate and $\nu_{1}$ is ordinarily inactive in the infrared. In a given crystalline environment $\nu_{1}$ may become active and the degeneracies may be removed from $\nu_{3}$ and $\nu_{4}$. The nominal positions expected are $\nu_{1}-950 \mathrm{~cm}^{-1}$, $\nu_{2}-750 \mathrm{~cm}^{-1}, \nu_{3}-1250 \mathrm{~cm}^{-1}$, and $\nu_{4}-600 \mathrm{~cm}^{-1}$ [57] with the exact positions varying somewhat with the crystal field. An isolated tetrahedral anion of symmetry $\mathrm{T}_{d}$ should also exhibit 4 fundamentals, a normally inactive symmetric stretch- $\nu_{1}$, an inactive doubly degenerate mode- $\nu_{2}$ which involves bond bending, a strongly active triply degenerate stretching mode- $\nu_{3}$, and another active bending mode- $\nu_{4}$ which is also triply degenerate. In a given crystal $\nu_{1}$ and $\nu_{2}$ may become active and the degeneracies may be removed from $\nu_{2}, \nu_{3}$, and $\nu_{4}$. The expected locations of the bands can be inferred from data obtained on similar tetrahedral anions [19]. It is anticipated that $\nu_{3}$ should occur near $1000 \mathrm{~cm}^{-1}, \nu_{1}$ below $950 \mathrm{~cm}^{-1}$, $\nu_{4}$ near $600 \mathrm{~cm}^{-1}$ and $\nu_{2}$ below $600 \mathrm{~cm}^{-1}$.

From isotope substitution in the trigonal ion it is expected that $\nu_{1}$ will be unchanged, $\nu_{2}{ }^{\mathrm{B}_{10}} / \nu_{2}{ }^{\mathrm{B}_{11}} \approx 1.04$ and $\nu_{3}{ }^{\mathrm{B}_{10}} \nu_{4}{ }^{\mathrm{B}_{10}} / \nu_{3}{ }^{\mathrm{B}_{11}} \nu_{4}{ }^{\mathrm{B}} 11 \approx 1.04$. For the tetrahedral anion $\nu_{1}$ and $\nu_{2}$ will be unchanged and $\nu_{3}{ }^{\mathrm{B}_{10}} \nu_{4}{ }^{\mathrm{B}_{10}}$ / $\nu_{3}^{B}{ }^{B 1} \nu_{4}{ }^{11^{\mathrm{B}}} \approx 1.04$. In the more complex anions it is possible that vibrations derived from those for the simple triangular or tetrahedral units might be detected. These vibrations would be shifted in frequency by the covalent bonding of the simple units into the complex anion structure but the isotopic frequency shift should serve to give some indication of the nature of the vibrations. As will be shown later, this type of identification which has been referred to as group frequency analysis in connection with spectra of organic materials, may have some justification.

In the pyroborate ion all $\mathrm{B}-\mathrm{O}$ bonds are not equivalent, as shown by B] ock et al. [6] in $2 \mathrm{MgO} \cdot \mathrm{B}_{2} \mathrm{O}_{3}$, and there is no symmetry. The ion is therefore in point group $\mathrm{C}_{1}$, all vibrations are of species $\mathrm{A}$ and all are infrared active. There are 15 normal modes of vibration and some idea of the nature of these modes may be obtained as follows:

Twelve normal modes would be expected from internal vibrations of the two coupled triangular units. There should be two each derived from the $\nu_{1}$ and $\nu_{2}$ type vibrations and 4 each from the $\nu_{3}$ and $\nu_{4}$ types. The extra 3 modes will be derived from the motions of one trigonal unit with respect to the other and arise essentially from the loss of the 3 translational modes of one unit. These latter three modes are expected to be of rather low frequency because of the large masses involved and might lie oustide the range of the present studies. The two modes derived from $\nu_{1}$ and $\nu_{2}$ can be visualized as in phase and out of phase motions in the coupled triangular units. Those derived from the originally degenerate $\nu_{3}$ and $\nu_{4}$ vibrations are somewhat difficult to visualize. However, the effect of isotopic substitution is expected to parallel the behavior of the isolated trigonal ion. Thus modes derived from $\nu_{1}$ and $\nu_{4}$ will be relatively unaffected, while those derived from $\nu_{2}$ and $\nu_{3}$ will be affected markedly. The three low frequency twisting or rocking modes should also be insensitive to isotopic substitution because of the relatively large masses involved.

The boroxol ring has been studied extensively by Goubeau and his coworkers [14, 15] who have proposed frequency assignments. The $\mathrm{B}_{3} \mathrm{O}_{6}$ ring is of point group symmetry $D_{3 \mathrm{~h}}$ and of the 21 total normal modes only a few are expected to be normally active in the isolated ring. The active modes are 2 of species $\mathrm{A}_{2}^{\prime \prime}$ and 5 of species $\mathrm{E}^{\prime}$. In metaboric acid Goubeau and Hummel have assigned these bands as follows: species $\mathrm{A}_{2}^{\prime \prime} ; \nu_{6}-591 \mathrm{~cm}^{-1} \nu_{7}-476$ $\mathrm{cm}^{-1}$; and species $\mathrm{E}^{\prime} ; \nu_{8}-1375 \mathrm{~cm}^{-1}, \nu_{9}-1150 \mathrm{~cm}^{-1}$, $\nu_{10}-735 \mathrm{~cm}^{-1}, \quad \nu_{11}-456 \mathrm{~cm}^{-1}, \quad \nu_{12}-280 \mathrm{~cm}^{-1}$. From these assignments it appears that not more than 6 fundamentals should be observed for this unit in these experiments, with, $\nu_{12}$ below the range studied here.

The other known metaborate structure consists of infinite chains of trigonal borate groups connected through two oxygen atoms. There is no symmetry and all vibrations will be infrared active in species $\mathrm{A}$. The unit cell contains two chains, each of empirical formula $\left(\mathrm{BO}_{2}\right)_{4}$. The spectrum, therefore, should resemble that of the pyroborate group, as the structural units consist of two coupled pyroborate groups. More bands can be expected because of the larger number of normal modes but the frequencies and isotope dependence should resemble similar data on the pyroborates.

The complex ring systems reported in $\mathrm{K}_{2} \mathrm{O} \cdot 5 \mathrm{~B}_{2} \mathrm{O}_{3}$, $\mathrm{Cs}_{2} \mathrm{O} \cdot 3 \mathrm{~B}_{2} \mathrm{O}_{3}, \quad \mathrm{Li}_{2} \mathrm{O} \cdot 2 \mathrm{~B}_{2} \mathrm{O}_{3}$, and $\mathrm{BaO} \cdot 2 \mathrm{~B}_{2} \mathrm{O}_{3}$ have no symmetry elements. Therefore, all modes are active and a very complex spectrum is to be expected. No detailed interpretation of these spectra are to be expected unless group frequency analysis should prove useful.

The zinc metaborate structure is very complex and complete analysis is not anticipated. From the x-ray structure analysis $[50,51]$, in a given tetrahedron one oxygen is connected to a zinc atom while the other 3 atoms are shared by 3 different tetrahedra. Although the structural analysis indicates all $\mathrm{B}-\mathrm{O}$ 
bonds to be similar, this appears to be most unlikely and it seems more reasonable to consider the oxygen coupled to the zinc to be unique. Under these circumstances it is useful to consider the svmmetry of the tetrahedral unit to approximate $\mathrm{C}_{3 \mathrm{v}}$ rather than $\mathrm{T}_{\mathrm{d}}$. In this approximation the basic unit can be visualized as containing a central atom bonded to two different kinds of atoms, one the oxygen bound to zinc, and the other, the three oxygens connected into the network. The latter three atoms can be visualized as having large effective masses conferred by the coupling into the other tetrahedra. On the basis of these assumptions the spectrum would be expected to bear some resemblance to that of an $\mathrm{XYZ}_{3}$ type molecule with allowances for network perturbation effects. As will be shown later this viewpoint permits a reasonable interpretation of the observed data.

\section{Presentation of Data}

The following system is adopted for presenting the data:

Observed absorption bands are tabulated for each material studied with the following abbreviations used to denote the character of the bands; s-strong, m-medium, w-weak, b-broad, sh-shoulder, $\mathrm{v}$-very. It is understood that the bands may vary in character with the method of obtaining the spectrum, concentration, etc., so that the descriptions apply only to the bands observed here. The existence of the bands listed is considered to be well established because all spectra were obtained at least in duplicate by two different methods. Doubtful bands are indicated with a question mark.

Representative spectra are given for some but not all materials studied with frequencies in wave numbers indicated for the various bands. Two or more spectra are given in each figure with the spectra displaced vertically to eliminate overlapping. The transmittance axis, therefore, cannot be subdivided quantitatively but all spectra are referred to the same intensity scale and are directly comparable. Spectra shown are in most instances composite tracings of mull spectra below $1000 \mathrm{~cm}^{-1}$ and film spectra above $1000 \mathrm{~cm}^{-1}$. In some instances film spectra are shown throughout the range used.

Borates are classified with respect to type of anion with all borates of a given type discussed together. Such a separation is desirable because spectra of compounds containing similar anions are expected to be comparable. Although the major separation is in terms of the empirical formula of the anion, subdivision in terms of actual structure is made where the structure is known.

\section{Results and Discussion}

\subsection{Orthoborates}

Orthoborates, $\mathrm{X}_{\mathrm{m}}\left(\mathrm{BO}_{3}\right)_{\mathrm{n}}$, are formed by the $3: 1$ divalent metal borates and the $1: 1$ trivalent metal borates. From the point of view of infrared spectroscopy these compounds may be interpreted, in many instances, in terms of the simple planar trigenal $\mathrm{BO}_{3}^{-3}$ ion.

\section{a. Divalent Metal Orthoborates}

The spectra of all of the divalent metal orthoborates with the exception of $3 \mathrm{BeO} \cdot \mathrm{B}_{2} \mathrm{O}_{3}$ can be interpreted in terms of the six fundamentals of the perturbed $\mathrm{BO}_{3}^{-3}$ ion. Typical spectra are shown in figures 1 and 2 and the observed bands and assignments are tabulated for the normal iostopic distribution in table 1. The assignments for the bands are supported by the isotopic shifts given in table 2 for some of the compounds. In figure 1 a definite split in the $\nu_{3}$ band is noted for the $\mathrm{B}^{11}$ and $\mathrm{B}^{10}$ compounds. The split is not observed in the normal strontium borate although structure in the $\nu_{3}$ band is apparent. All isotopically "pure" compounds showed such a split which produced two highly unsymmetrical $\nu_{3}$ bands. The unsymmetrical nature of the bands caused some concern that the apparent splitting might be an artifact caused by variation of index of refraction of the specimen with frequency. Several different experiments were performed using different dispersing media without changing the position or shape of the splitting peak. The split of $\nu_{3}$ is concluded to be real. Several weak bands in the 750 $\mathrm{cm}^{-1}-1000 \mathrm{~cm}^{-1}$ region are of uncertain origin. Several of these bands observed in the normal strontium borate are eliminated in the $\mathrm{B}^{10}$ and $\mathrm{B}^{11}$ compounds so that they may arise from coupling of vibrations between trigonal ions containing different boron isotopes. Such effects have been discussed by Decius [11]. In addition it is not clear from the spectrum or the experiments on isotope substitution which band corresponds to $\nu_{1}$. From comparisons with the carbonates and nitrates and from other data to be given later it is concluded that the weak band near $1000 \mathrm{~cm}^{-1}$ in these spectra corresponds to $\nu_{1}$. The bands near $900 \mathrm{~cm}^{-1}$ are taken to represent combinations of lower frequency modes with $\nu_{4}$ or $\nu_{2}$ or overtones of a lower frequency mode. The alternate hypothesis that two dissimilar $\mathrm{BO}_{3}^{-3}$ groups are present in the unit cell and give rise to two different symmetric stretching modes is untenable in these compounds. The structure of $3 \mathrm{MgO} \cdot \mathrm{B}_{2} \mathrm{O}_{3}$ and $3 \mathrm{CoO} \cdot \mathrm{B}_{2} \mathrm{O}_{3}$ by Burger [35] shows that all $\mathrm{BO}_{3}^{-3}$ groups are equivalent. However, the $\mathrm{B}-\mathrm{O}$ bonds are not identical and there is no trigonal symmetry. All modes should be active and nondegenerate as shown by the spectra of the isostructural magnesium, cobalt, nickel, and cadmium compounds.

In table 1 the data for $3 \mathrm{BaO} \cdot \mathrm{B}_{2} \mathrm{O}_{3}$ are incomplete. $\mathrm{BaCO}_{3}$ contamination produced such strong interferences that the borate bands could not be located with certainty. The known carbonate bands [57] are not listed in table 1 . The table lists only limits of the broad, strong $\nu_{3}$ band. From figure 1 it is clear that the breadth of this band arises in part from overlapping of bands arising from the two boron isotopes. An additional source of strength is probably due to resonance with overtones of $\nu_{4}$ which fall in this region.

The compounds $3 \mathrm{MgO} \cdot \mathrm{B}_{2} \mathrm{O}_{3}, 3 \mathrm{NiO} \cdot \mathrm{B}_{2} \mathrm{O}_{3}, 3 \mathrm{CoO}$ $\cdot \mathrm{B}_{2} \mathrm{O}_{3}$, and $3 \mathrm{CdO} \cdot \mathrm{B}_{2} \mathrm{O}_{3}$ are isostructural with ortho- 


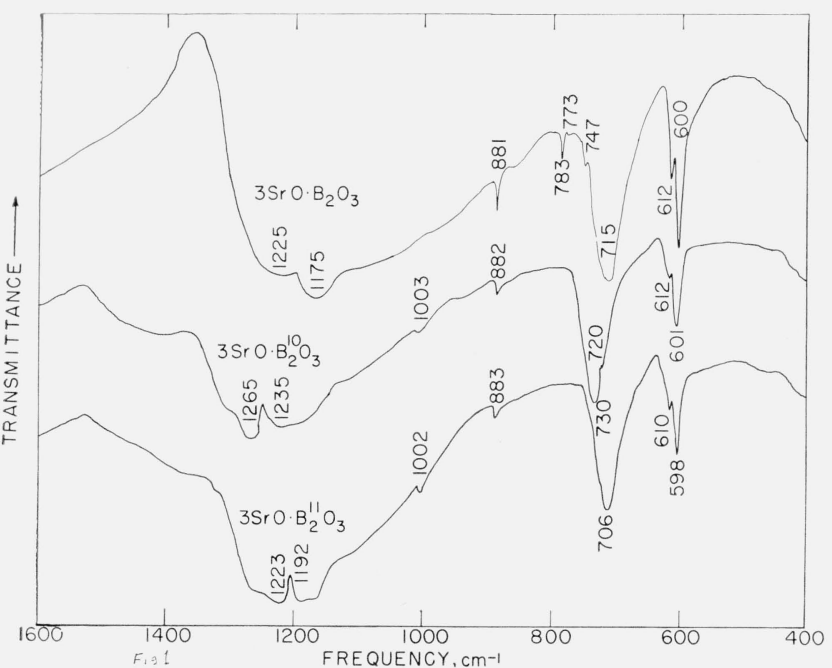

FIGURE 1. Absorption spectra of strontium orthoborates.

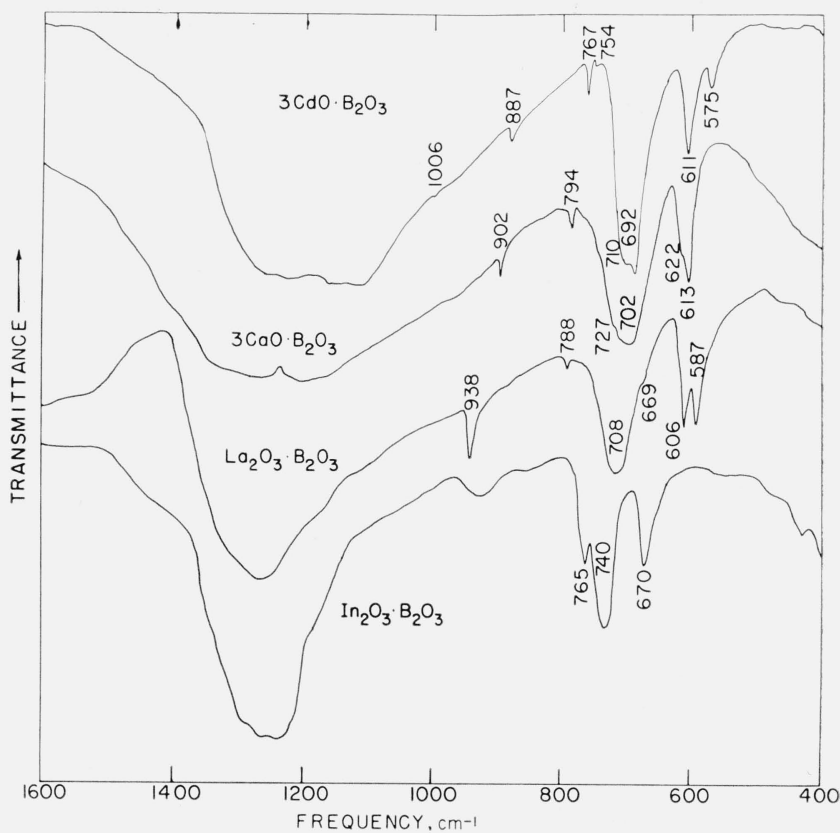

IGURE 2. Absorption spectra for different crystal structures in the orthoborates.

TABLE 1. Infrared absorption spectra of divalent metal orthoborates

$\left(\mathrm{cm}^{-1}\right)$

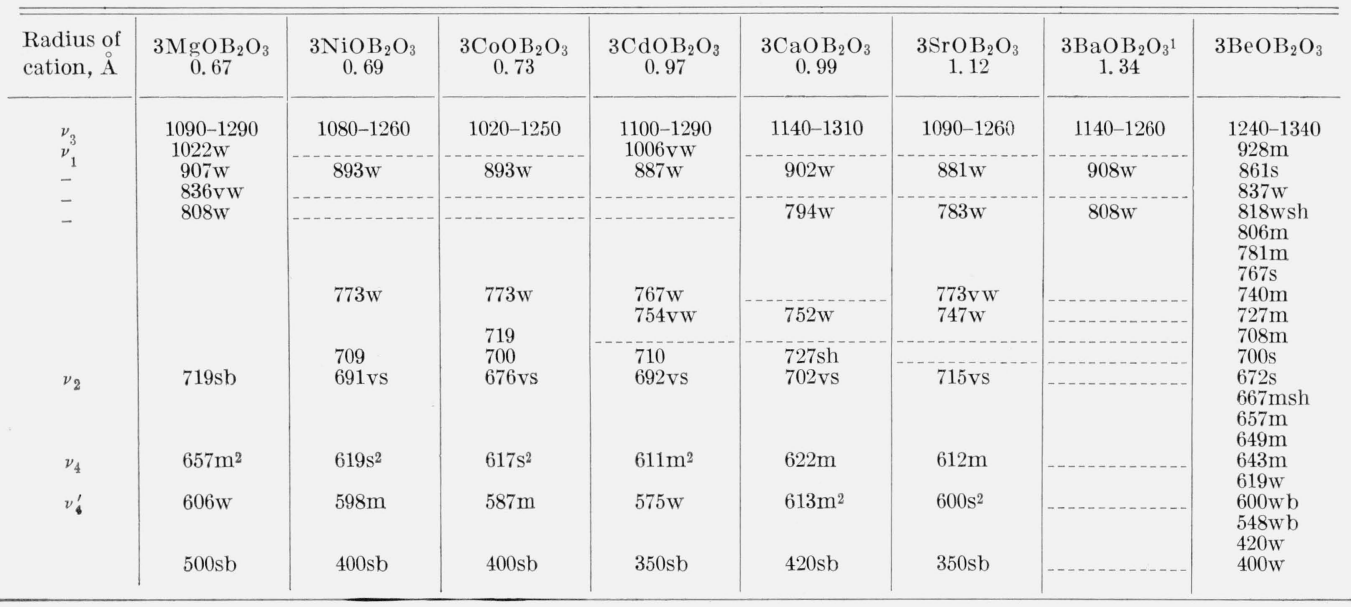

1 All specimens of $3 \mathrm{BaOB}_{2} \mathrm{O}_{3}$ were contaminated with $\mathrm{BaCO}_{3}$. The known absorption bands for $\mathrm{BaCO}_{3}$ are not tabulated here. 2 The stronger of the two bands is denoted by the superscript.

TABLE 2. Infrared absorption spectra of isotopically enriched divalent metal orthoborates

$\left(\mathrm{cm}^{-1}\right)$

\begin{tabular}{|c|c|c|c|c|c|c|c|c|c|c|}
\hline \multirow{2}{*}{ Assignment } & \multicolumn{2}{|c|}{$3 \mathrm{MgOB}_{2} \mathrm{O}_{3}$} & \multicolumn{2}{|c|}{$3 \mathrm{CaOB}_{2} \mathrm{O}_{3}$} & \multicolumn{2}{|c|}{$3 \mathrm{SrOB}_{2} \mathrm{O}_{3}$} & \multicolumn{2}{|c|}{$3 \mathrm{BaOB}_{2} \mathrm{O}_{3}$} & \multicolumn{2}{|c|}{$3 \mathrm{CdOB}{ }_{2} \mathrm{O}_{3}$} \\
\hline & $\mathrm{B}^{10}$ & $\mathrm{~B}^{11}$ & $\mathrm{~B}^{10}$ & $\mathrm{~B}^{11}$ & $\mathrm{~B}^{10}$ & $\mathrm{~B}^{11}$ & $\mathrm{~B}^{10}$ & $\mathrm{~B}^{11}$ & $\mathrm{~B}^{10}$ & $\mathrm{~B}^{11}$ \\
\hline$\nu_{3}$ & 1332 & 1264 & 1303 & 1261 & 1265 & 1223 & 1262 & 1222 & 1250 & 1210 \\
\hline$\nu_{3^{\prime}}^{\prime}$ & 1290 & 1224 & 1266 & 1227 & 1235 & 1192 & 1223 & 1185 & 1190 & 1160 \\
\hline$\nu_{1}$ & 1025 & 1021 & 1014 & 1013 & $\begin{array}{c}1003 \\
882 ?\end{array}$ & $\begin{array}{c}1002 \\
883 ?\end{array}$ & & & - & - \\
\hline$\nu_{2}$ & 733 & 720 & 730 & 708 & 729 & 706 & $\begin{array}{l}778 \\
792\end{array}$ & $\begin{array}{l}749 \\
761\end{array}$ & 726 & 702 \\
\hline$\nu_{4}$ & 659 & 655 & 624 & 619 & 612 & 610 & 602 & 599 & 608 & 606 \\
\hline$\nu_{4^{\prime}}^{\prime}$ & 608 & 604 & 617 & 612 & 601 & 598 & 568 & 567 & 574 & 572 \\
\hline
\end{tabular}


rhomic cells having the parameters shown in table 3 [42]. From tables 3 and 1 it will be noted that as the unit cell dimensions decrease, the absorption frequencies generally shift to higher frequencies. This behavior parallels that found previously in isostructural carbonates and nitrates where it was attributed to the effect of anion repulsion in the closer packed structures [57]. For these compounds the behavior of the two components of $\nu_{4}$ is of interest. It will be noted from table 1 that the higher frequency component of $\nu_{4}$ is stronger in contrast to $3 \mathrm{SrO} \cdot \mathrm{B}_{2} \mathrm{O}$ and $3 \mathrm{CaO} \cdot \mathrm{B}_{2} \mathrm{O}$ (figs 1 and 2 ) in which the lower frequency component of $\nu_{4}$ is stronger. The amount of splitting between the components of $\nu_{4}$ appears to be least in the nickel compound and increases as the unit cell gets larger.

TABLE 3. Unit cell parameters of isostructural orthorhombic orthoborates

\begin{tabular}{l|r|r|r}
\hline & \multicolumn{1}{|c|}{$\mathrm{a}$} & \multicolumn{1}{c|}{$\mathrm{b}$} & \multicolumn{1}{c}{$\mathrm{c}$} \\
& & & \multicolumn{1}{c}{} \\
& & & \\
& $10^{-8} \mathrm{~cm}$ & $10^{-8} \mathrm{~cm}$ & $10^{-8} \mathrm{~cm}$ \\
$3 \mathrm{MgOB}_{2} \mathrm{O}_{3}$ & 5.398 & 8.416 & 4.497 \\
$3 \mathrm{NiOB}_{2} \mathrm{O}_{3}$ & 5.398 & 8.305 & 4.462 \\
$3 \mathrm{CoOB}_{2} \mathrm{O}_{3}$ & 5.642 & 8.436 & 4.526 \\
$3 \mathrm{CdOB}_{2} \mathrm{O}_{3}$ & 5.967 & 9.010 & 4.785 \\
& & & \\
\hline
\end{tabular}

In view of the reversal of intensities in the strontium, calcium, and barium orthoborates it is to be expected that the two groups of compounds are not isostructural. X-ray diffraction shows this to be true and indicates that $3 \mathrm{SrO} \cdot \mathrm{B}_{2} \mathrm{O}_{3}, 3 \mathrm{CaO} \cdot \mathrm{B}_{2} \mathrm{O}_{3}$, and $3 \mathrm{BaO} \cdot \mathrm{B}_{2} \mathrm{O}_{3}$ might also form an isostructural group. However, even though the details of the structure are unknown, it can be concluded from the infrared spectra that all these compounds contain isolated planar $\mathrm{BO}_{3}^{-3}$ ions. In order for the splitting of $\nu_{3}$ and $\nu_{4}$ to occur, the ions must either be nontrigonal or be located in a crystal field of low symmetry.

The assignments given here differ considerably from those of Hart and Smallwood [18] who considered the weak sharp bands near $900 \mathrm{~cm}^{-1}$ to correspond to $\nu_{2}$ and the strong band near $700 \mathrm{~cm}^{-1}$ to be $\nu_{4}$. In view of the effects of isotopic substitution observed here, these assignments cannot be correct. The error appears to be due to the fact that $\nu_{4}$ is located outside the spectral range available to Hart and Smallwood [18]. In view of these discrepancies the force constants were recalculated assuming valence forces [19] and the results are tabulated in table 4 . The constants shown were calculated using the data of table 2 for compounds containing the $\mathrm{B}^{11}$ isotope. The splitting of $\nu_{3}$ and $\nu_{4}$ requires at least 2 values for the planar bending constant, $\mathrm{K}_{\delta} / l^{2}$, and in this calculation the higher frequency values of $\nu_{3}$ and $\nu_{4}$ were considered to represent a corresponding set and the lower frequency values the second set. The value of $\nu_{1}$ for $3 \mathrm{CdO} \cdot \mathrm{B}_{2} \mathrm{O}_{3}$ was taken from table 1 and the value for $3 \mathrm{BaO} \cdot \mathrm{B}_{2} \mathrm{O}_{3}$ which was not observed was assumed to be equal to the value observed in $3 \mathrm{SrO} \cdot \mathrm{B}_{2} \mathrm{O}_{3}$. As this assumption may be incorrect, data depending on the value are enclosed in parentheses in table 4 . The values for the force constants differ from these given by Hart and Smallwood [18] and are in reasonable good agreement with previous calculations based on the calcite and aragonite forms of the rare earth borates [57].

TABLE 4. Force constants of orthoborate ions assuming valence forces

\begin{tabular}{|c|c|c|c|}
\hline & $K_{1}$ & $K \Delta / l^{2}$ & $K \delta / l^{2}$ \\
\hline $3 \mathrm{MgOB}_{2} \mathrm{O}_{3}$ & $\begin{array}{c}10^{5} \text { dyne } / \mathrm{cm} \\
9.82\end{array}$ & $\begin{array}{c}10^{5} \text { dyne } / \mathrm{cm} \\
0.92\end{array}$ & $\begin{array}{c}10^{5} \text { dyne } / \mathrm{cm} \\
0.39\end{array}$ \\
\hline $3 \mathrm{CaOB}_{2} \mathrm{O}_{3}$ & 9.67 & 0.89 & $\begin{array}{l}0.31 \\
0.35 \\
0.32\end{array}$ \\
\hline $3 \mathrm{SrOB}_{2} \mathrm{O}_{3}$ & 9.42 & 0.91 & $\begin{array}{l}0.32 \\
0.33 \\
0.30\end{array}$ \\
\hline $3 \mathrm{BaOB}_{2} \mathrm{O}_{3}$ & $(9.4)$ & 1. 0 & $\begin{array}{l}0.30 \\
(0.31)\end{array}$ \\
\hline $3 \mathrm{CdOB}_{2} \mathrm{O}_{3}$ & 9.54 & 0.87 & $\begin{array}{l}(0.26) \\
0.31 \\
0.26\end{array}$ \\
\hline
\end{tabular}

The spectrum of $3 \mathrm{BeO} \cdot \mathrm{B}_{2} \mathrm{O}_{3}$ appears to be different from the spectra of the other divalent orthoborates, showing a large number of bands in the $600 \mathrm{~cm}^{-1}$ to $850 \mathrm{~cm}^{-1}$ range. The differences, however, may be more apparent than real because the spectrum is probably complicated by bands arising from $\mathrm{Be}-\mathrm{O}$ vibrational modes. BeO itself exhibits broad absorption bands near $960 \mathrm{~cm}^{-1}, 880 \mathrm{~cm}^{-1}$, and 750 $\mathrm{cm}^{-1}$ and the bands in beryllium borate appear to be superimposed on these bands which may arise from excess $\mathrm{BeO}$ or from $\mathrm{Be}-\mathrm{O}$ vibrational modes in the borate itself.

\section{b. Trivalent Metal Orthoborates}

This series of orthoborates is of particular interest because of the formation of calcite-, aragonite-, and vaterite-type structures in the borates [31]. Earlier infrared studies demonstrated the similarity of the absorption spectra of the calcite and aragonite type structures [57] but showed no correlation in the spectra of the carbonate and borate vaterites. Later Levin, Roth, and Martin [31] found that the boratetype vaterites all exhibit a transition at elevated temperatures forming a nonquenchable high-temperature phase whose x-ray powder diffraction pattern is more nearly like that of the carbonate vaterite than the diffraction pattern of the room temperature phase. Although it is not possible, at present, to obtain the absorption spectrum of the high temperature phase, it seems probable that it will resemble the spectrum of the carbonate vaterite which can be interpreted on the basis of trigonal $\mathrm{CO}_{3}^{-2}$ ions. The previous data on the borate vaterites could not be interpreted readily in this manner and the problem was unresolved. Isotopic substitution data and comparison with the spectra of other borates permits some conclusions to be drawn at this time.

Considering first the results for calcite and aragonite-type structures, absorption data are compiled in table 5 for $\mathrm{Sc}_{2} \mathrm{O}_{3} \cdot \mathrm{B}_{2} \mathrm{O}_{3}$ and $\mathrm{In}_{2} \mathrm{O}_{3} \cdot \mathrm{B}_{2} \mathrm{O}_{3}$ which form calcite-type structures and for $\mathrm{La}_{2} \mathrm{O}_{3} \cdot \mathrm{B}_{2} \mathrm{O}_{3}$ which forms the aragonite type structure. The spectra of 
scandium and indium borates show the spectra associated with the calcite-type structure with $\nu_{1}$ inactive and $\nu_{4}$ degenerate and unsplit. Isotopic shifts found with the indium borate confirm the assignments. In the spectra shown in figure 2 the $765 \mathrm{~cm}^{-1}$ band observed in $\operatorname{In}_{2} \mathrm{O}_{3} \cdot \mathrm{B}_{2} \mathrm{O}_{3}$ with a normal isotope distribution can be identified with the $\nu_{2}$ band of the $\mathrm{B}^{10}$ compound by means of the data of table 5. The three bands below $600 \mathrm{~cm}^{-1}$ listed in table 5 did not appear in all preparations and were found to be present in $\mathrm{In}_{2} \mathrm{O}_{3}$. They presumably arise from excess $\operatorname{In}_{2} \mathrm{O}_{3}$.

TABLE 5. Infrared absorption spectra of calcite and aragonite type borates

$\left(\mathrm{cm}^{-1}\right)$

\begin{tabular}{|c|c|c|c|c|c|}
\hline & \multirow{2}{*}{$\begin{array}{c}\mathrm{Sc}_{2} \mathrm{O}_{3} \mathrm{~B}_{2} \mathrm{O}_{3} \\
\text { (calcite) }\end{array}$} & \multicolumn{2}{|c|}{$\mathrm{In}_{2} \mathrm{O}_{3} \mathrm{~B}_{2} \mathrm{O}_{3}$ (calcite) } & \multicolumn{2}{|c|}{$\mathrm{La}_{2} \mathrm{O}_{3} \mathrm{~B}_{2} \mathrm{O}_{3}$ (aragonite) } \\
\hline & & $\mathrm{B}^{10}$ & $\mathrm{~B}^{11}$ & $\mathrm{~B}^{10}$ & $\mathrm{~B}^{11}$ \\
\hline$\nu_{3}$ & $1198 \mathrm{svb}$ & 1230 svb & $1202 \mathrm{svb}$ & $\begin{array}{l}1350 \mathrm{sbsh} \\
1289 \mathrm{svb}\end{array}$ & $\begin{array}{l}1310 \mathrm{sbsh} \\
1244 \mathrm{svb}\end{array}$ \\
\hline$\nu_{1}$ & $722 \mathrm{sb}$ & $765 \mathrm{sb}$ & $740 \mathrm{sb}$ & $\begin{array}{l}938 \mathrm{mb} \\
733 \mathrm{sb}\end{array}$ & $708 \mathrm{sb}$ \\
\hline$\nu_{4}$ & $636 \mathrm{~m}$ & $\begin{array}{l}672 \mathrm{~s} \\
596 \mathrm{~m} \\
560 \mathrm{~m} \\
533 \mathrm{~m}\end{array}$ & $\left.\begin{array}{l}670 \mathrm{~s} \\
596 \mathrm{~m} \\
561 \mathrm{~m} \\
533 \mathrm{~m}\end{array}\right\} \mathrm{In}_{2} \mathrm{O}_{3}$ & $\begin{array}{l}610 \mathrm{~m} \\
591 \mathrm{~m}\end{array}$ & $\begin{array}{l}606 \mathrm{~m} \\
587 \mathrm{~m}\end{array}$ \\
\hline
\end{tabular}

The assignments and isotopic shifts in $\mathrm{La}_{2} \mathrm{O} \cdot \mathrm{B}_{2} \mathrm{O}_{3}$ confirm the behavior expected for the aragonite type structure. The symmetric stretch, $\nu_{1}$, is active and unaffected by the boron isotope, $\nu_{4}$, is split and affected slightly by the boron mass, and $\nu_{3}$ is apparently split and strongly dependent on boron mass. Strong bands at $1350 \mathrm{~cm}^{-1}$ and $1310 \mathrm{~cm}^{-1}$ were taken to represent the high frequency components of $\nu_{3}$ for the $\mathrm{B}^{10}$ and $\mathrm{B}^{11}$ compounds. Alternate assignments as combinations of $\nu_{2}$ and $\nu_{4}$ will not satisfy the isotopic dependence observed. In $\mathrm{La}_{2} \mathrm{O}_{3} \cdot \mathrm{B}_{2} \mathrm{O}_{3}$ with the normal isotopic distribution a band is observed near $790 \mathrm{~cm}^{-1}$ (see fig. 2). This band is not found in the isotopically pure compounds and probably arises from coupling effects as noted by Decius [11]. This band was previously found in both neodymium and lanthanum borate and considered to be part of $\nu_{2}$. The absence of the band in the isotopically "pure", compounds shows this is not correct. The results obtained here agree well with previous data reported by Steele and Decius [52].

In figure 2 the infrared spectra of the four different crystal structures are compared. The close similarities in the spectra are evident. It will be noted that the behavior of $\nu_{4}$ in the different structures serves as a distinguishing feature. This band is split in $3 \mathrm{CdO} \cdot \mathrm{B}_{2} \mathrm{O}_{3}$ with the higher frequency the stronger, it is split in $3 \mathrm{CaO} \cdot \mathrm{B}_{2} \mathrm{O}_{3}$ with the separation small and the lower frequency the stronger, it is split in $\mathrm{La}_{2} \mathrm{O}_{3} \cdot \mathrm{B}_{2} \mathrm{O}_{3}$ with both components of about equal intensity but separated about $30 \mathrm{~cm}^{-1}$, and it is unsplit in $\mathrm{In}_{2} \mathrm{O}_{3} \cdot \mathrm{B}_{2} \mathrm{O}_{3}$. In the first three compounds the position of $\nu_{4}$ is about the same but in the $\operatorname{In}_{2} \mathrm{O}_{3} \cdot \mathrm{B}_{2} \mathrm{O}_{3}$ it has shifted to much higher frequency, an indication of much tighter packing.
Absorption spectra of the rare earth borates having the vaterite type structure were studied only for the holmium, erbium, thulium, ytterbium, and lutecium compounds. Spectra for the holmium, thulium, and ytterbium borates were obtained with the normal isotopic distribution, for lutecium borate in the isotopically enriched compounds only, and for erbium borate in both the normal and enriched forms. Typical spectra are shown in figure 3 for the normal isotopic distribution and in figure 4 for the isotopically "pure" borates of erbium and lutecium. The observed bands are tabulated in table 6 .

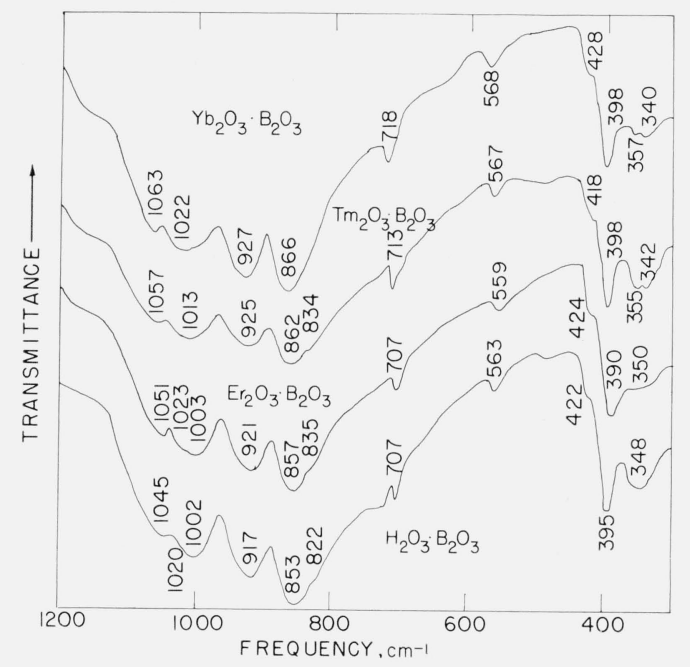

FIGURE 3. Absorption spectra of rare earth vaterite-type borates.

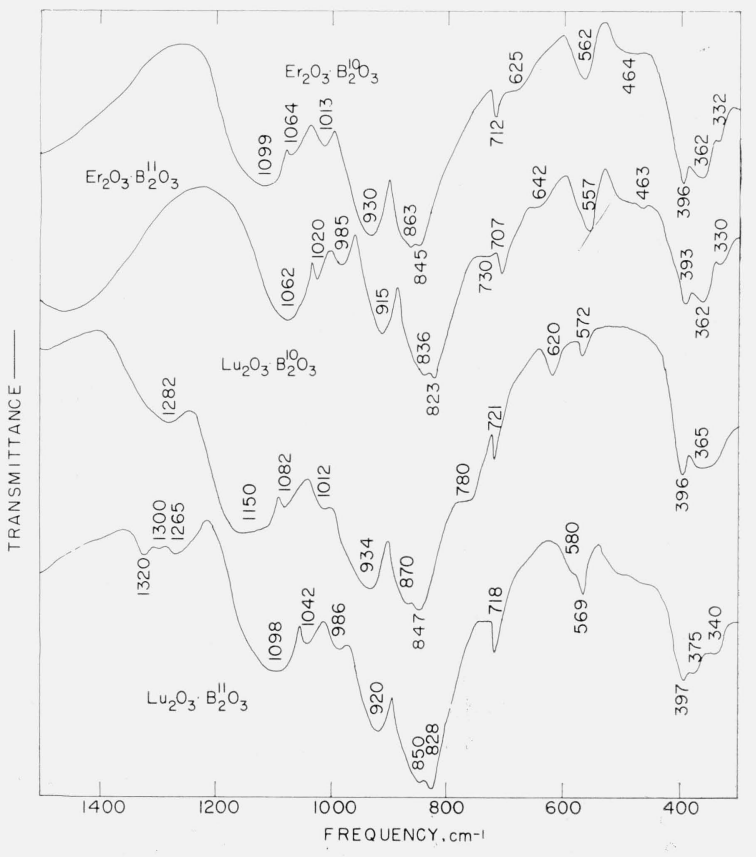

Figure 4. Isotope effects in rare earth vaterite-type borates 
$\left(\mathrm{cm}^{-1}\right)$

\begin{tabular}{|c|c|c|c|c|c|c|c|}
\hline \multirow{2}{*}{$\mathrm{H}_{2} \mathrm{O}_{3} \mathrm{~B}_{2} \mathrm{O}_{3}$} & \multicolumn{3}{|c|}{$\mathrm{Er}_{2} \mathrm{O}_{3} \mathrm{~B}_{2} \mathrm{O}_{3}$} & \multirow{2}{*}{$\mathrm{Tm}_{2} \mathrm{O}_{3} \mathrm{~B}_{2} \mathrm{O}_{3}$} & \multirow{2}{*}{$\mathrm{Yb}_{2} \mathrm{O}_{3} \mathrm{~B}_{2} \mathrm{O}_{3}$} & \multicolumn{2}{|c|}{$\mathrm{Lu}_{2} \mathrm{O}_{3} \mathrm{~B}_{2} \mathrm{O}_{3}$} \\
\hline & $\mathrm{B}^{10}+\mathrm{B}^{11}$ & $\mathrm{~B} 10$ & B11 & & & $\mathrm{B} 10$ & B 11 \\
\hline $\begin{array}{l}1045 \mathrm{sbsh} \\
1020 \mathrm{sbsh}\end{array}$ & $\begin{array}{l}1051 \text { bsh } \\
1023 \mathrm{sbsh}\end{array}$ & $\begin{array}{l}1099 \mathrm{sb} \\
1064 \mathrm{~m}\end{array}$ & $\begin{array}{l}1062 \mathrm{sb} \\
1020 \mathrm{~m}\end{array}$ & $1057 \mathrm{bsh}$ & $1063 \mathrm{bsh}$ & $\begin{array}{l}1282 \mathrm{mvb} \\
1150 ? \mathrm{mb} \\
1082 \mathrm{mb}\end{array}$ & $\begin{array}{l}1320-1265 \mathrm{wb} \\
1098 \mathrm{svb} \\
1042 \mathrm{mb}\end{array}$ \\
\hline $\begin{array}{l}1002 \mathrm{svb} \\
917 \mathrm{sb} \\
853 \mathrm{vsb} \\
822 \mathrm{bsh}\end{array}$ & $\begin{array}{l}1003 \mathrm{svb} \\
921 \mathrm{vsb} \\
857 \mathrm{vsb}\end{array}$ & $\begin{array}{l}1013 \mathrm{~m} \\
930 \mathrm{sb} \\
863 \mathrm{sb} \\
845 \mathrm{~s}\end{array}$ & $\begin{array}{l}985 \mathrm{~m} \\
915 \mathrm{sb} \\
836 \mathrm{sb} \\
823 \mathrm{~s}\end{array}$ & $\begin{array}{l}1013 \mathrm{svb} \\
925 \mathrm{vsb} \\
862 \mathrm{vsb} \\
834 \mathrm{bsh}\end{array}$ & $\begin{array}{l}1022 \mathrm{svb} \\
927 \mathrm{sb} \\
866 \mathrm{vsb}\end{array}$ & $\begin{array}{l}1012 \mathrm{mb} \\
934 \mathrm{sb} \\
870 \mathrm{vsb} \\
847 \mathrm{vsb}\end{array}$ & $\begin{array}{l}986 \mathrm{mb} \\
920 \mathrm{sb} \\
850 \mathrm{vsb} \\
828 \mathrm{vsb}\end{array}$ \\
\hline $707 \mathrm{~m}$ & $707 \mathrm{~m}$ & $712 \mathrm{~m}$ & $707 \mathrm{~m}$ & $713 \mathrm{~m}$ & $718 \mathrm{~m}$ & $721 \mathrm{~m}$ & $718 \mathrm{~m}$ \\
\hline $563 \mathrm{mb}$ & $559 \mathrm{mb}$ & $\begin{array}{l}562 \mathrm{mb} \\
464 \mathrm{bsh}\end{array}$ & $\begin{array}{l}557 \mathrm{mb} \\
463 \mathrm{wsh}\end{array}$ & $567 \mathrm{mb}$ & $568 \mathrm{mb}$ & $572 \mathrm{mb}$ & $569 \mathrm{mb}$ \\
\hline $\begin{array}{l}424 \text { wsh } \\
395 \mathrm{~s}\end{array}$ & $\begin{array}{l}424 \text { wsh } \\
390 \text { s }\end{array}$ & $396 \mathrm{~s}$ & $393 \mathrm{~s}$ & $\begin{array}{l}418 \mathrm{wsh} \\
398 \mathrm{~s}\end{array}$ & $\begin{array}{l}428 \mathrm{wsh} \\
398 \mathrm{~s}\end{array}$ & $396 \mathrm{~s}$ & $\begin{array}{l}397 \mathrm{~s} \\
375 \mathrm{sb}\end{array}$ \\
\hline $348 \mathrm{sb}$ & $350 \mathrm{sb}$ & $\begin{array}{l}362 \mathrm{sb} \\
332 \mathrm{msh}\end{array}$ & $\begin{array}{l}362 \mathrm{sb} \\
330 \mathrm{msh}\end{array}$ & $\begin{array}{l}355 \mathrm{w} \\
342 \mathrm{w}\end{array}$ & $\begin{array}{l}357 \mathrm{w} \\
340 \mathrm{wb}\end{array}$ & $365 \mathrm{sb}$ & $340 \mathrm{mb}$ \\
\hline
\end{tabular}

In figure 3 it will be noted that the four strong bands between $800 \mathrm{~cm}^{-1}$ and $1100 \mathrm{~cm}^{-1}$ confirm the previous observations where only three of these bands could be detected with assurance in all the borates [57]. When isotope substitution is employed it is clear that at least six bands can be resolved in this region. In figure 4 it will be noted that almost without exception each band shifts to higher frequency as the cation mass increases from 167 in Er to 175 in Lu. The same tendency is apparent in figure 3 where the bands are not as well resolved. This shift has been attributed to increased anion repulsion produced by contraction of the unit cell dimensions. The bands between $800 \mathrm{~cm}^{-1}$ and $1100 \mathrm{~cm}^{-1}$ show marked shifts with change in mass of the boron. It is most likely that these bands are fundamentals for the following reasons: first, they are all quite strong, second, the dependence on mass is much greater than to be expected for overtones of low frequency modes, and third, there do not appear to be any reasonably constant differences between these bands. It may be concluded therefore that most of the six strong bands are fund amentals and correspond to a stretching type vibration. The weak bands in the $1300 \mathrm{~cm}^{-1}$ region may be combination modes or arise from contamination with the $3: 1$ borates whose spectra will be described later.

To interpret these spectra it is necessary to apply certain results which will be demonstrated later. First, every borate which is known to contain trigonal borate groups alone or in complex polymeric anions invariably exhibits strong absorption in the region of $1200 \mathrm{~cm}^{-1}$ or higher. The isotopic mass dependence of these bands shows that they may be considered to be derived from or due to the antisymmetric stretch of planar $\mathrm{BO}_{3}$ groups. Second, there is always at least one band attributable to the out-of-plane bending mode of the trigonal group occurring in the $650 \mathrm{~cm}^{-1}$ to $750 \mathrm{~cm}^{-1}$ region which can be identified by its strong isotopic shift. The bands in the $700 \mathrm{~cm}^{-1}$ region for $\mathrm{Lu}_{2} \mathrm{O}_{3} \cdot \mathrm{B}_{2} \mathrm{O}_{3}$ and $\mathrm{Er}_{2} \mathrm{O}_{3} \cdot \mathrm{B}_{2} \mathrm{O}_{3}$ do not exhibit an isotopic shift sufficiently large for the trigonal $\nu_{2}$ band. Third the spectrum of zine borate which is known to contain only tetrahedrally coordinated boron shows strong broad fundamentals in the $900 \mathrm{~cm}^{-1}$ to $1100 \mathrm{~cm}^{-1}$ region and a band near $717 \mathrm{~cm}^{-1}$ with a small isotopic shift. From these considerations it is necessary to conclude that the spectra of the rare earth borates of the vaterite type are consistent with the presence of only four-fold coordinated boron in the structure. The longer $\mathrm{B}-\mathrm{O}$ bonds in the tetrahedra would account for the shift of the strong stretching bands to frequencies below $1100 \mathrm{~cm}^{-1}$. Furthermore, the number of fundamentals observed and their isotopic dependence cannot be reconciled with the behavior to be expected from isolated tetrahedra. These facts lead to the conclusion that the anion in these borates is a complex polymeric structure containing only $\mathrm{BO}_{4}$ tetrahedra. It is suggested that a six-membered ring containing alternate $\mathrm{B}-\mathrm{O}$ bonds with each boron connected to 2 off-ring oxygen atoms is not inconsistent with the empirical formula or the spectrum.

\subsection{Metaborates}

\section{a. Alkali Metaborates}

Of the alkali metaborates only the lithium, sodium, and potassium compounds were studied. The spectra of $\mathrm{Na}_{2} \mathrm{O} \cdot \mathrm{B}_{2} \mathrm{O}_{3}$ and $\mathrm{K}_{2} \mathrm{O} \cdot \mathrm{B}_{2} \mathrm{O}_{3}$ are very poor and are characterized by few resolvable bands. Typical spectra are shown in figure 5 and the data are given

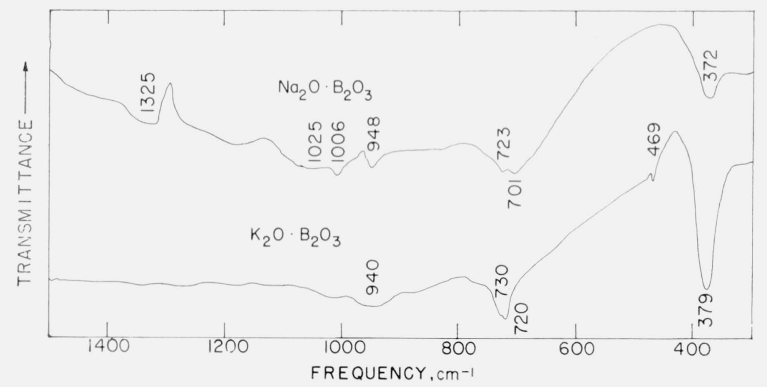

Figure 5. Absorption spectra of alkali metaborates. 
in table 7 . As shown in figure 5 few bands can be resolved in the $1000 \mathrm{~cm}^{-1}$ to $1400 \mathrm{~cm}^{-1}$ either because of overlapping bands or because of strong scattering. The distortion region below $800 \mathrm{~cm}^{-1}$, however, shows several characteristic bands. From comparisons with previously reported spectra on $\mathrm{NaBO}_{2}$ $[8,14,25]$ it is clear that the present spectrum agrees reasonably well in the distortion region. The strong bands above $1200 \mathrm{~cm}^{-1}$ are not distinguishable in the present spectra, however, Using the terminology and assignments of Goubeau and Hummel [14] the $723 \mathrm{~cm}^{-1}$ and $701 \mathrm{~cm}^{-1}$ bands correspond to two components of $\nu_{10}$ in $\mathrm{NaBO}_{2}$ and the corresponding bands in $\mathrm{KBO}_{2}$ would be at $730 \mathrm{~cm}^{-1}$ and 721 $\mathrm{cm}^{-1}$. The $469 \mathrm{~cm}^{-1}$ band observed in $\mathrm{KBO}_{2}$ but not in $\mathrm{NaBO}_{2}$ probably corresponds to $\nu_{11}$ while the $952 \mathrm{~cm}^{-1}$ band in $\mathrm{NaBO}_{2}$ and the corresponding $940 \mathrm{~cm}^{-1}$ band in $\mathrm{KBO}_{2}$ represent the 1st overtone of $\nu_{11}$. The small discrepancy noted between calculated and observed values for the overtone is not considered significant in view of the breadth of the bands. The bands at $372 \mathrm{~cm}^{-1}$ in $\mathrm{NaBO}_{2}$ and 379 $\mathrm{cm}^{-1}$ in $\mathrm{KBO}_{2}$ are obviously similar but their assignments are not apparent from the data of Goubeau and Hummel [14] except possibly as combinations or overtones of lower frequency modes. Positions of higher frequency bands listed for $\mathrm{NaBO}_{2}$ are so inexact that they have little significance.

TABLE 7. Infrared absorption spectra of alkali metaborates $\left(\mathrm{cm}^{-1}\right)$

\begin{tabular}{|c|c|c|c|c|c|c|}
\hline \multirow{2}{*}{$\mathrm{NaBO}_{2}$} & \multicolumn{3}{|c|}{$\mathrm{KBO}_{2}$} & \multicolumn{3}{|c|}{$\mathrm{LiBO}_{2}$} \\
\hline & $\mathrm{B}^{10} \& \mathrm{~B}^{11}$ & $\mathrm{~B}^{10}$ & B11 & $\mathrm{B}^{10} \& \mathrm{~B}^{11}$ & $\mathrm{~B}^{10}$ & $\mathrm{~B}^{11}$ \\
\hline $\begin{array}{l}1025 \mathrm{svb} ? \\
1006 ?\end{array}$ & & & & $\begin{array}{l}1400 \mathrm{svb} \\
1157 \mathrm{vsb}\end{array}$ & $\begin{array}{l}1482 \mathrm{sb} \\
1385 \mathrm{sb} \\
1358 \mathrm{sb} \\
1298 \mathrm{wsh} \\
1166 \mathrm{sb} \\
1073 \mathrm{wb}\end{array}$ & $\begin{array}{l}1435 \mathrm{~s} \\
1345 \mathrm{sb} \\
1316 \mathrm{sb} \\
1160 \mathrm{sb} \\
1123 \mathrm{sb} \\
1072 \mathrm{wb}\end{array}$ \\
\hline $948 w$ & $\begin{array}{l}940 \mathrm{vb} ? \\
775 \mathrm{sbs}\end{array}$ & $942 \mathrm{~m}$ & $942 \mathrm{~m}$ & $\begin{array}{l}973 \mathrm{~m} \\
882 \mathrm{mb}\end{array}$ & $\begin{array}{l}986 \mathrm{sb} \\
915 \mathrm{sb}\end{array}$ & $\begin{array}{l}967 \mathrm{sb} \\
895 \mathrm{~s}\end{array}$ \\
\hline $\begin{array}{l}741 \mathrm{wsh} \\
723 \mathrm{~s} \\
701 \mathrm{ssh}\end{array}$ & $\begin{array}{l}730 \mathrm{ssh} \\
720 \mathrm{~s}\end{array}$ & $730 \mathrm{sb}$ & $712 \mathrm{sb}$ & $\begin{array}{l}810 \mathrm{vw} \\
775 \mathrm{wsh} \\
722 \mathrm{sb} \\
685 \mathrm{mbsh} \\
626 \mathrm{mb}\end{array}$ & $\begin{array}{l}865 \mathrm{wsh} \\
778 \mathrm{wb} \\
722 \mathrm{mb} \\
715 \mathrm{mb}\end{array}$ & $\begin{array}{l}877 \mathrm{~s} \\
777 \mathrm{wb} \\
715 \mathrm{sb} \\
677 \mathrm{wsh} \\
620 \mathrm{mb}\end{array}$ \\
\hline $372 \mathrm{~m}$ & $\begin{array}{l}469 \mathrm{w} \\
379 \mathrm{~m}\end{array}$ & $\begin{array}{l}473 \mathrm{w} \\
382 \mathrm{~s}\end{array}$ & $\begin{array}{l}470 \mathrm{w} \\
381 \mathrm{~s}\end{array}$ & $\begin{array}{l}522 \mathrm{sb} \\
420 \mathrm{mb} \\
406 \mathrm{msh}\end{array}$ & $\begin{array}{l}545 \mathrm{mb} \\
510 \mathrm{mb} \\
420 \mathrm{mb} \\
410 \mathrm{mb}\end{array}$ & $\begin{array}{l}538 \mathrm{mb} \\
510 \mathrm{mb} \\
420 \mathrm{mb} \\
410 \mathrm{mb}\end{array}$ \\
\hline
\end{tabular}

As can be seen from table 7 the spectrum of $\mathrm{LiBO}_{2}$ is completely different from those of the other alkali borates. In the $1000 \mathrm{~cm}^{-1}$ to $1400 \mathrm{~cm}^{-1}$ region there is overlapping and loss of resolution in the compound with the normal isotopic distribution but in the isotopically enriched specimens the resolution improves and the region is found to contain many bands. From the x-ray powder diffraction pattern, it appears that the $\mathrm{LiBO}_{2}$ studied here is the $\alpha$-form and contains anions consisting of chains of $\mathrm{BO}_{3}$ groups sharing corners [21]. The spectrum should resemble that for $\mathrm{Ca}\left(\mathrm{BO}_{2}\right)_{2}$ to be discussed later. There are, in fact, many similarities in the spectra of these two compounds, but there are many more absorption bands present in $\mathrm{LiBO}_{2}$ particularly at the lower fre- quencies. Because of the small mass of the lithium ion it is expected that vibrational modes arising from motion of the cation might be observed in this spectral region. Such vibrations and their combinations and overtones would be expected to produce a more complex absorption spectrum in $\mathrm{LiBO}_{2}$ than in $\mathrm{Ca}\left(\mathrm{BO}_{2}\right)_{2}$. It is also of interest to note that strong bands extend to as high as $1400 \mathrm{~cm}^{-1}$ in $\mathrm{LiBO}_{2}$. These bands appear to be fundamentals because of their strengths and the fact that their isotopic dependence is inconsistent with overtones and combinations of lower frequency bands. The presence of fundamentals in this range supports the supposition that some of the $\mathrm{B}-\mathrm{O}$ bonds are much stronger than those found in the $\mathrm{BO}_{3}$ trigonal ion.

\section{b. Alkaline Earth Metaborates}

Typical spectra for the alkaline earth metaborates are shown in figures 6 and 7 and the data for normal isotope distributions are given in table 8 and for isotopically enriched compounds in table 9. The structure of the anion of $\mathrm{CaO} \cdot \mathrm{B}_{2} \mathrm{O}_{3}$ is known to consist of endless chains of triangles [36, 58, 59] which may be considered as coupled pyroborate groups. Consequently, the spectrum should resemble that of a pyroborate and the relationship of the bands

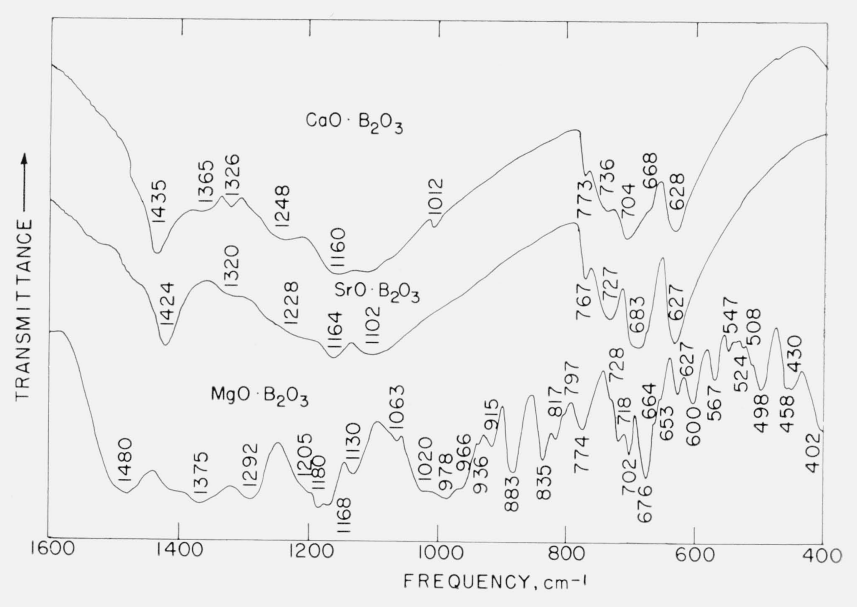

Figure 6. Absorption spectra of alkaline earth metaborates.

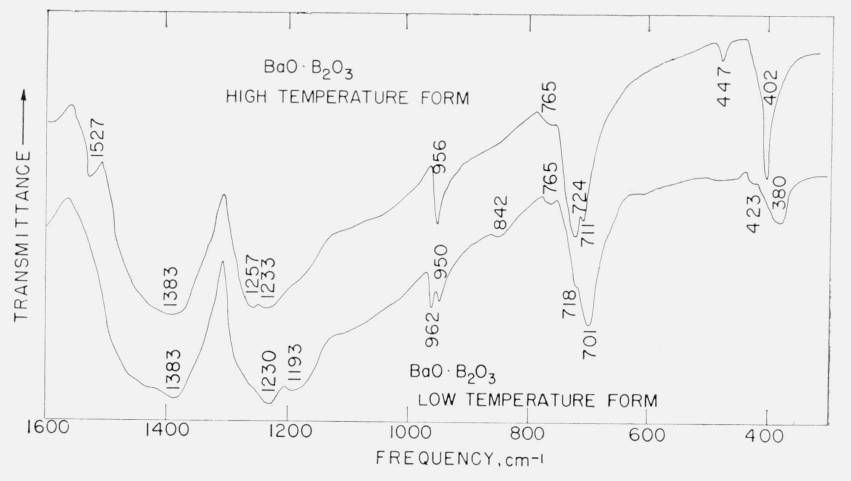

Figure 7. Absorption spectra of two forms of barium metaborate. 
observed to the fundamentals of a trigonal group should be clear in many instances. Comparing the data of $\mathrm{CaO} \cdot \mathrm{B}_{2} \mathrm{O}_{3}$ with that of $2 \mathrm{CaO} \cdot \mathrm{B}_{2} \mathrm{O}_{3}$ (table 12) it is apparent that the spectra show a close relationship. As in the pyroborate, the group of bands between $1100 \mathrm{~cm}^{-1}$ and $1450 \mathrm{~cm}^{-1}$ are strong, broad, and very strongly dependent on isotopic mass. These bands are therefore derived from $\nu_{3}$ of the trigonal group. The $1012 \mathrm{~cm}^{-1}$ corresopnds to the symmetric stretch derived from $\nu_{1}$ because it is isotope independent, and the bands below $800 \mathrm{~cm}^{-1}$ are derived from the distortion modes $\nu_{2}$ and $\nu_{4}$. The close similarity between the spectra of $\mathrm{CaO} \cdot \mathrm{B}_{2} \mathrm{O}_{3}$ and $\mathrm{SrO} \cdot \mathrm{B}_{2} \mathrm{O}_{3}$ is apparent in figure 6. This similarity led to the prediction that these compounds were probably isostructural. The prediction was verified by x-ray powder diffraction and it may be concluded that the strontium metaborate also contains anions consisting of chains of $\mathrm{BO}_{3}$ groups. The spectra of $\mathrm{CaO} \cdot \mathrm{B}_{2} \mathrm{O}_{3}$ and $\mathrm{SrO} \cdot \mathrm{B}_{2} \mathrm{O}_{3}$ are very simple in view of the large number of active normal modes. Apart from the fact that some bands appear to overlap it seems that many bands must either be very weak or coincide in frequency with other bands to produce a spectrum of such apparent simplicity. Marezio, Plettinger, and Zachariasen [36] recently refined the structure of $\mathrm{CaO} \cdot \mathrm{B}_{2} \mathrm{O}_{3}$ and showed that the unique oxygen atom attached to each boron atom in the chain is more tightly bonded than the oxygen atoms of the normal trigonal $\mathrm{BO}_{3}$ group. This tighter bond can be used to account for the existence of fundamentals of much higher frequency than are normally found in isolated trigonal groups.

TABLE 8. Infrared absorption spectra of alkaline earth metaborates with normal isotope content

$\left(\mathrm{cm}^{-1}\right)$

\begin{tabular}{|c|c|c|c|c|}
\hline \multirow[b]{2}{*}{$\mathrm{Mg}\left(\mathrm{BO}_{2}\right)_{2}$} & \multirow{2}{*}{$\mathrm{Ca}\left(\mathrm{BO}_{2}\right)_{2}$} & \multirow{2}{*}{$\mathrm{Sr}\left(\mathrm{BO}_{2}\right)_{2}$} & \multicolumn{2}{|c|}{$\mathrm{Ba}\left(\mathrm{BO}_{2}\right)_{2}$} \\
\hline & & & $\begin{array}{l}\text { High temp } \\
\text { form }\end{array}$ & $\begin{array}{l}\text { Low temp } \\
\text { form }\end{array}$ \\
\hline $1480 \mathrm{~b}$ & $1435 \mathrm{vs}$ & $1424 \mathrm{~s}$ & $1527 \mathrm{~m}$ & \\
\hline $1375 \mathrm{vbs}$ & $1365 \mathrm{~m}$ & $1320 \mathrm{vb}$ & $1383 \mathrm{sb}$ & $1383 \mathrm{sb}$ \\
\hline $1292 \mathrm{sb}$ & $1326 \mathrm{~m}$ & $1228 \mathrm{svb}$ & $1257 \mathrm{~s}$ & \\
\hline $\begin{array}{l}1205 \mathrm{msh} \\
180 \mathrm{~s}\end{array}$ & $1248 \mathrm{mb}$ & & $1233 \mathrm{sb}$ & $1030 \mathrm{sb}^{-1}$ \\
\hline $1168 \mathrm{~s}$ & - & & $1233 \mathrm{sb}$ & $1230 \mathrm{sb}$ \\
\hline $1130 \mathrm{mb}$ & $1160 \mathrm{svb}$ & $1164 \mathrm{~s}$ & & $1193 \mathrm{~b}$ \\
\hline $\begin{array}{l}1063 \mathrm{msh} \\
1020 \mathrm{~s}\end{array}$ & & $1102 \mathrm{sb}$ & & \\
\hline $978 \mathrm{~s}$ & $1012 \mathrm{VW}$ & $1002 \mathrm{svb}$ & & $962 \mathrm{~m}$ \\
\hline $\begin{array}{l}966 \mathrm{~s} \\
936 \mathrm{~s}\end{array}$ & & & & $\cdots$ \\
\hline $915 \mathrm{~m}$ & & & $956 \mathrm{~s}$ & $950 \mathrm{~m}$ \\
\hline $\begin{array}{l}883 \mathrm{~s} \\
835 \mathrm{~s}\end{array}$ & & & & $842 \mathrm{wb}$ \\
\hline $817 \mathrm{~m}$ & (n) & & 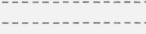 & 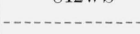 \\
\hline $\begin{array}{l}797 \mathrm{w} \\
774 \mathrm{~m}\end{array}$ & $773 \mathrm{~m}$ & $767 \mathrm{~m}$ & $765 \mathrm{wb}$ & $765 \mathrm{wb}$ \\
\hline $728 w$ & & & & 10000 \\
\hline $718 \mathrm{~m}$ & $736 \mathrm{mb}$ & $727 \mathrm{mb}$ & $724 \mathrm{~s}$ & \\
\hline $\begin{array}{l}702 \mathrm{~s} \\
676 \mathrm{~s}\end{array}$ & $704 \mathrm{sb}$ & & $711 \mathrm{ssh}$ & $\begin{array}{l}718 \mathrm{ssh} \\
701 \mathrm{~s}\end{array}$ \\
\hline $664 \mathrm{wsh}$ & $668 \mathrm{wsh}$ & $683 \mathrm{sb}$ & - & (2010 \\
\hline 653 wsh & & & -.- & - - \\
\hline $\begin{array}{l}627 \mathrm{~m} \\
600 \mathrm{~m}\end{array}$ & $628 \mathrm{sb}$ & $627 \mathrm{sb}$ & & - - - - \\
\hline $567 \mathrm{~m}$ & & & & - \\
\hline $547 \mathrm{w}$ & -2 & & - & 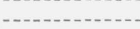 \\
\hline $524 \mathrm{wsh}$ & . & & sengen & - \\
\hline $\begin{array}{l}508 \text { wsh } \\
498 \mathrm{~m}\end{array}$ & $475 \mathrm{wb}$ & & $477 \mathrm{w}$ & \\
\hline $458 \mathrm{mb}$ & Trown & & 40 & $423 \mathrm{wsh}$ \\
\hline $430 \mathrm{~m}$ & 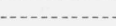 & & & - \\
\hline $402 \mathrm{~m}$ & & $\ldots$ & $402 \mathrm{~s}$ & $-2-1-10-1$ \\
\hline $375 \mathrm{~m}$ & & & & $380 \mathrm{mb}$ \\
\hline $355 \mathrm{~m}$ & & & & - \\
\hline
\end{tabular}

TABLE 9. Infrared absorption spectra of isotopically enriched alkaline ear th metaborates

$\left(\mathrm{cm}^{-1}\right)$

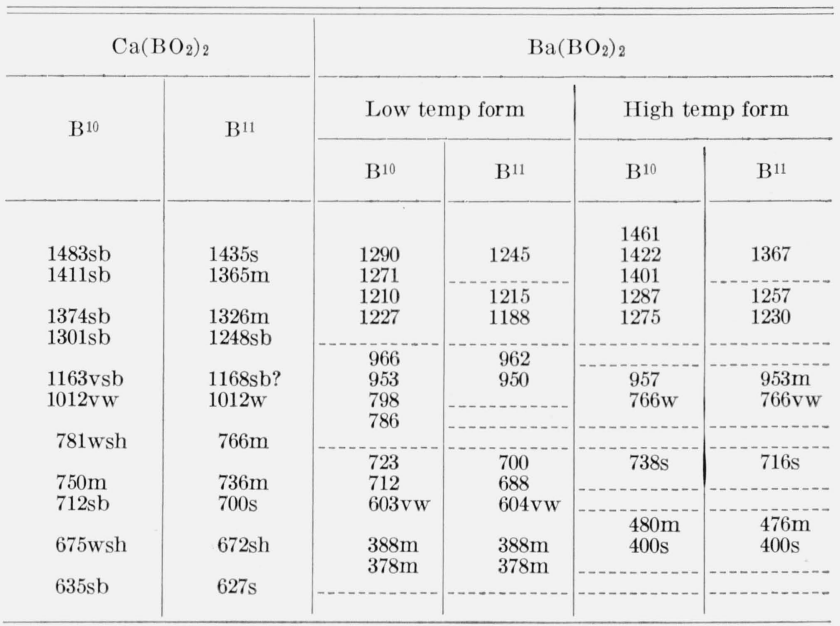

The spectrum of $\mathrm{MgO} \cdot \mathrm{B}_{2} \mathrm{O}_{3}$ as shown in figure 6 is quite complex and not analogous to the calcium and strontium compounds. As noted earlier, it is believed that the spectrum is representative of the compound and is not complicated by the presence of other magnesium borates. It appears plausible that because of the tighter packing produced by the small $\mathrm{Mg}^{+2}$ ion, the chains present in $\mathrm{CaO} \cdot \mathrm{B}_{2} \mathrm{O}_{3}$ and $\mathrm{SrO} \cdot \mathrm{B}_{2} \mathrm{O}_{3}$ might be in such close proximity that cross linking by means of the unique atoms might occur. Cross linking would produce some tetrahedral boron atoms and give rise to strong absorption in the $800 \mathrm{~cm}^{-1}$ to $1000 \mathrm{~cm}^{-1}$ region as shown in figure 6 . Some indirect support for this hypothesis may be drawn from the fact that a strongly cross-linked material might be expected to decompose at elevated temperatures, a behavior exhibited by $\mathrm{MgO} \cdot \mathrm{B}_{2} \mathrm{O}_{3}$ which decomposes into $\mathrm{B}_{2} \mathrm{O}_{3}$ and the $2: 1$ compound. However, some strongly bonded oxygen atoms must be present in the structure as shown by strong absorption bands as high as $1480 \mathrm{~cm}^{-1}$.

Barium metaborate undergoes a transition forming a quenchable high temperature phase and both forms were studied. From the spectra shown in figure 7 it may be concluded that the anion has high symmetry and is unlike the chain anions of $\mathrm{SrO} \cdot \mathrm{B}_{2} \mathrm{O}_{3}$ and $\mathrm{CaO} \cdot \mathrm{B}_{2} \mathrm{O}_{3}$. Both the low and high temperature forms give similar spectra with some evidence of lowering of the symmetry in the low temperature form as shown by the splitting of the $956 \mathrm{~cm}^{-1}$ band into two components at $962 \mathrm{~cm}^{-1}$ and $950 \mathrm{~cm}^{-1}$. The isotopic substitution data of table 9 strengthen the indication that bands in the high temperature form split into two components in the low temperature form. Although the structure of the anion is not known in this compound it may be suggested on the basis of the spectrum alone that $\mathrm{B}_{3} \mathrm{O}_{6}$ rings of the boroxol type may constitute the anion in the high temperature form and that the rings are coupled in some manner in the low temperature form. Single crystal x-ray work, now under way, is expected to confirm or refute the correctness of this suggestion 
in the near future. The x-ray powder diffraction pattern of the high temperature form indexes readily in the hexagonal system with the lattice parameters, $\mathrm{a}=7.23 \times 10^{-8} \mathrm{~cm}, \mathrm{c}=39.17 \times 10^{-8} \mathrm{~cm} \mathrm{[7].}$

\section{c. Zinc Metaborate}

Zinc metaborate, the $4: 3$ compound, has the structural formula $\mathrm{Zn}_{4} \mathrm{O}\left(\mathrm{BO}_{2}\right)_{6}$ and represents one of the few anhydrous borates known to contain only tetrahedrally coordinated boron which have been studied in this investigation. Typical spectra for the compound are shown in figure 8 and the corresponding absorption frequencies are tabulated in table 10. The spectra appear to agree well with spectra given by Krogh-Moe [24]. From the structural analysis $[50,51]$ the $\mathrm{B}-\mathrm{O}$ bond distance is known to be $1.48 \AA$ and the maximum frequencies observed should be lower than those of any trigonal borate group which has $\mathrm{B}-\mathrm{O}$ bonds of the order of $1.35 \AA$. From these considerations it appears likely that the $1082 \mathrm{~cm}^{-1}$ band is the highest fundamental and that the weaker bands observed at $1160 \mathrm{~cm}^{-1}$ and $1200 \mathrm{~cm}^{-1}$ are overtones or combinations. As noted earlier (see 4.2) the spectrum may be assigned completely in this frequency range by considering the bonded tetrahedra to be effective $\mathrm{XYZ}_{3}$-type molecules. The assignments given in table 10 were made on this basis using the terminology of Hertzberg [19]. Although the specific assignments are subject to some uncertainty, they show that the three highest frequency bands, i.e., weak broad bands above $1100 \mathrm{~cm}^{-1}$ can be interpreted as combinations of the observed fundamentals and an unobserved $v_{6}$ located near $230 \mathrm{~cm}^{-1}$. The internal consistency of the assignments is indicated by the fact that application of the Teller-Redlich product rule [19] to the isotopically enriched specimens gives results in good agreement with the observed frequencies. It is required that $\nu_{1} \nu_{2} \nu_{3} / \nu_{1}^{\prime} \nu_{2}^{\prime} \nu_{3}^{\prime}=\frac{11}{10} \approx \nu_{4} \nu_{5} \nu_{6} / \nu_{4}^{\prime} \nu_{5}^{\prime} \nu_{6}{ }^{\prime}$

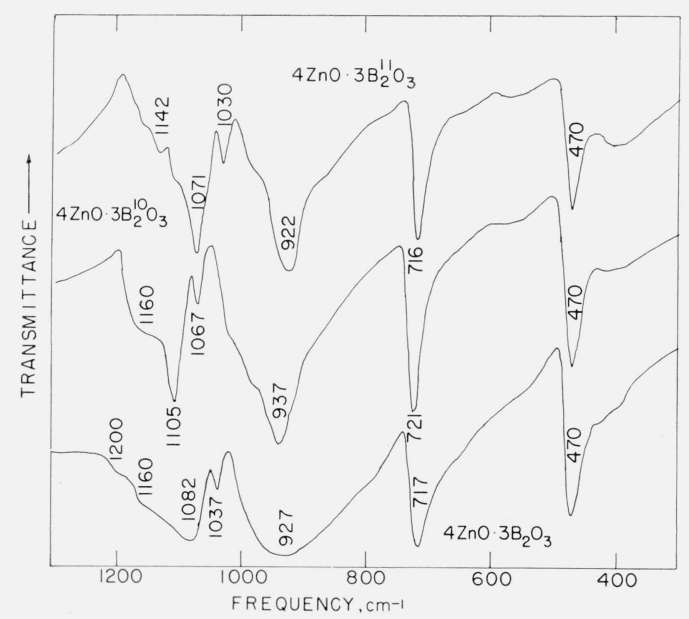

Figure 8. Absorption spectra of zinc metaborate $\left(\mathrm{Zn}_{4} \mathrm{O}\left(\mathrm{BO}_{6}\right)_{6}\right)$ where the unprimed frequencies refer to the $\mathrm{B}^{10}$ compound and the primed frequencies to the $\mathrm{B}^{11}$ compound. The values of the ratios agree within the experimental error of the measurements with the assumption that the ratio $\nu_{6} / \nu_{6}{ }^{\prime}$ is unity. It may be noted that both the $470 \mathrm{~cm}^{-1}$ and $922 \mathrm{~cm}^{-1}$ bands of the $\mathrm{B}^{11}$ compound might arise from overtones and/or combinations in view of the derived $230 \mathrm{~cm}^{-1}$ frequency. The strength of the bands, however, makes this interpretation unlikely. Some of the internal structure observed in the $922 \mathrm{~cm}^{-1}$ band may arise from resonance effects between the fundamental and a combination of $v_{4}$ and $v_{6}$ which would be located near the same frequency.

TABLE 10. Infrared absorption spectra of zinc metaborate $\left[\mathrm{Zn}_{4} \mathrm{O}(\mathrm{cm}-1)\left(\mathrm{BO}_{i}\right)_{6}\right]$

\begin{tabular}{|c|c|c|c|}
\hline \multicolumn{3}{|c|}{$4 \mathrm{ZnO} \cdot 3 \mathrm{~B}_{2} \mathrm{O}_{3}$} & \multirow{2}{*}{ Assignment 1} \\
\hline $\mathrm{B}^{10} \& \mathrm{~B}^{11}$ & $\mathrm{~B}^{10}$ & B11 & \\
\hline $\begin{array}{l}1200 \mathrm{wsh} \\
1160 \mathrm{wsh} \\
1082 \mathrm{svb} \\
1037 \mathrm{~m} \\
927 \mathrm{vb} \\
717 \mathrm{~s} \\
470 \mathrm{~s}\end{array}$ & $\begin{array}{l}1340 \mathrm{vwb} \\
1275 \mathrm{wb} \\
1160 \mathrm{wsh} \\
1105 \mathrm{sb} \\
1067 \mathrm{~m} \\
937 \mathrm{svb} \\
721 \mathrm{~s} \\
470 \mathrm{~s}\end{array}$ & $\begin{array}{l}1296 \mathrm{vwb} \\
1232 \mathrm{wb} \\
1142 \mathrm{wsh} \\
1071 \mathrm{sb} \\
1030 \mathrm{~m} \\
922 \mathrm{svb} \\
716 \mathrm{~s} \\
470 \mathrm{~s} \\
(230)\end{array}$ & $\begin{array}{l}\nu_{5}+\nu_{6} \\
\nu_{1}+\nu_{6} \\
\nu_{2}+\nu_{6} \\
\nu_{5}(\mathrm{E}) \\
\nu_{1}\left(\mathrm{~A}_{1}\right) \\
\nu_{2}\left(\mathrm{~A}_{1}\right) \\
\nu_{4}(\mathrm{E}) \\
\nu_{3}\left(\mathrm{~A}_{1}\right) \\
\nu_{6}(\mathrm{E})\end{array}$ \\
\hline
\end{tabular}

1 Assignments on basis of effective $\mathrm{C}_{3 \mathrm{v}}$ symmetry for $\mathrm{BO}_{4}$ groups.

Regardless of the details of the assignment there is evidence for concluding that no fundamentals occur above $1100 \mathrm{~cm}^{-1}$ in the $\mathrm{B}^{11}$ compound, a conclusion which is in accord with the weak $\mathrm{B}-\mathrm{O}$ bond obtained from the x-ray structure analysis. From this result and additional spectra to be discussed later, it is concluded that when tetrahedrally coordinated boron is present strong fundamentals derived from $\nu_{3}$ of the tetrahedral ion should occur in the $800 \mathrm{~cm}^{-1}$ to 1100 $\mathrm{cm}^{-1}$ region. In these studies compounds containing three-fold coordinated boron always show strong fundamentals above $1100 \mathrm{~cm}^{-1}$ which can be considered as derived from the $\nu_{3}$ of the trigonal ion. For purposes of determining coordination the region between $800 \mathrm{~cm}^{-1}$ and $1400 \mathrm{~cm}^{-1}$ is considered to be important. It may also be noted that the zinc metaborate shows a band in the $700 \mathrm{~cm}^{-1}$ region. This band might be misinterpreted as corresponding to the out-of-plane mode, $\nu_{2}$ of a trigonal $\mathrm{BO}_{3}$ group which falls in the same frequency region. However, isotopic substitution distinguishes these bands because the shift observed in the zinc metaborate is much smaller than the corresponding shift in the trigonal ions.

The rare earth vaterite-type borates (sec. 6.1.b) have spectra showing similarities with the spectrum of zinc metaborate both with respect to band position and with respect to isotope shift. The corresponding: bands are $1042 \mathrm{~cm}^{-1}, 920 \mathrm{~cm}^{-1}$, and $718 \mathrm{~cm}^{-1}$ in $\mathrm{Lu}_{2} \mathrm{O}_{3} \cdot \mathrm{B}_{2}{ }^{11} \mathrm{O}_{3}$ and $1071 \mathrm{~cm}^{-1}, 922 \mathrm{~cm}^{-1}$ and $716 \mathrm{~cm}^{-1}$ in $\mathrm{Zn}_{4} \mathrm{O}\left(\mathrm{B}^{11} \mathrm{O}_{2}\right)_{6}$. These similarities were considered in 
the previous conclusions concerning the presence of tetrahedrally coordinated boron in the vaterite structures.

\section{d. Rare Earth Metaborates}

The first few members of the rare earth series form borates having a nominal ratio of metal oxide to boric oxide of $1: 3$. The composition is known for lanthanum borate [33] but it is less certain for the other borates and the system is presently being studied by Levin and McDaniel [35]. Although the composition is uncertain all the borates will be considered to have the $1: 3$ ratio at this time. Assuming a $1: 3$ ratio, the empirical formula can be written $\mathrm{M}\left(\mathrm{BO}_{2}\right)_{3}$ and the compounds can be considered to be metaborates.

Typical absorption spectra are shown in figure 9 and the observed absorption bands are compiled in table 11. From figure 9 it will be observed that there are large numbers of bands throughout the frequency range extending as high as $1450 \mathrm{~cm}^{-1}$. Further it can be observed that there is a very marked correspondence between the spectra, so that it is reasonably certain that the anions are the same or are very closely related in all compounds. The strong broad bands between $1100 \mathrm{~cm}^{-1}$ and $1500 \mathrm{~cm}^{-1}$ and their large shift with isotopic substitution is indicative of trigonal borate groups. Similarly the strong bands between $800 \mathrm{~cm}^{-1}$ and $1100 \mathrm{~cm}^{-1}$ and their strong isotopic dependence is indicative of tetrahedral boron. The bands at $725 \mathrm{~cm}^{-1}$ and $662 \mathrm{~cm}^{-1}$ in $\mathrm{La}_{2} \mathrm{O}_{3} \cdot 3 \mathrm{~B}_{2}{ }^{11} \mathrm{O}_{3}$ and their observed shifts may also be taken to indicate the presence of 4 -fold and 3 -fold coordinated boron, respectively. As shown later, these spectra have many similarities with these of the pentaborates.

TABLE 11. Infrared absorption spectra of rare earth metaborates 1

$\left(\mathrm{cm}^{-1}\right)$

\begin{tabular}{|c|c|c|c|c|}
\hline \multicolumn{2}{|c|}{$\mathrm{La}_{2} \mathrm{O}_{3} 3 \mathrm{~B}_{2} \mathrm{O}_{3}$} & \multirow{2}{*}{$\mathrm{Nd}_{2} \mathrm{O}_{3} 3 \mathrm{~B}_{2} \mathrm{O}_{3}$} & \multirow{2}{*}{$\mathrm{Sm}_{2} \mathrm{O}_{3} 3 \mathrm{~B}_{2} \mathrm{O}_{3}$} & \multirow{2}{*}{$\mathrm{Eu}_{2} \mathrm{O}_{3} 3 \mathrm{~B}_{2} \mathrm{O}_{3}$} \\
\hline $\mathrm{B}^{10}$ & $\mathrm{~B}^{11}$ & & & \\
\hline \multirow{2}{*}{$\begin{array}{l}1495 \mathrm{sb} \\
1410 \mathrm{sb} \\
1380 \mathrm{svb}\end{array}$} & $1445 \mathrm{sb}$ & $1456 \mathrm{sb}$ & \multirow{2}{*}{$\begin{array}{l}1470 \mathrm{svb} \\
1376 \mathrm{sb} \\
1308 \mathrm{svb}\end{array}$} & $1460 \mathrm{svb}$ \\
\hline & \multirow[b]{2}{*}{$1167 \mathrm{sb}$} & $1280 \mathrm{svb}$ & & \\
\hline \multirow{2}{*}{$\begin{array}{l}1183 \mathrm{svb} \\
1108 \mathrm{sb} \\
1053 \mathrm{sb}\end{array}$} & & $1210 \mathrm{svb}$ & $\begin{array}{l}1215 \mathrm{sb} \\
1165 \mathrm{svb}\end{array}$ & $1215 \mathrm{sb}$ \\
\hline & $1044 \mathrm{sb}$ & $\begin{array}{c}1042 \mathrm{sb} \\
972 \mathrm{~s}\end{array}$ & \multirow{5}{*}{$\begin{array}{l}1056 \mathrm{svb} \\
981 \mathrm{~s} \\
937 \mathrm{wsh} \\
911 \mathrm{svb} \\
863 \mathrm{msh} \\
813 \mathrm{~s} \\
795 \mathrm{wsh} \\
761 \mathrm{~s} \\
756 \mathrm{~s}\end{array}$} & $\begin{array}{c}1115 \mathrm{wsh} \\
1048 \mathrm{~s} \\
975 \mathrm{~s}\end{array}$ \\
\hline \multirow[t]{2}{*}{$\begin{array}{l}964 \mathrm{sb} \\
905 \mathrm{svb}\end{array}$} & $\begin{array}{l}952 \mathrm{sb} \\
870 \mathrm{sb}\end{array}$ & $950 \mathrm{~m}$ & & $903 \mathrm{svb}$ \\
\hline & & $808 \mathrm{~s}$ & & $\begin{array}{l}861 \mathrm{msh} \\
810 \mathrm{~s}\end{array}$ \\
\hline $811 \mathrm{sb}$ & $789 \mathrm{sb}$ & $\begin{array}{l}792 \mathrm{msh} \\
767 \mathrm{~m}\end{array}$ & & $\begin{array}{l}795 \mathrm{wsh} \\
770 \mathrm{~m}\end{array}$ \\
\hline & $\begin{array}{l}757 \mathrm{~m} \\
744 \mathrm{msh}\end{array}$ & $755 \mathrm{msh}$ & & $756 \mathrm{msh}$ \\
\hline \multirow{4}{*}{$\begin{array}{l}730 \mathrm{~s} \\
717 \mathrm{wsh} \\
689 \mathrm{sb} \\
661 \mathrm{~s} \\
614 \mathrm{~s} \\
578 \mathrm{~s} \\
523 \mathrm{~s}\end{array}$} & $725 \mathrm{wsh}$ & $710 \mathrm{mb}$ & $727 \mathrm{~s}$ & \\
\hline & $662 \mathrm{~s}$ & $672 \mathrm{~s}$ & $668 \mathrm{~s}$ & $670 \mathrm{~s}$ \\
\hline & $\begin{array}{l}605 \mathrm{~s} \\
572 \mathrm{~s} \\
516 \mathrm{~s}\end{array}$ & $\begin{array}{l}612 \mathrm{~s} \\
580 \mathrm{~s} \\
522 \mathrm{~s}\end{array}$ & $\begin{array}{l}612 \mathrm{~s} \\
581 \mathrm{~m} \\
556 \mathrm{~m}\end{array}$ & $\begin{array}{l}611 \mathrm{~s} \\
583 \mathrm{sb}\end{array}$ \\
\hline & & & $\begin{array}{l}525 \mathrm{~s} \\
492\end{array}$ & $\begin{array}{l}524 \mathrm{sb} \\
490\end{array}$ \\
\hline
\end{tabular}

${ }_{1}^{1}$ The molar ratio of only $\mathrm{La}_{2} \mathrm{O}_{3} \cdot 3 \mathrm{~B}_{2} \mathrm{O}_{3}$ is known. The others are not known. $\mathrm{X}$-ray diffraction and phase equilibrium data indicate that the europium and possibly samarium may have different compositions from that given here.

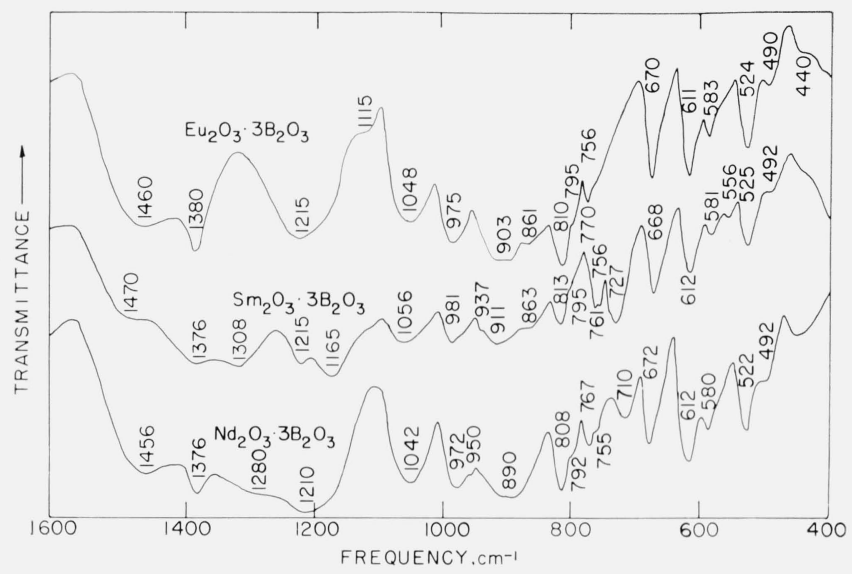

Figure 9. Absorption spectra of rare earth metaborates.

\subsection{Pyroborates}

The divalent metals form compounds with a $2: 1$ ratio of oxides which have empirical formulas $\mathrm{X}_{2} \mathrm{~B}_{2} \mathrm{O}_{5}$ and can be classed as pyroborates. Typical spectra are shown in figure 10 and the absorption bands are tabulated in table 12. From the figure it is observed that the spectra are quite similar and are of intermediate complexity. The lead pyroborate, however, as shown by the tabular data is somewhat different. Considering first the isotopic substitution data on $2 \mathrm{CaO} \cdot \mathrm{B}_{2} \mathrm{O}_{3}$, the two modes derived from $\nu_{2}$ of the trigonal ion are probably represented by the $723 \mathrm{~cm}^{-1}$ and $713 \mathrm{~cm}^{-1}$ bands tabulated for the $\mathrm{B}^{11}$ compound. The $713 \mathrm{~cm}^{-1}$ band is not shown in figure 10 but is irequently resolved as a shoulder on the $723 \mathrm{~cm}^{-1}$ band. The overlap of the two modes is believed to produce the rather broad intense band above $700 \mathrm{~cm}^{-1}$ in all spectra of figure 10 . The bands at $670 \mathrm{~cm}^{-1}$ and $618 \mathrm{~cm}^{-1}$ are identified by their relative independence of isotope mass as two of the modes derived from $\nu_{4}$. The other two components of $\nu_{4}$ are not apparent. They may be too weak to be observed, may coincide in frequency with the observed bands, or may overlap the band at 723 $\mathrm{cm}^{-1}$ which is apparently complex. The $474 \mathrm{~cm}^{-1}$ mode is probably an ionic distortion mode and may be tentatively assigned as the coupled bending mode. Two twisting modes probably are beyond the frequency range used. The symmetric stretch can be identified with the isotope independent frequency at $1012 \mathrm{~cm}^{-1}$. The other mode derived from $\nu_{1}$ is not apparent and may correspond to the $803 \mathrm{~cm}^{-1}$ band. This band, however, may also originate from combinations or overtones from a low frequency mode. The four modes derived from $v_{3}$ of the trigonal ion are located between $1150 \mathrm{~cm}^{-1}$ and $1400 \mathrm{~cm}^{-1}$. There are at least six bands observed in this region for $2 \mathrm{CaO} \cdot \mathrm{B}_{2}{ }^{11} \mathrm{O}_{3}$ and at least two of these- 1177 $\mathrm{cm}^{-1}$ and $1450 \mathrm{~cm}^{-1}$ - may be combinations or overtones. Therefore, with reasonable assurance the bands of table 12 can be assigned to the $\mathrm{B}_{2} \mathrm{O}_{5}^{-4}$ ion in terms of the corresponding vibrations of the 
TABLE 12. Infrared absorption spectra of divalent pyroborates

$\left(\mathrm{cm}^{-1}\right)$

\begin{tabular}{|c|c|c|c|c|c|c|c|}
\hline \multirow{2}{*}{$2 \mathrm{MgOB}_{2} \mathrm{O}_{3}$} & \multicolumn{3}{|c|}{$2 \mathrm{CaO} \cdot \mathrm{B}_{2} \mathrm{O}_{3}$} & \multirow{2}{*}{$2 \mathrm{SrOB}_{2} \mathrm{O}_{3}$} & \multirow{2}{*}{$2 \mathrm{CdOB}_{2} \mathrm{O}_{3}$} & \multirow{2}{*}{$2 \mathrm{CoOB}_{2} \mathrm{O}_{3}$} & \multirow{2}{*}{$2 \mathrm{PbOB}_{2} \mathrm{O}_{3}$} \\
\hline & $\mathrm{B}^{10} \& \mathrm{~B}^{11}$ & $\mathrm{~B}^{10}$ & $\mathrm{~B}^{11}$ & & & & \\
\hline \multirow[t]{2}{*}{$1450 \mathrm{vsvb}$} & & $1450 \mathrm{msh}$ & $1450 \mathrm{msh}$ & & & & \\
\hline & 1366 & $1411 \mathrm{vs}$ & $1365 \mathrm{vs}$ & $1350 \mathrm{sb}$ & $1350 \mathrm{svb}$ & $1400 \mathrm{svb}$ & \multirow{4}{*}{$\begin{array}{l}1352 \mathrm{w} \\
1315 \mathrm{sh} \\
1284 \mathrm{~s} \\
1248 \mathrm{~s} \\
1233 \mathrm{~s}\end{array}$} \\
\hline $1290 \mathrm{~m}$ & $\begin{array}{l}1328 \\
1292\end{array}$ & $\begin{array}{l}1374 \mathrm{~s} \\
1335 \mathrm{~s}\end{array}$ & $\begin{array}{l}1327 \mathrm{~s} \\
1290 \mathrm{~s}\end{array}$ & $\begin{array}{l}1323 \mathrm{sb} \\
1261 \mathrm{sb}\end{array}$ & n & - & \\
\hline $1260 \mathrm{~m}$ & 1248 & $1302 \mathrm{vs}$ & $1255 \mathrm{vs}$ & $1220 \mathrm{sb}$ & $1250 \mathrm{sb}$ & $1250 \mathrm{svb}$ & \\
\hline $1150 \mathrm{svb}$ & 1140 svb & 1172 & $1158 \mathrm{svb}$ & $1161 \mathrm{sb}$ & 1130 svb & $1150 \mathrm{svb}$ & \\
\hline $\begin{array}{c}1022 \mathrm{~m} \\
975 \mathrm{bsh}\end{array}$ & $\begin{array}{l}1011 \mathrm{~m} \\
973 \mathrm{vw}\end{array}$ & $1012 \mathrm{~m}$ & $\begin{array}{l}1127 \mathrm{sbsh} \\
1012 \mathrm{~m}\end{array}$ & $\begin{array}{l}1092 \mathrm{sb} \\
1000 \mathrm{~m}\end{array}$ & $998 \mathrm{~m}$ & 1007 & \multirow{2}{*}{$\begin{array}{l}1017 \mathrm{sb} \\
971 \mathrm{~s} \\
877 \mathrm{vs} \\
835\end{array}$} \\
\hline $834 w b$ & & & & & & & \\
\hline $789 w b$ & $\begin{array}{l}806 \mathrm{~W} \\
775 \mathrm{vw}\end{array}$ & $813 \mathrm{~m}$ & $803 \mathrm{~m}$ & $\begin{array}{l}789 \mathrm{w} \\
772 \mathrm{w}\end{array}$ & 800 & 817 & \\
\hline $745 \mathrm{msh}$ & & & & $735 \mathrm{msh}$ & & & $734 \mathrm{~m}$ \\
\hline $712 \mathrm{~s}$ & $718 \mathrm{~s}$ & $\begin{array}{l}738 \mathrm{~s} \\
735 \mathrm{~s}\end{array}$ & $723 \mathrm{~s}$ & $\begin{array}{l}726 \mathrm{msh} \\
717 \mathrm{~s}\end{array}$ & $\begin{array}{l}707 \\
691 \mathrm{~s}\end{array}$ & $\begin{array}{l}698 \mathrm{~s} \\
693\end{array}$ & $\begin{array}{l}710 \\
703\end{array}$ \\
\hline $683 \mathrm{~s}$ & & $728 \mathrm{sh}$ & (n) & & & & \multirow{5}{*}{$\begin{array}{l}685 \mathrm{bsh} \\
661 \\
640 \\
615 \\
595 \\
578 \\
547 \mathrm{~m}\end{array}$} \\
\hline $668 \mathrm{msh}$ & $667 \mathrm{~m}$ & $671 \mathrm{~s}$ & $670 \mathrm{~s}$ & $656 \mathrm{~m}$ & $667 \mathrm{~s}$ & 658 & \\
\hline $603 \mathrm{~s}$ & $618 \mathrm{~s}$ & $618 \mathrm{~s}$ & $618 \mathrm{~s}$ & $616 \mathrm{~s}$ & $591 \mathrm{~s}$ & 587 & \\
\hline $568 \mathrm{w}$ & & & & & & 572 & \\
\hline $\begin{array}{l}535 \text { wsh } \\
484 \mathrm{~s}\end{array}$ & $475 \mathrm{~W}$ & 475 & $474 \mathrm{w}$ & $460 \mathrm{w}$ & $497 \mathrm{w}$ & 449 & \\
\hline
\end{tabular}

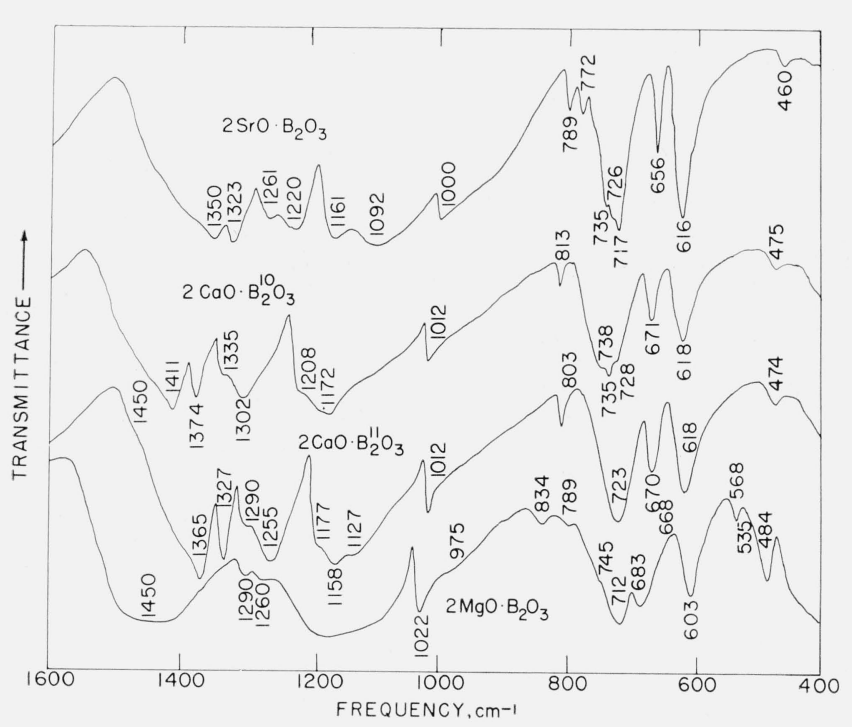

Figure 10. Absorption spectra of pyroborates.

parent $\mathrm{BO}_{3}{ }^{-3}$ group. It is of interest to note that although the symmetric type stretching frequency in the pyroborates is essentially the same in the orthoborates, modes derived from $\nu_{3}$ of the trigonal ion extend to much higher frequencies. The higher frequencies are not unexpected in this case because all $\mathrm{B}$ - $\mathrm{O}$ bonds are not equivalent in the pyroborates [6] and a greater partial double bond character may be attributed to some bonds.

From the data of table 12 it can be observed that the lead pyroborate exhibits a spectrum similar to the other pyroborates but containing more bands, particularly several strong bands in $800 \mathrm{~cm}^{-1}$ to
$1100 \mathrm{~cm}^{-1}$ region. There are also other bands at lower frequencies not found in the other pyroborates. Therefore, the anion in this compound probably does not consist of two coupled trigonal groups. The bands in the $800 \mathrm{~cm}^{-1}$ to $1100 \mathrm{~cm}^{-1}$ region may be taken to indicate that tetrahedral boron is present and the low frequency bands are indicative of a large complex anion.

\subsection{Triborates}

Alkali borates formed with the 1:3 ratio of oxides have the empirical formula $\mathrm{XB}_{3} \mathrm{O}_{5}$. For purposes of this discussion they are classed as triborates. No structural data appear to be available on the compounds studied except $\mathrm{Cs}_{2} \mathrm{O} \cdot 3 \mathrm{~B}_{2} \mathrm{O}_{3}$ [29]. The anion is quite complex and is composed of six-membered rings each containing 2 triangular and one tetrahedral boron, with the tetrahedral boron atoms being shared by two rings. Typical spectra are given in figure 11 for the isotopically substituted lithium compounds with the observed data being tabulated in table 13 . From figure 11 it can be observed that the spectra are complex and indicative of a low symmetry and a large anion. The spectra are consistent with the presence of both trigonal and tetrahedral boron. The persistence of absorption bands which appear to be fundamentals to high frequencies is indicative that at least some of the $\mathrm{B}-\mathrm{O}$ bonds have partial double bond character. The spectra and the shifts observed are not inconsistent with the six membered ring found in $\mathrm{Cs}_{2} \mathrm{O} \cdot 3 \mathrm{~B}_{2} \mathrm{O}_{3}$ although the spectra are too complex to warrant any specific conclusions on this point without further information on the origin of the various bands. 
TABLE 13. Infrared absorption spectra of alkali triborates $\left(\mathrm{XB}_{3} \mathrm{O}_{5}\right)$

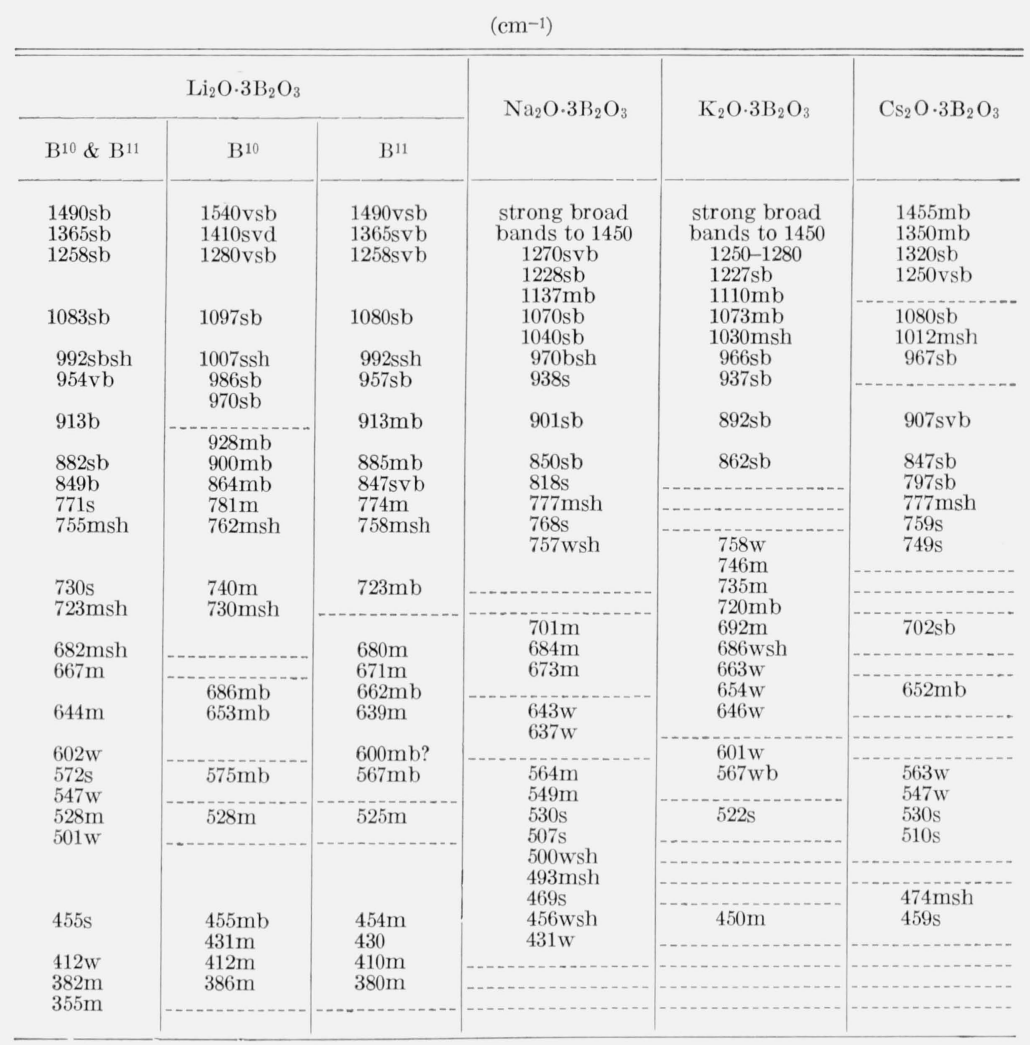

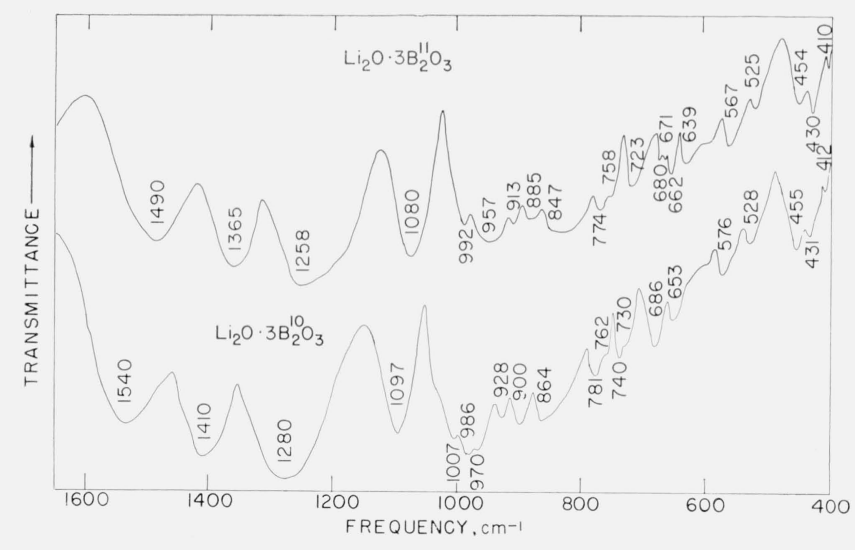

Figure 11. Absorption spectra of lithium triborates.

\subsection{Tetraborates $\left(\mathrm{XnB}_{4} \mathrm{O}_{7}\right)$}

Both monovalent (alkali) and divalent metals form borates in a 1:2 ratio of oxides which have empirical formulas $\mathrm{X}_{2} \mathrm{~B}_{4} \mathrm{O}_{7}$ and $\mathrm{YB}_{4} \mathrm{O}_{7}$, respectively. These compounds are classified as tetraborates.

\section{a. Alkali Tetraborates}

From the structure of lithium tetraborate reported by Krogh-Moe [28] it is expected that the spectra of the alkali tetraborates might give evidence for both 3 - and 4 -fold coordinated boron in a complex ring system of low symmetry. The spectra shown in figure 12 and the data of table 14 show that the results are in accord with the predictions. The strong bands and the isotopic shifts in $\mathrm{Li}_{2} \mathrm{O} \cdot 2 \mathrm{~B}_{2} \mathrm{O}_{3}$ in the $800 \mathrm{~cm}^{-1}$ to $1100 \mathrm{~cm}^{-1}$ region are indicative of tetrahedrally coordinated boron and the similar bands in the 1100 $\mathrm{cm}^{-1}$ to $1400 \mathrm{~cm}^{-1}$ region are indicative of 3 -fold coordination. Similarly the $773 \mathrm{~cm}^{-1}$ and $676 \mathrm{~cm}^{-1}$ bands of the $\mathrm{B}^{11}$ compound are taken as indicative of the presence of the two types of boron. These conclusions have been verified by the NMR data of Ring and Bray [43]. The absorption at higher frequencies is strong and broad and is not tabulated for the compounds with the normal isotopic distribution. These bands, however, are resolved in the two isotopically substituted lithium tetraborates. There is a very close correlation between the spectra of the sodium and potassium tetraborates and the anions in these compounds are apparently identical but it is not clear from the spectra that the anion in $\mathrm{Li}_{2} \mathrm{O} \cdot \mathrm{B}_{2} \mathrm{O}_{3}$ is similar. In the case of the sodium and potassium compounds the correlation is so close that it is suspected that they may be isostructural. The data obtained on $\mathrm{Na}_{2} \mathrm{O} \cdot 2 \mathrm{~B}_{2} \mathrm{O}_{3}$ appear to agree reasonably well with the spectrum given by Krogh-Moe [25]. It may be noted that some of the apparent discrepancies between the data for the lithium tetraborate and the sodium and potassium tetraborates may arise from the tighter packing which presumably occurs with the small lithium ion. 


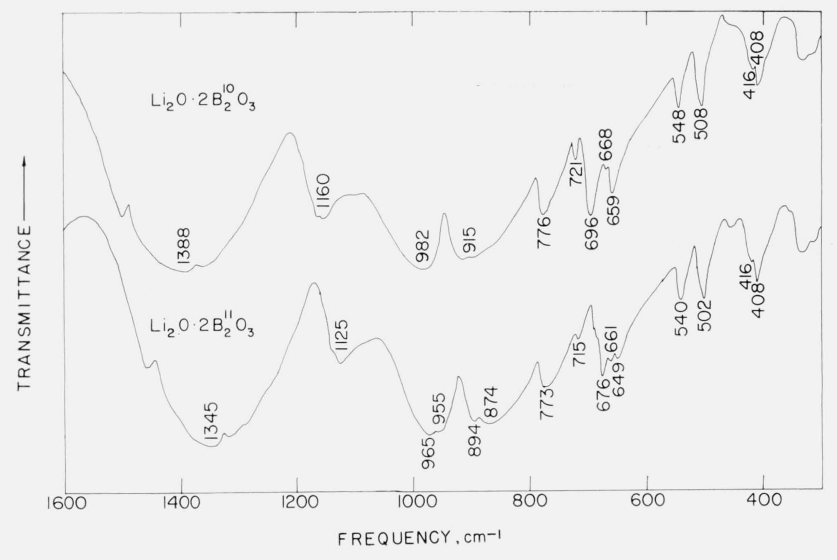

Figure 12. Absorption spectra of alkali tetraborates.

TABLE 14. Infrared absorption spectra of alkali tetraborates $\left(\mathrm{X}_{2} \mathrm{~B}_{4} \mathrm{O}_{7}\right)$

$\left(\mathrm{cm}^{-1}\right)$

\begin{tabular}{|c|c|c|c|c|}
\hline \multicolumn{3}{|c|}{$\mathrm{Li}_{2} \mathrm{O} \cdot 2 \mathrm{~B}_{2} \mathrm{O}_{3}$} & \multirow{2}{*}{$\mathrm{Na}_{2} \mathrm{O} \cdot 2 \mathrm{~B}_{2} \mathrm{O}_{3}$} & \multirow{2}{*}{$\mathrm{K}_{2} \mathrm{O} \cdot 2 \mathrm{~B}_{2} \mathrm{O}_{3}$} \\
\hline $\mathrm{B}^{10} \& \mathrm{~B}^{11}$ & $\mathrm{~B}^{10}$ & $\mathrm{~B}^{11}$ & & \\
\hline \multirow{6}{*}{$\begin{array}{l}970 \text { sb } \\
886 \text { sb } \\
861 \text { sb }\end{array}$} & $1388 \mathrm{vsb}$ & $1345 \mathrm{svb}$ & & \multirow{16}{*}{$\begin{array}{l}1130 \mathrm{msh} \\
1085 \mathrm{mb} \\
1032 \mathrm{sb} \\
978 \mathrm{sb} \\
915- \\
835 \mathrm{svb} \\
779 \\
763 \\
748 \\
730 \\
718 \\
687 \mathrm{~s} \\
670 \mathrm{msh} \\
660 \mathrm{~m} \\
637 \mathrm{~m} \\
612 \mathrm{~m} \\
596 \mathrm{~s} \\
553 \mathrm{~m} \\
517 \mathrm{~m} \\
492 \mathrm{w} \\
476 \mathrm{w}\end{array}$} \\
\hline & $1160 \mathrm{sb}$ & $1125 \mathrm{sb}$ & $1148 \mathrm{sb}$ & \\
\hline & & & $\begin{array}{l}1090 \mathrm{sb} \\
1046 \mathrm{sb}\end{array}$ & \\
\hline & $982 \mathrm{svb}$ & $965 \mathrm{sb}$ & $1010 \mathrm{sb}$ & \\
\hline & & $\begin{array}{l}955 \mathrm{ssh} \\
894 \mathrm{ssh}\end{array}$ & $900-$ & \\
\hline & $915 \mathrm{svb}$ & $874 \mathrm{svb}$ & 836 svb & \\
\hline $771 \mathrm{~s}$ & $776 \mathrm{sb}$ & $773 \mathrm{sb}$ & $767 \mathrm{~m}$ & \\
\hline & & & $\begin{array}{l}745 \mathrm{sh} \\
725\end{array}$ & \\
\hline $\begin{array}{l}718 \mathrm{msh} \\
707 \mathrm{msh}\end{array}$ & $721 \mathrm{~m}$ & $715 \mathrm{~m}$ & 717 & \\
\hline $678 \mathrm{~m}$ & $696 \mathrm{~s}$ & $676 \mathrm{~s}$ & $675 \mathrm{mb}$ & \\
\hline $650 \mathrm{mb}$ & $\begin{array}{l}668 \mathrm{w} \\
659 \mathrm{~s}\end{array}$ & $661 \mathrm{msh}$ & $661 \mathrm{~m}$ & \\
\hline \multirow{6}{*}{$\begin{array}{l}596 \mathrm{msh} \\
566 \mathrm{wsh} \\
543 \mathrm{~s} \\
508 \mathrm{msh} \\
504 \mathrm{~s} \\
455 \mathrm{w}\end{array}$} & & & $\begin{array}{l}030 \mathrm{~m} \\
611 \mathrm{~m}\end{array}$ & \\
\hline & & & $583 \mathrm{~m}$ & \\
\hline & & & $554 \mathrm{~m}$ & \\
\hline & $548 \mathrm{~s}$ & $540 \mathrm{~s}$ & $\begin{array}{l}513 \mathrm{~m} \\
490 \mathrm{w}\end{array}$ & \\
\hline & $508 \mathrm{~s}$ & $502 \mathrm{~s}$ & $472 \mathrm{w}$ & \\
\hline & $\begin{array}{l}416 \mathrm{sh} \\
408 \mathrm{~s}\end{array}$ & $\begin{array}{l}416 \mathrm{sh} \\
408 \mathrm{~s}\end{array}$ & & \\
\hline
\end{tabular}

\section{b. Divalent Metal Tetraborates}

The divalent metal tetraborates fall into two distinct groups with respect to their infrared spectra. Typical spectra for one type are shown in figure 13 and the data for all the compounds studied are compiled in table 15 . From the tabulated absorption data it is clear that strong absorption occurs at much higher frequencies in the spectra of the calcium, barium, and zinc compounds than in those of strontium and lead. The presence of both 3-fold and 4-fold coordinated boron is indicated in the former compounds with a large anion of low symmetry. The structure reported for $\mathrm{BaO} \cdot 2 \mathrm{~B}_{2} \mathrm{O}_{3}$ fulfills these requirements [7]. Although the tabular data indicate that the spectra of $\mathrm{CaO} \cdot 2 \mathrm{~B}_{2} \mathrm{O}_{3}$, and $\mathrm{ZnO} \cdot 2 \mathrm{~B}_{2} \mathrm{O}_{3}$ are very similar, this does not appear to be true. Comparison of the actual spectra shows marked differences in positions and relative intensities of many bands. On the basis of these

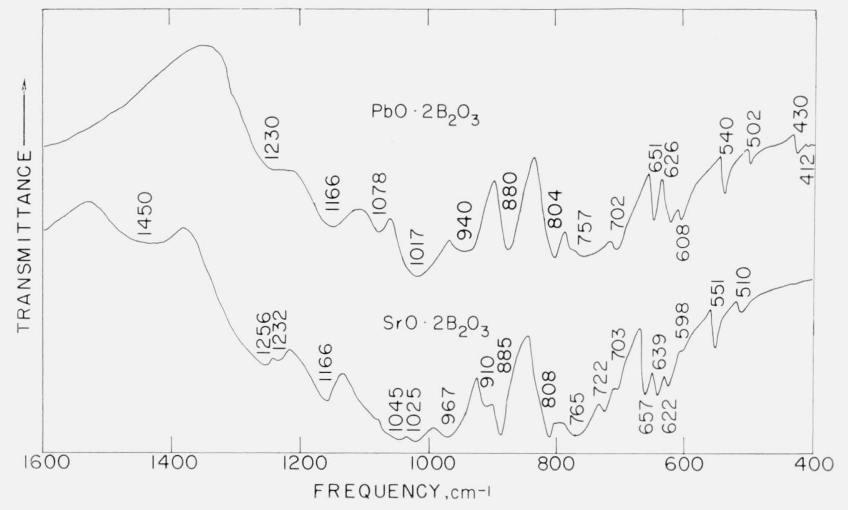

Figure 13. Absorption spectra of divalent metal tetraborates.

data it seems improbable that the anions in these compounds are identical.

From figure 13 , however, it can be seen that the spectra of $\mathrm{SrO} \cdot 2 \mathrm{~B}_{2} \mathrm{O}_{3}$ and $\mathrm{PbO} \cdot 2 \mathrm{~B}_{2} \mathrm{O}_{3}$ are so similar that a structural relationship is indicated. X-ray powder diffraction patterns show that these two compounds are isostructural [7]. The spectra may be interpreted in the usual manner to indicate tetrahedrally coordinated boron. There appear to be bands in the region above $1100 \mathrm{~cm}^{-1}$ which would ordinarily be taken as indicative of the presence of boron in 3-fold coordination. However, bands in this region are not intense, being much weaker than expected for fundamentals presumed to be related to the $\nu_{3}$ mode of triangular units. Therefore, it seems probable that these bands may represent overtones or combinations of some of the lower frequency modes. Although there is some evidence for the presence of boron in 3-fold coordination in the isotopic shifts observed for some bands in the $700 \mathrm{~cm}^{-1}$ region, the evidence cannot be considered unequivocal in the presence of such a complex spectrum. It is clear that the anions in these compounds are probably identical and complex. On the basis of the infrared spectrum it is concluded that the anions consist of tetrahedrally coordinated boron atoms with the presence of any boron in 3-fold coordination being doubtful. These conclusions are substantiated by the rather high density reported for $\mathrm{SrO} \cdot 2 \mathrm{~B}_{2} \mathrm{O}_{3}[7]$.

Note added in proof: Work on the crystal structure of $\mathrm{SrO} \cdot 2 \mathrm{~B}_{2} \mathrm{O}_{3}$ and $\mathrm{PbO} \cdot 2 \mathrm{~B}_{2} \mathrm{O}_{3}$ has been completed by $\mathrm{S}$. Block and A. Perloff. The structure, reported at the Annual Meeting of the American Crystallographic Association in Bozeman, Mont., July 1964, is found to contain only tetrahedral boron atoms. This result confirms the conclusions drawn from spectroscopic evidence alone. A paper on the structure is in preparation.

\subsection{Pentaborates $\left(\mathrm{XB}_{5} \mathrm{O}_{8}\right)$}

Some alkalies form compounds having a $1: 5$ ratio of the oxides and an empirical formula $\mathrm{XB}_{5} \mathrm{O}_{8}$ which are classified here as pentaborates. From the known structures [27] it is expected that the spectra should be complex and show evidence for both trigonal and tetrahedral boron. The spectra shown in figure 14 and the tabulated data of table 16 verify this prediction. In figure 14 it can be noted that the 
TABLE 15. Infrared absorption spectra of divalent metal tetraborates $\left(\mathrm{XB}_{4} \mathrm{O}_{7}\right)$

\begin{tabular}{|c|c|c|c|c|c|c|}
\hline \multirow{2}{*}{$\mathrm{CaO} \cdot 2 \mathrm{~B}_{2} \mathrm{O}_{3}$} & \multirow{2}{*}{$\mathrm{BaO} \cdot 2 \mathrm{~B}_{2} \mathrm{O}_{3}$} & \multirow{2}{*}{$\mathrm{ZnO} \cdot 2 \mathrm{~B}_{2} \mathrm{O}_{3}$} & \multicolumn{3}{|c|}{$\mathrm{SrO} \cdot 2 \mathrm{~B}_{2} \mathrm{O}_{3}$} & \multirow{2}{*}{$\mathrm{PbO} \cdot 2 \mathrm{~B}_{2} \mathrm{O}_{3}$} \\
\hline & & & $\mathrm{B}^{10} \& \mathrm{~B}^{11}$ & $\mathrm{~B}^{10}$ & $\mathrm{~B}^{11}$ & \\
\hline \multirow{6}{*}{$\begin{array}{l}1435 \mathrm{sb} \\
1390 \mathrm{sb} \\
1363 \mathrm{sb} \\
1305 \mathrm{sb} \\
1247 \mathrm{sb} \\
1188 \mathrm{sb}\end{array}$} & $1443 \mathrm{mb}$ & & $1450 \mathrm{mvb}$ & & & \\
\hline & $1400 \mathrm{mb}$ & 1390sb & & & & \\
\hline & $1332-$ & $1342 \mathrm{sb}$ & $2-1+2-1$ & & & \\
\hline & $1292 \mathrm{svb}$ & $1298 \mathrm{sb}$ & - & & & (n) \\
\hline & $1245 \mathrm{sb}$ & $1260 \mathrm{sb}$ & $1256 \mathrm{sb}$ & - & & \\
\hline & $1163 \mathrm{~m}$ & $\begin{array}{l}1237 \mathrm{sb} \\
1192 \mathrm{msh}\end{array}$ & $1232 \mathrm{sb}$ & $1260 \mathrm{sb}$ & $1223 \mathrm{sb}$ & $1230 \mathrm{sb}$ \\
\hline \multirow{12}{*}{$\begin{array}{l}1090 \mathrm{sb} \\
1052 \mathrm{sb} \\
993 \mathrm{sb} \\
942 \mathrm{sb} \\
910 \mathrm{sb} \\
850 \mathrm{sb} \\
818 \mathrm{mb} \\
793 \mathrm{wsh} \\
776 \mathrm{mb} \\
728 \mathrm{~m} \\
706 \mathrm{~s} \\
691 \mathrm{wsh} \\
668 \mathrm{~m} \\
658 \mathrm{wsh} \\
632 \\
600\end{array}$} & $1107 \mathrm{msh}$ & $1165 \mathrm{sb}$ & $1166 \mathrm{sb}$ & $1168 \mathrm{sb}$ & $1157 \mathrm{sb}$ & $1166 \mathrm{~s}$ \\
\hline & $1082 \mathrm{wsh}$ & $1072 \mathrm{sb}$ & $1045 \mathrm{sb}$ & $1080-$ & $1060-$ & $1078 \mathrm{sb}$ \\
\hline & $1068 \mathrm{mb}$ & $1047 \mathrm{wsh}$ & $1025 \mathrm{sb}$ & $970 v s v b$ & $950 \mathrm{vsvb}$ & $1017 \mathrm{sb}$ \\
\hline & $995 \mathrm{sb}$ & $988 \mathrm{sb}$ & $967 \mathrm{sb}$ & - & (n) & 940 sb \\
\hline & $\begin{array}{l}926 \mathrm{sb} \\
887 \mathrm{sb}\end{array}$ & $\begin{array}{l}965 \\
906 \mathrm{sb}\end{array}$ & $910 \mathrm{mb}$ & (n)- & $905 \mathrm{msh}$ & \\
\hline & $835 \mathrm{sb}$ & $858 \mathrm{sb}$ & $885 \mathrm{~s}$ & $891 \mathrm{~s}$ & $880 \mathrm{~s}$ & $880 \mathrm{sb}$ \\
\hline & $790 \mathrm{~m}$ & $810 \mathrm{mb}$ & $808 \mathrm{~s}$ & $811 \mathrm{~s}$ & $806 \mathrm{~s}$ & $804 \mathrm{~s}$ \\
\hline & $\begin{array}{l}761 \mathrm{~m} \\
735 \mathrm{sb}\end{array}$ & $763 \mathrm{msh}$ & $765 \mathrm{sb}$ & $769 \mathrm{sb}$ & $750 \mathrm{sb}$ & $757 \mathrm{sb}$ \\
\hline & $711 \mathrm{~m}$ & $716 \mathrm{~s}$ & $722 \mathrm{~m}$ & $731 \mathrm{~s}$ & $717 \mathrm{ssh}$ & \\
\hline & $\begin{array}{l}679 \mathrm{~s} \\
660 \mathrm{~m}\end{array}$ & $\begin{array}{l}698 \mathrm{msh} \\
672 \mathrm{w}\end{array}$ & $703 \mathrm{~m}$ & $702 \mathrm{ssh}$ & $700 \mathrm{ssh}$ & $702 \mathrm{~s}$ \\
\hline & $653 w$ & $655 \mathrm{w}$ & $657 \mathrm{~s}$ & $669 \mathrm{~s}$ & $653 \mathrm{~s}$ & $651 \mathrm{~s}$ \\
\hline & $606 \mathrm{~s}$ & - & $059 \mathrm{~s}$ & $633 \mathrm{vw}$ & $629 \mathrm{vw}$ & \\
\hline \multirow{7}{*}{$\begin{array}{l}585 \\
567 \mathrm{~s} \\
534 \mathrm{~m} \\
505\end{array}$} & $\begin{array}{l}592 \mathrm{~W} \\
580 \mathrm{w}\end{array}$ & & $\begin{array}{l}622 \mathrm{~s} \\
508 \mathrm{msh}\end{array}$ & $619 \mathrm{~s}$ & $618 \mathrm{~s}$ & $608 \mathrm{~s}$ \\
\hline & $557 \mathrm{~m}$ & $582 \mathrm{w}$ & $598 \mathrm{msn}$ & 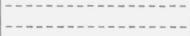 & $\begin{array}{l}\text { 601wsh } \\
581 \mathrm{w}\end{array}$ & \\
\hline & $\begin{array}{l}529 \\
496 \mathrm{~m}\end{array}$ & 545 & $551 \mathrm{~s}$ & $549 \mathrm{~s}$ & $\begin{array}{l}566 \text { wsh } \\
549 \text { s }\end{array}$ & $540 \mathrm{~s}$ \\
\hline & 483 & $469 \mathrm{~s}$ & & 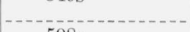 & $540 \mathrm{msh}$ & 年 \\
\hline & $\begin{array}{l}451 \mathrm{~s} \\
388 \mathrm{~m}\end{array}$ & (n) & $510 \mathrm{w}$ & $508 \mathrm{~s}$ & $508 \mathrm{~s}$ & $502 \mathrm{~s}$ \\
\hline & & & & 411 & $\begin{array}{l}435 \\
411\end{array}$ & $\begin{array}{l}430 \mathrm{~m} \\
412 \mathrm{w}\end{array}$ \\
\hline & & & $358 \mathrm{~m}$ & $357 \mathrm{~s}$ & $356 \mathrm{~s}$ & $342 w$ \\
\hline
\end{tabular}

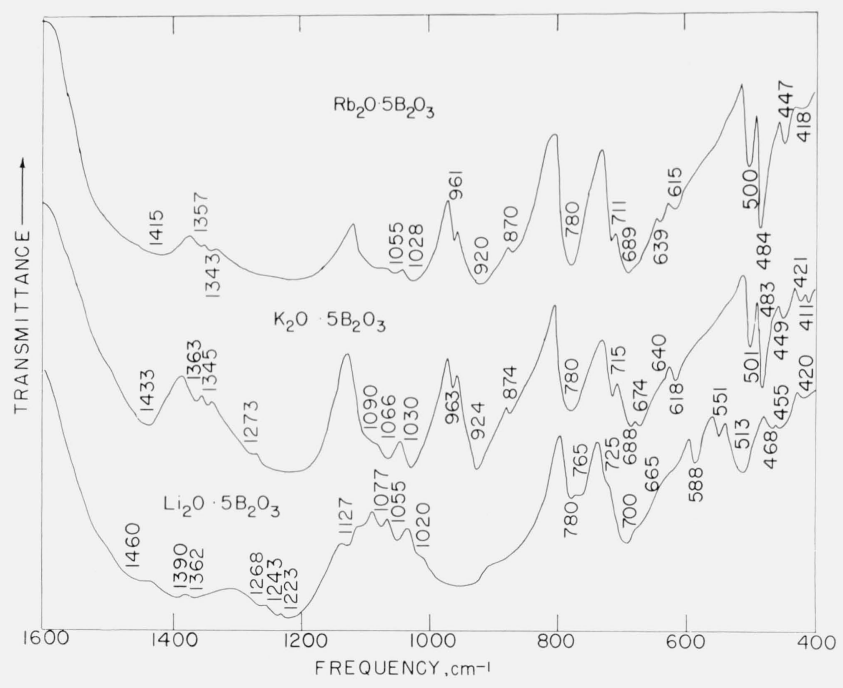

Figure 14. Absorption spectra of alkali pentaborates.

close similarity between the spectra of the rubidium and potassium compounds is indicative of their isostructural relationship [27]. The positions and isotopic shifts shown for the potassium pentaborate in table 16 are indicative of both 3 -fold and 4-fold coordinated boron atoms. In the isotopically substituted compounds there appear to be several sets of "doublets" consisting of bands of equal strength, with a small separation, and similar isotopic shifts. Apparently overlapping of bands from $\mathrm{B}^{10}$ and $\mathrm{B}^{11}$ compounds obscure these doublets in the spectrum of the normal compound. In view of the fact that the anion is formed by coupling two six-membered ring by means of a tetrahedral boron atom common to both rings, the doublets may arise from similar coupled vibrations of the rings. The spectrum of $\mathrm{Li}_{2} \mathrm{O} \cdot 5 \mathrm{~B}_{2} \mathrm{O}_{3}$ is very similar to those of the other two borates and it would not be surprising if the anion structure in all three pentaborates studied was identical.

TABLE 16. Infrared absorption spectra of alkali pentaborates $\left(\mathrm{XB}_{5} \mathrm{O}_{8}\right)$

\begin{tabular}{|c|c|c|c|c|}
\hline \multirow{2}{*}{$\mathrm{Li}_{2} \mathrm{O} \cdot 5 \mathrm{~B}_{2} \mathrm{O}_{3}$} & \multicolumn{3}{|c|}{$\mathrm{K}_{2} \mathrm{O} \cdot 5 \mathrm{~B}_{2} \mathrm{O}_{3}$} & \multirow{2}{*}{$\mathrm{Rb}_{2} \mathrm{O} \cdot 5 \mathrm{~B}_{2} \mathrm{O}_{3}$} \\
\hline & $\mathrm{B}^{10} \& \mathrm{~B}^{11}$ & $\mathrm{~B}^{10}$ & $B^{11}$ & \\
\hline $1400-1300$ & \multirow{8}{*}{$\begin{array}{l}1433 \mathrm{sb} \\
1363 \mathrm{~m} \\
1345 \mathrm{~m} \\
1273 \mathrm{sh} \\
1250-1190 \mathrm{~b} \\
1090 \mathrm{bsh} \\
1066 \mathrm{~s} \\
1030 \mathrm{~s} \\
963 \mathrm{~m} \\
924 \mathrm{sb} \\
874 \mathrm{~s}\end{array}$} & \multirow{4}{*}{$\begin{array}{l}1468 \mathrm{sb} \\
1405 \mathrm{~m} \\
1387 \mathrm{~m} \\
1372 \mathrm{~m} \\
1257 \mathrm{svb}\end{array}$} & \multirow{4}{*}{$\begin{array}{l}1419 \mathrm{sb} \\
1359 \mathrm{~s} \\
1338 \mathrm{~m} \\
1334 \mathrm{~m} \\
1202 \mathrm{svb}\end{array}$} & \multirow{3}{*}{$\begin{array}{l}1415 \mathrm{svb} \\
1357 \mathrm{~m} \\
1343 \mathrm{~m}\end{array}$} \\
\hline $1275-1175 \mathrm{vsb}$ & & & & \\
\hline $1127 \mathrm{~m}$ & & & & \\
\hline $1077 \mathrm{~m}$ & & & & $1250-1150 \mathrm{svb}$ \\
\hline $1055 \mathrm{~m}$ & & \multirow{4}{*}{$\begin{array}{l}1084 \mathrm{~m} \\
1040 \mathrm{svb} \\
974 \mathrm{ssh} \\
940 \mathrm{svb} \\
877 \mathrm{~s}\end{array}$} & \multirow{4}{*}{$\begin{array}{l}1061 \mathrm{~m} \\
1030 \mathrm{svb} \\
962 \mathrm{~s} \\
923 \mathrm{svb} \\
872 \mathrm{~s}\end{array}$} & \multirow{4}{*}{$\begin{array}{l}1055 \mathrm{~m} \\
1028 \mathrm{svb} \\
961 \mathrm{~m} \\
920 \mathrm{sb} \\
870 \mathrm{~s}\end{array}$} \\
\hline $1020 \mathrm{bsh}$ & & & & \\
\hline $1010-875 \mathrm{svb}$ & & & & \\
\hline $780 \mathrm{~s}$ & & & & \\
\hline $\begin{array}{l}765 \mathrm{~s} \\
725 \mathrm{msh}\end{array}$ & $\begin{array}{l}780 \mathrm{~s} \\
715 \mathrm{~s}\end{array}$ & \multirow{9}{*}{$\begin{array}{l}791 \mathrm{~s} \\
732 \mathrm{~s} \\
711 \mathrm{~s} \\
702 \mathrm{~s} \\
692 \mathrm{msh} \\
660 \mathrm{msh} \\
636 \mathrm{~m} \\
630 \mathrm{~m} \\
508 \mathrm{~s} \\
504 \mathrm{~s} \\
489 \mathrm{~s} \\
452 \mathrm{w} \\
422 \mathrm{w} \\
412 \mathrm{w}\end{array}$} & $\begin{array}{l}780 \mathrm{~s} \\
714 \mathrm{~s}\end{array}$ & $\begin{array}{l}780 \mathrm{sb} \\
711 \mathrm{~s}\end{array}$ \\
\hline & & & & \\
\hline $\begin{array}{l}700 \mathrm{sb} \\
665 \mathrm{ssh}\end{array}$ & $\begin{array}{l}688 \mathrm{~s} \\
674 \mathrm{~s} \\
640 \mathrm{wsh}\end{array}$ & & $\begin{array}{l}684 \mathrm{~s} \\
673 \mathrm{ssh} \\
635 \mathrm{msh}\end{array}$ & $\begin{array}{l}689 \mathrm{sb} \\
670 \mathrm{msh} \\
639 \mathrm{~m}\end{array}$ \\
\hline $588 \mathrm{~m}$ & $618 \mathrm{~m}$ & & \multirow{6}{*}{$\begin{array}{l}616 \mathrm{~m} \\
503 \mathrm{~s} \\
500 \mathrm{~s} \\
483 \mathrm{~s} \\
449 \mathrm{w} \\
421 \mathrm{w} \\
412 \mathrm{w}\end{array}$} & \multirow{6}{*}{$\begin{array}{l}615 \mathrm{~m} \\
509 \mathrm{~s} \\
500 \mathrm{~s} \\
484 \mathrm{~s} \\
447 \mathrm{~m} \\
418 \mathrm{w}\end{array}$} \\
\hline $551 \mathrm{~m}$ & & & & \\
\hline $513 \mathrm{~m}$ & $501 \mathrm{~s}$ & & & \\
\hline $468 w$ & $483 \mathrm{~s}$ & & & \\
\hline $455 \mathrm{w}$ & $449 \mathrm{~m}$ & & & \\
\hline $420 \mathrm{w}$ & $\begin{array}{l}421 w \\
411 w\end{array}$ & & & \\
\hline
\end{tabular}


The anions of the potassium and rubidium compounds may be considered as coupled modified boroxol rings. The presence of the tetrahedral boron should tend to decrease the strength of some of the $\mathrm{B}-\mathrm{O}$ bonds in the ring and the coupling should tend to increase the effective mass of the coupling boron atom. Both effects would tend to decrease some observed frequencies below the corresponding modes of the boroxol ring. Furthermore from the lack of symmetry all modes of the modified boroxol ring should be active in this instance. Comparison of these spectra with those of the alkali metaborates is not too informative because of the poor spectra of the metaborates and their low infrared activity arising from symmetry. The only mode common to both compounds appears to be represented by the strong band identified as $\nu_{10}$ [14] in the alkali metaborates. This band occurs at $723 \mathrm{~cm}^{-1}$ in $\mathrm{NaBO}_{2}$ at $712 \mathrm{~cm}^{-1}$ in $\mathrm{KBO}_{2}, 711 \mathrm{~cm}^{-1}$ in $\mathrm{Rb}_{2} \mathrm{O} \cdot 5 \mathrm{~B}_{2} \mathrm{O}_{3}$, and $714 \mathrm{~cm}^{-1}$ in $\mathrm{K}_{2} \mathrm{O} \cdot 5 \mathrm{~B}_{2}^{11} \mathrm{O}_{3}$. The position, character, and isotopic shift noted in the $\mathrm{KBO}_{2}$ and $\mathrm{K}_{2} \mathrm{O} \cdot 5 \mathrm{~B}_{2} \mathrm{O}_{3}$ compounds are so similar that this band can be assigned tentatively as corresponding to $\nu_{10}\left(\mathrm{E}^{\prime}\right)$. Comparing the present data with these of Goubeau and Keller; the following tentative assignments may be made in the pentaborates: for $\mathrm{Rb}_{2} \mathrm{O} \cdot 5 \mathrm{~B}_{2} \mathrm{O}_{3}$, $\nu_{1}\left(\mathrm{~A}_{1}^{\prime}\right)$ 1150-1250 $\mathrm{cm}^{-1}, \nu_{2}\left(\mathrm{~A}_{1}^{\prime}\right)-780 \mathrm{~cm}^{-1}, \nu_{3}\left(\mathrm{~A}_{1}^{\prime}\right)$ $500 \mathrm{~cm}^{-1}$ or $509 \mathrm{~cm}^{-1}, \nu_{10}\left(\mathrm{E}^{\prime}\right)-711 \mathrm{~cm}^{-1}$; for $\mathrm{K}_{2} \mathrm{O} \cdot 5 \mathrm{~B}_{2} \mathrm{O}_{3}, \quad \nu_{1}-1190 \mathrm{~cm}^{-1}-1250 \mathrm{~cm}^{-1} ; \nu_{2} \quad\left(\mathrm{~A}_{1}^{\prime}\right)$ $780 \mathrm{~cm}^{-1}, \nu_{3}\left(\mathrm{~A}_{1}^{\prime}\right)-501 \mathrm{~cm}^{-1}$ or $508 \mathrm{~cm}^{-1}, \nu_{10}\left(\mathrm{E}^{\prime}\right)$ $715 \mathrm{~cm}^{-1}$. It is also expected that $\nu_{9}\left(\mathrm{E}^{\prime}\right)$ may fall in the regions given for $\nu^{1}$ contributing to the strength and broadness of these bands. The bands at 484 $\mathrm{cm}^{-1}$ and $483 \mathrm{~cm}^{-1}$ in the pentaborates probably correspond to $\nu_{7}\left(\mathrm{~A}_{2}^{\prime \prime}\right)$ which are strongly active in these compounds because of low symmetry. With this assignment it seems probable that the bands at $963 \mathrm{~cm}^{-1}$ and $961 \mathrm{~cm}^{-1}$ are the first overtones of $\nu_{7}$. Although these assignments can only be taken as possibilities the relative insensitivity of these band positions to the substituents as demonstrated by Goubeau and Keller [15] lends some support to the proposed assignment.

\subsection{Octoborates $\left(\mathrm{X}_{\mathrm{n}} \mathrm{B}_{8} \mathrm{O}_{13}\right)$}

The alkali metals together with barium of the alkaline earth metals form borates with a $1: 4$ ratio of the oxides. The empirical formula of the anion is $\mathrm{B}_{8} \mathrm{O}_{13}^{-2}$, classified here as an octaborate. Typical spectra of these compounds are given in figure 15 and the data obtained are compiled in table 17 . As expected and as shown in figure 15 a spectrum extremely rich with bands is obtained. All compounds show bands in positions taken to be characteristic of both 3-fold and 4-fold coordination of boron, and the isotopic shifts observed with lithium octaborate strengthens this conclusion. From the spectral data alone it seems very unlikely that the same anion is present in any of these compounds. Lithium octaborate in particular shows a large number of absorption bands but these may be due

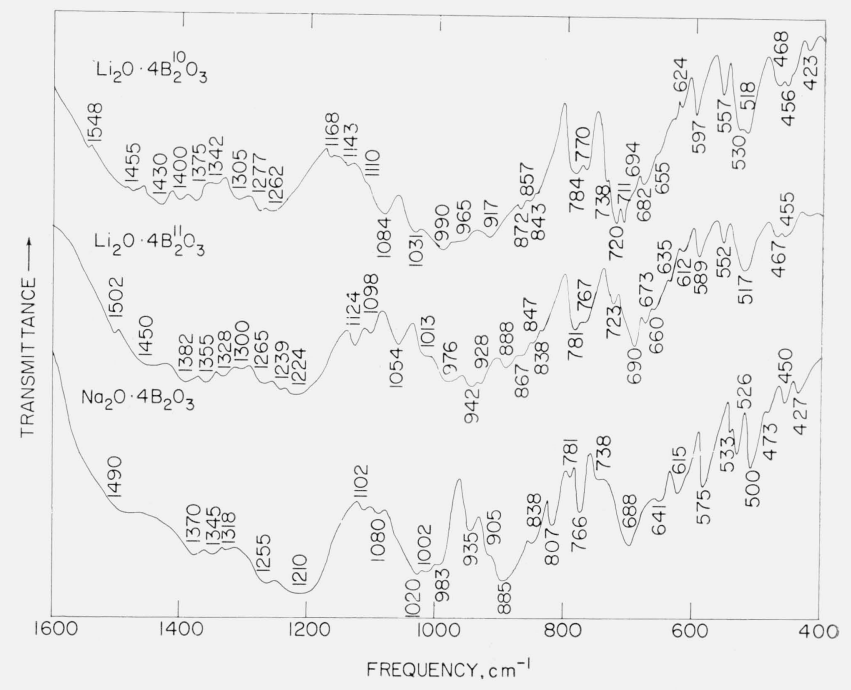

Figure 15. Absorption spectra of alkali octaborates.

in part to $\mathrm{Li}-\mathrm{O}$ vibrational modes, detected in this range because of the small mass of the cation. No structural data are available to assist in the interpretation and without some information of this type any attempt to explain these spectra is of dubious value.

TABLE 17. Infrared absorption spectra of the octaborates $\left(\mathrm{X}_{\mathrm{n}} \mathrm{B}_{8} \mathrm{O}_{13}\right)$

$\left(\mathrm{cm}^{-1}\right)$

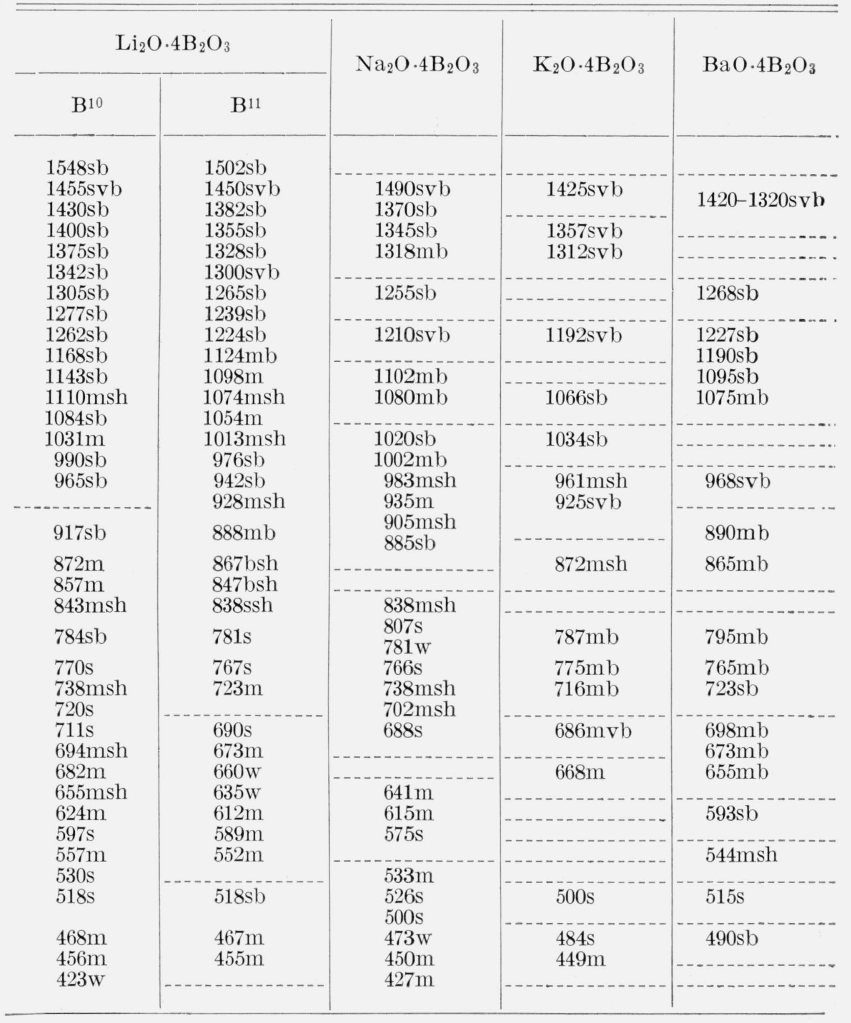




\subsection{Miscellaneous Borates}

In this section data are presented for those borates which cannot be readily classified in the previous categories. These will represent in most instances individual borates of odd compositions or groups of borates whose classification as to anion type is obviously of no value.

\section{a. Rare Earth 3:1 Borates}

Levin and McDaniel [35] have observed that the rare earths form borates having a nominal oxide ratio of $3: 1$. There is doubt at this time that the ratio remains constant throughout the series of rare earth borates but there is no question that the compounds are formed. Inasmuch as the rare earth oxides produce no appreciable absorption in the frequency range used here, satisfactory spectra of the desired borates will be obtained if the quantity of oxide is in excess of the amount required for compound formation. If, as now appears likely, the compounds are of the $3: 1$ ratios or less, materials formed by a 3:1 oxide ratio should produce spectra of the borate only. From powder x-ray diffraction data on the compounds it is found that the $3: 1 \mathrm{com}-$ pounds of lanthanum, praseodymium, and neodymium are most probably isostructural. From samarium to ytterbium, however, a new structure or perhaps new structures (and probably different compositions) appear to form. This behavior is observed in typical spectra shown in figures 16 and 17 and the data tabulated in table 18 . It is noted in figure 16 that the spectrum is characteristic of trigonal $\mathrm{BO}_{3}$ groups with bands derived from the 4 modes of the trigonal ion apparent. The isotopic substitution effects shown for the lanthanum compound in figure 16 show that the bands in the 1200 $\mathrm{cm}^{-1}$ region are analogous to $\nu_{3}$, the $937 \mathrm{~cm}^{-1}$ band to $\nu_{1}$, the $700 \mathrm{~cm}^{-1}$ region bands to $\nu_{2}$ and the 600 $\mathrm{cm}^{-1}$ region bands to $\nu_{4}$ of the trigonal ion. However, at least 3 bands appear in each of the $\nu_{3}, \nu_{2}$, and $\nu_{4}$ regions and the spectra are not typical of isolated trigonal ions. They are also not typical of either the pyroborate ion, the boroxol ring, or chains of triangular groups. It appears that the spectra of the first few members of the $3: 1$ rare earth borates are indicative of a new type of anion which is most probably a polymer formed of $\mathrm{BO}_{3}$ groups.

Starting at $3 \mathrm{Eu}_{2} \mathrm{O}_{3} \cdot \mathrm{B}_{2} \mathrm{O}_{3}$ and continuing to $3 \mathrm{Tm}_{2} \mathrm{O}_{3} \cdot \mathrm{B}_{2} \mathrm{O}_{3}$ the marked change observed in figure 17 occurs in these spectra. Strong bands in the 800 $\mathrm{cm}^{-1}$ to $1100 \mathrm{~cm}^{-1}$ range occur which are indicative of boron with 4 -fold coordination. Simultaneously new absorption bands appear in the $700 \mathrm{~cm}^{-1}$ to $800 \mathrm{~cm}^{-1}$ region which tend to confirm the indication. As the increase in atomic weight in the rare earth series is accompanied by a decrease in ionic radius, it would be expected that the packing in the unit cell increases as the mass of the cation increases. In the anion, however, closer packing can be accomplished by increase in coordination of boron from 3 to 4 .

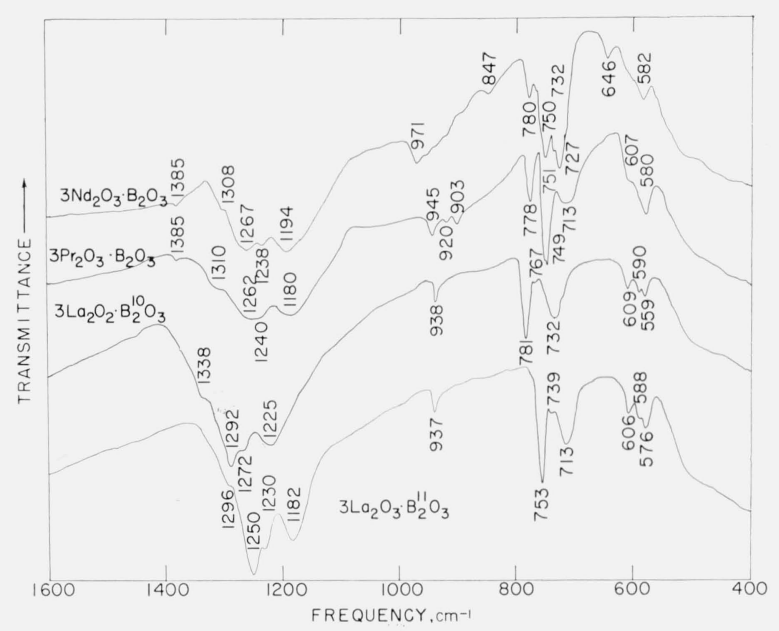

Figure 16. Absorption spectra of $3: 1$ rare earth borates.

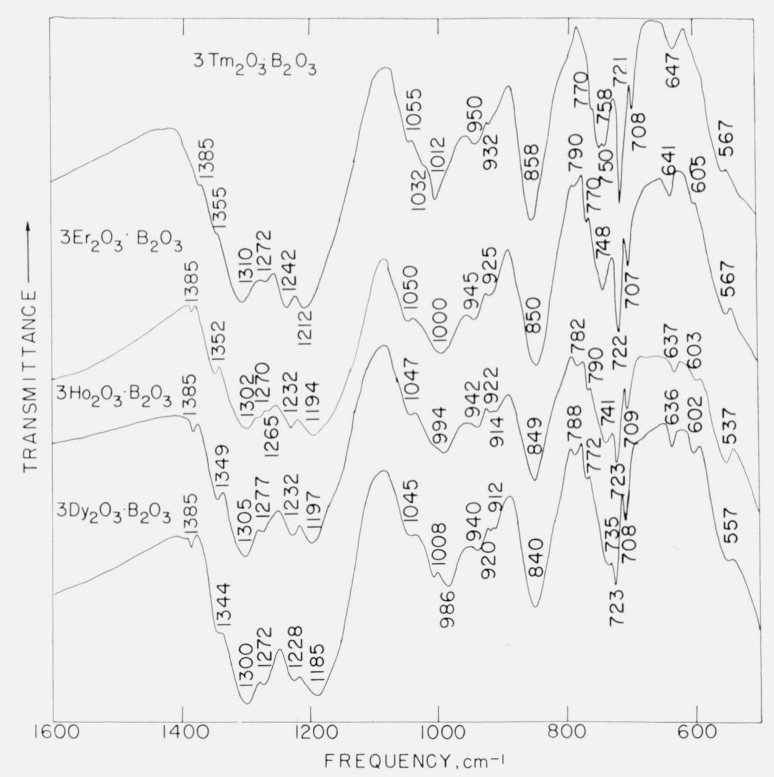

Figure 17. Absorption spectra of $3: 1$ rare earth borates.

Therefore, the increase in coordination indicated by these spectra is not surprising, and it would not be surprising if the composition of the compounds also changed. It should be noted, however, that there is still evidence for boron in 3-fold coordination in addition to the 4 -fold coordination so that the anions are probably quite complex.

\section{b. Bismuth Borates}

The bismuth borates form in ratios of oxides which are unlike the other trivalent ions in most instances and the spectra of all the compounds are discussed here. No isotopically pure compounds were prepared for these compounds. Typical spectra are shown in figure 18 and the absorption frequencies are tabulated in table 19 . The spectra of figure 18 all exhibit strong bands to low frequencies as well as 
TABLE 18.- Infrared absorption spectra of the 3:1 rare earth borates

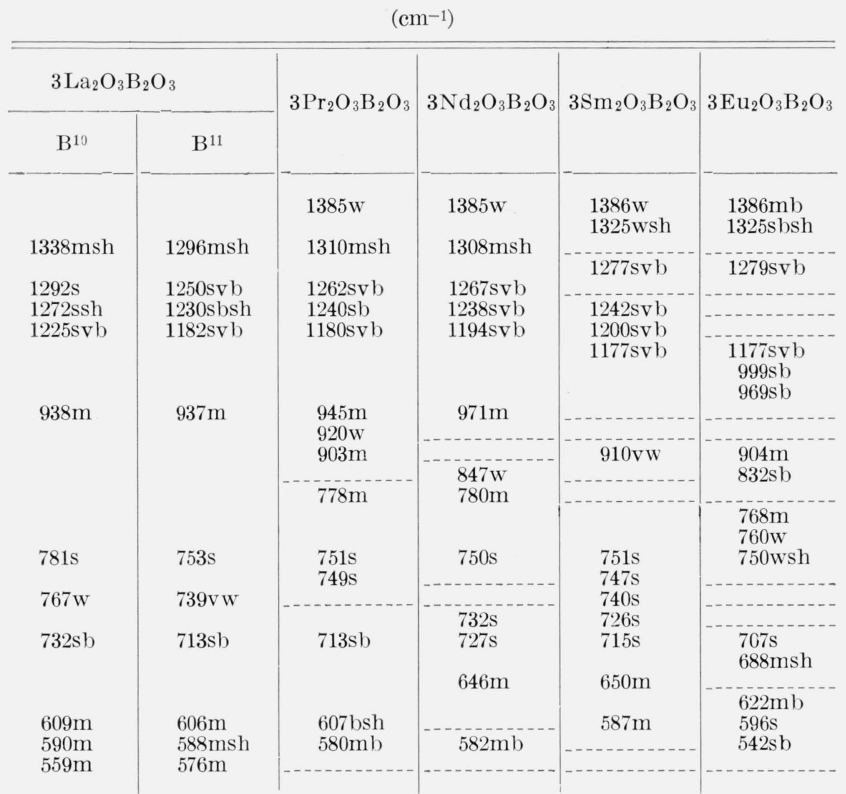

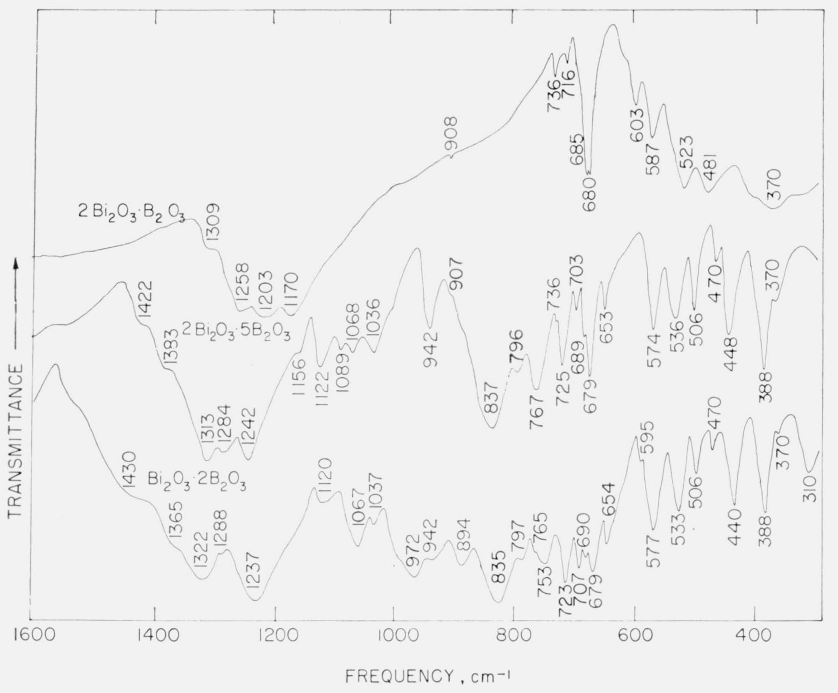

Figure 18. Absorption spectra of bismuth borates.

numerous bands which are nearly coincident in the different compounds. It was suspected that these bands might arise, in part from bismuth oxide impurities or from $\mathrm{Bi}-\mathrm{O}$ bond modes. However, the pure oxide itself shows no absorption spectrum in this frequency range. The spectrum of the $2: 1$ compound is surprisingly simple and gives evidence of boron only in 3-fold coordination. The absence of strong bands just above $700 \mathrm{~cm}^{-1}$ (the $\nu_{2}$ region for trigonal ions) and the apparent presence of modes derived from $\nu_{2}$ at $685 \mathrm{~cm}^{-1}$ and $680 \mathrm{~cm}^{-1}$ may be taken to indicate that the anion is a complex polymer of trigonal $\mathrm{BO}_{3}$ groups. The occurrence of low frequency bands supports this idea. Because of the simplicity of the spectrum it is probable that a highly symmetrical ion is present. The other bis-
TABLE 18. Infrared absorption spectra of the 3:1 rare earth borates - Continued

$\left(\mathrm{cm}^{-1}\right)$

\begin{tabular}{|c|c|c|c|c|c|}
\hline $3 \mathrm{Gd}_{2} \mathrm{O}_{3} \mathrm{~B}_{2} \mathrm{O}_{3}$ & $3 \mathrm{~Tb}_{2} \mathrm{O}_{3} \mathrm{~B}_{2} \mathrm{O}_{3}$ & $3 \mathrm{Dy}_{2} \mathrm{O}_{3} \mathrm{~B}_{2} \mathrm{O}_{3}$ & $3 \mathrm{Ho}_{2} \mathrm{O}_{3} \mathrm{~B}_{2} \mathrm{O}_{3}$ & $3 \mathrm{Er}_{2} \mathrm{O}_{3} \mathrm{~B}_{2} \mathrm{O}_{3}$ & $3 \mathrm{Tm}_{2} \mathrm{O}_{3} \mathrm{~B}_{2} \mathrm{O}_{3}$ \\
\hline \multirow{2}{*}{$\begin{array}{l}1392 \mathrm{wb} \\
1325 \mathrm{sbsh}\end{array}$} & $1385 \mathrm{w}$ & $1385 \mathrm{~W}$ & $1385 \mathrm{~W}$ & \multirow{6}{*}{$\begin{array}{l}1385 \mathrm{w} \\
1352 \mathrm{msh} \\
1302 \mathrm{sb} \\
1270 \mathrm{msh} \\
1265 \mathrm{msh} \\
1232 \mathrm{sb} \\
1194 \mathrm{sb}\end{array}$} & $1385 \mathrm{vwsh}$ \\
\hline & $1335 \mathrm{sbsh}$ & $1344 \mathrm{msh}$ & $1349 \mathrm{msh}$ & & $1355 \mathrm{msh}$ \\
\hline & $1295 \mathrm{sb}$ & $1300 \mathrm{sb}$ & $1305 \mathrm{sb}$ & & $1310 \mathrm{sb}$ \\
\hline \multirow[t]{3}{*}{$1280 \mathrm{svb}$} & 21 & $1272 \mathrm{ssh}$ & $1277 \mathrm{msh}$ & & $1272 \mathrm{mb}$ \\
\hline & $1220 \mathrm{sbsh}$ & $1228 \mathrm{ssh}$ & $1232 \mathrm{ssh}$ & & $1242 \mathrm{sb}$ \\
\hline & & $1185 \mathrm{sb}$ & $1197 \mathrm{sb}$ & & $1212 \mathrm{sb}$ \\
\hline $1180 \mathrm{svb}$ & $1045 \mathrm{svb}$ & $1045 \mathrm{ssh}$ & $1047 \mathrm{ssh}$ & $1050 \mathrm{ssh}$ & $\begin{array}{l}1055 \mathrm{ssh} \\
1032 \mathrm{ssh}\end{array}$ \\
\hline $998 \mathrm{sb}$ & $1008 \mathrm{sb}$ & $1008 \mathrm{msh}$ & & & \\
\hline \multirow[t]{2}{*}{$968 \mathrm{sb}$} & $982 \mathrm{sb}$ & $\begin{array}{l}986 \mathrm{~s} \\
940 \mathrm{~m}\end{array}$ & $\begin{array}{l}994 \mathrm{sb} \\
942 \mathrm{~m}\end{array}$ & $\begin{array}{c}1000 \mathrm{sb} \\
945 \mathrm{~m}\end{array}$ & $\begin{array}{r}1012 \mathrm{sb} \\
950 \mathrm{sb}\end{array}$ \\
\hline & $910 \mathrm{sb}$ & $\begin{array}{l}920 w \\
912 w\end{array}$ & $\begin{array}{l}922 \mathrm{w} \\
914 \mathrm{wsh}\end{array}$ & $925 \mathrm{~m}$ & $932 \mathrm{~m}$ \\
\hline $830 \mathrm{sb}$ & $840 \mathrm{sb}$ & $\begin{array}{l}840 \mathrm{sb} \\
788 \mathrm{wb}\end{array}$ & $\begin{array}{l}849 \mathrm{sb} \\
782 \mathrm{wb}\end{array}$ & $\begin{array}{l}850 \mathrm{sb} \\
790 \mathrm{wb}\end{array}$ & $858 \mathrm{sb}$ \\
\hline $\begin{array}{l}770 \mathrm{~m} \\
767 \mathrm{w} \\
752 \mathrm{msh}\end{array}$ & $770 \mathrm{~m}$ & $\begin{array}{l}772 \mathrm{msh} \\
735 \mathrm{sbsh}\end{array}$ & $\begin{array}{l}770 \mathrm{msh} \\
741 \mathrm{ssh}\end{array}$ & $\begin{array}{l}770 \mathrm{msh} \\
748 \mathrm{~s}\end{array}$ & $\begin{array}{l}770 \mathrm{msh} \\
758 \mathrm{~s} \\
750 \mathrm{~s}\end{array}$ \\
\hline \multirow{3}{*}{$\begin{array}{l}734 \mathrm{msh} \\
707 \mathrm{~s} \\
682 \mathrm{mb}\end{array}$} & & & & & \\
\hline & $723 \mathrm{~s}$ & $723 \mathrm{~s}$ & $723 \mathrm{~s}$ & $722 \mathrm{~s}$ & $721 \mathrm{~s}$ \\
\hline & $\begin{array}{l}708 \mathrm{~s} \\
680 \mathrm{wb}\end{array}$ & $708 \mathrm{~s}$ & $709 \mathrm{~s}$ & $707 \mathrm{~s}$ & $708 \mathrm{~s}$ \\
\hline \multirow{2}{*}{$\begin{array}{l}598 \mathrm{~s} \\
550 \mathrm{sb}\end{array}$} & $000 \mathrm{~W}$ & $636 \mathrm{mb}$ & $637 \mathrm{~m}$ & $641 \mathrm{mb}$ & $647 \mathrm{mb}$ \\
\hline & $000 \mathrm{w}$ & $557 \mathrm{~m}$ & $557 \mathrm{sb}$ & $567 \mathrm{sb}$ & $567 \mathrm{sb}$ \\
\hline
\end{tabular}

TABLE 19. Infrared absorption spectra of the bismuth borates

\begin{tabular}{|c|c|c|c|}
\hline $2 \mathrm{Bi}_{2} \mathrm{O}_{3} \cdot \mathrm{B}_{2} \mathrm{O}_{3}$ & $3 \mathrm{Bi}_{2} \mathrm{O}_{3} \cdot 5 \mathrm{~B}_{2} \mathrm{O}_{3}$ & $\mathrm{Bi}_{2} \mathrm{O}_{3} \cdot 3 \mathrm{~B}_{2} \mathrm{O}_{3}$ & $\mathrm{Bi}_{2} \mathrm{O}_{3} \cdot 4 \mathrm{~B}_{2} \mathrm{O}_{3}$ \\
\hline \multirow{4}{*}{$\begin{array}{l}1309 \mathrm{msh} \\
1258 \mathrm{sh} \\
1203 \mathrm{sb} \\
1170 \mathrm{sb}\end{array}$} & $\begin{array}{l}1422 \mathrm{msh} \\
1383 \mathrm{msh}\end{array}$ & 1430bsh & $\begin{array}{l}1448 \mathrm{svb} \\
1376 \mathrm{svb}\end{array}$ \\
\hline & \multirow{2}{*}{$\begin{array}{l}1313 \mathrm{sb} \\
1284 \mathrm{sb} \\
1242 \mathrm{sb}\end{array}$} & \multirow{2}{*}{$\begin{array}{l}1365 \mathrm{bh} \\
1322 \mathrm{sb} \\
1288 \mathrm{bsh} \\
1237 \mathrm{vsb}\end{array}$} & \\
\hline & & & $\begin{array}{l}1238 \mathrm{svb} \\
1191 \mathrm{ssh}\end{array}$ \\
\hline & \multirow{2}{*}{$\begin{array}{l}1156 \mathrm{msh} \\
1122 \mathrm{sb} \\
1089 \mathrm{~s} \\
1068 \mathrm{sb} \\
1036 \mathrm{sb}\end{array}$} & $1120 \mathrm{mb}$ & $1130 \mathrm{msh}$ \\
\hline \multirow{3}{*}{$908 w$} & & \multirow{3}{*}{$\begin{array}{l}1067 \mathrm{sb} \\
1037 \mathrm{sb} \\
972 \mathrm{svb} \\
942 \mathrm{~m} \\
894 \mathrm{mb} \\
835 \mathrm{svb} \\
797 \mathrm{~m} \\
765 \mathrm{~m} \\
753 \mathrm{~m}\end{array}$} & $1074 \mathrm{sb}$ \\
\hline & $\begin{array}{l}942 \mathrm{sb} \\
907 \mathrm{wsh} \\
837 \mathrm{svb} \\
796 \mathrm{~m}\end{array}$ & & $\begin{array}{l}930 \mathrm{msh} \\
890 \mathrm{svb} \\
835 \mathrm{svb}\end{array}$ \\
\hline & \multirow{4}{*}{$\begin{array}{l}736 \mathrm{wsh} \\
725 \mathrm{~s} \\
703 \mathrm{~m} \\
689 \mathrm{~m} \\
679 \mathrm{~s} \\
655 \mathrm{~m}\end{array}$} & & $750 \mathrm{~s}$ \\
\hline $716 \mathrm{~m}$ & & \multirow{3}{*}{$\begin{array}{l}723 \mathrm{~s} \\
707 \mathrm{~m} \\
690 \mathrm{w} \\
679 \mathrm{~s} \\
654 \mathrm{~m}\end{array}$} & $722 \mathrm{~s}$ \\
\hline $\begin{array}{l}685 \mathrm{~s} \\
680 \mathrm{~s}\end{array}$ & & & $689 \mathrm{mb}$ \\
\hline & & & \multirow{2}{*}{$\begin{array}{l}653 \mathrm{w} \\
623 \mathrm{w} \\
595 \mathrm{msh} \\
579 \mathrm{~s} \\
529 \mathrm{~s}\end{array}$} \\
\hline $\begin{array}{l}603 \mathrm{sb} \\
578 \mathrm{sb}\end{array}$ & $\begin{array}{l}574 \mathrm{~s} \\
536 \mathrm{~s}\end{array}$ & $\begin{array}{l}577 \mathrm{~s} \\
533 \mathrm{~s}\end{array}$ & \\
\hline $\begin{array}{l}523 \mathrm{sb} \\
481 \mathrm{svb}\end{array}$ & $506 \mathrm{~s}$ & $506 \mathrm{~s}$ & $503 \mathrm{~s}$ \\
\hline $370 \mathrm{sb}$ & $\begin{array}{l}470 \mathrm{~m} \\
448 \mathrm{~s} \\
388 \mathrm{~s} \\
370 \mathrm{ssh}\end{array}$ & $\begin{array}{l}470 \mathrm{w} \\
440 \mathrm{~s} \\
388 \mathrm{~s} \\
370 \mathrm{ssh} \\
310 \mathrm{sb}\end{array}$ & $\begin{array}{l}470 \mathrm{w} \\
436 \mathrm{sb} \\
389 \mathrm{sb}\end{array}$ \\
\hline
\end{tabular}

muth borates show evidence of polymeric anions containing both 3 -fold and 4-fold coordinated boron. It is apparent from the many points of similarity that the anions are very closely related in the $3: 5$, $1: 3$, and $1: 4$ compounds. Furthermore, the spectrum of the 1:3 bismuth borate is quite similar (but not identical) with the spectra of the $1: 3$ rare earth borates, and all the bismuth borate compounds except the 2:1 compound show spectra with marked 
resemblances to the spectra the other metal borates that have high proportions of $\mathrm{B}_{2} \mathrm{O}_{3}$.

\section{c. Odd Borates}

Several borates are formed in systems already discussed in apparent odd ratios of metal oxide to boric oxide. These spectra are given here, together with those of compounds of doubtful composition. Representative spectra are not shown but the observed absorption bands are given in table 20. No detailed discussion of these spectra will be attempted. The questions concerning the composition of the 5:2 zinc borate have been noted previously (sec. 6.2.c). The spectrum would be consistent with boron in 3 -fold coordination except for the strong band at $940 \mathrm{~cm}^{-1}$ which may indicate tetrahedral boron. In the 4:1 lead borate only trigonal boron is indicated. The 3:1 copper borate, whose exact composition is not established, gives indications of only 3-told coordination of boron as would be expected from the nominal formula. The spectrum shows an interesting series of weak broad bands in the $858 \mathrm{~cm}^{-1}$ to $1032 \mathrm{~cm}^{-1}$ range which may be indicative of impurities. In the 5:2 zinc borate, the $4: 1$ lead borate and the 3:1 copper borate the spectra all indicate polymeric anions composed of trigonal $\mathrm{BO}_{3}$ groups. The 5:4 lead borate spectrum indicates both coordinations of boron and the aluminum borate spectrum is complicated by the possibility of $\mathrm{Al}-\mathrm{O}$ bond vibrations occurring in this spectral range. The 1:9 cesium borate spectrum shows very strong absorption throughout the range $500 \mathrm{~cm}^{-1}$ to $1500 \mathrm{~cm}^{-1}$ with no clearly resolved bands. At least a part of the broad absorption may arise from the glassy phase which is known to be present in small amounts. The only clearly recognizable feature of this spectrum consists of a complex group of bands near $460 \mathrm{~cm}^{-1}$.

TABLE 20. Infrared absorption frequencies of "odd" borates $\left(\mathrm{cm}^{-1}\right)$

\begin{tabular}{|c|c|c|c|c|c|}
\hline $5 \mathrm{ZnO} 2 \mathrm{~B}_{2} \mathrm{O}_{3}$ & $4 \mathrm{PbOB}_{2} \mathrm{O}_{3}$ & $5 \mathrm{PbO}_{4} \mathrm{~B}_{2} \mathrm{O}_{3}$ & $3 \mathrm{CuOB}{ }_{2} \mathrm{O}_{3}$ & $9 \mathrm{Al}_{2} \mathrm{O}_{3} 2 \mathrm{~B}_{2} \mathrm{O}_{3}$ & $\mathrm{Cs}_{2} \mathrm{O}_{9 \mathrm{~B}_{2} \mathrm{O}_{3}}$ \\
\hline $1307 \mathrm{svb}$ & $1329 \mathrm{~m}$ & $1292 \mathrm{sb}$ & $1500 \mathrm{~m}$ & $1412 \mathrm{sb}$ & \\
\hline $1237 \mathrm{svb}$ & $\begin{array}{l}1278 \mathrm{~s} \\
1247 \mathrm{~s}\end{array}$ & $1232 \mathrm{sb}$ & $\begin{array}{l}1480 \mathrm{~m} \\
1340 \mathrm{sb}\end{array}$ & $\begin{array}{l}1390 \mathrm{sb} \\
1327 \mathrm{sb}\end{array}$ & Very strong \\
\hline $1085 \mathrm{sb}$ & $1179 \mathrm{sb}$ & $1196 \mathrm{~m}$ & $1192 \mathrm{mb}$ & $1260 \mathrm{sb}$ & broad \\
\hline $1040 \mathrm{mb}$ & & $\begin{array}{l}1132 \mathrm{~m} \\
1107 \mathrm{~m}\end{array}$ & $1152 \mathrm{sb}$ & $\begin{array}{l}1230 \mathrm{~m} \\
1189 \mathrm{~s}\end{array}$ & $\begin{array}{c}\text { absorption } \\
1500 \mathrm{~cm}^{-1}\end{array}$ \\
\hline & & $1037 \mathrm{sb}$ & $1032 \mathrm{wb}$ & $1100 \mathrm{mbsh}$ & to \\
\hline 991wsh & $972 \mathrm{~m}$ & $\begin{array}{l}975 \mathrm{sb} \\
927 \mathrm{sb}\end{array}$ & $\begin{array}{l}980 w b \\
942 w b\end{array}$ & $1025 \mathrm{mbsh}$ & $600 \mathrm{~cm}^{-1}$ \\
\hline $940 \mathrm{svb}$ & $891 \mathrm{~W}$ & 900 ssh & $\begin{array}{l}910 w b \\
888 w b\end{array}$ & $875 \mathrm{sb}$ & \\
\hline & $001 \mathrm{n}$ & $820 \mathrm{svb}$ & $858 w b$ & & \\
\hline $\begin{array}{l}883 \mathrm{~W} \\
863 \mathrm{w}\end{array}$ & & $792 \mathrm{sb}$ & & $\begin{array}{l}827 \mathrm{mvb} \\
798 \mathrm{sb}\end{array}$ & \\
\hline $715 \mathrm{sb}$ & $\begin{array}{l}756 \mathrm{~s} \\
728 \mathrm{~s}\end{array}$ & $\begin{array}{l}765 \mathrm{sb} \\
750 \mathrm{msh} \\
722 \mathrm{~m}\end{array}$ & $\begin{array}{l}737 \mathrm{msh} \\
722 \mathrm{~s}\end{array}$ & $\begin{array}{l}775 \mathrm{msh} \\
732 \mathrm{~s} \\
710 \mathrm{msh}\end{array}$ & \\
\hline $672 \mathrm{~s}$ & $\begin{array}{l}709 \mathrm{w} \\
690 \mathrm{~s}\end{array}$ & $\begin{array}{l}711 \mathrm{~m} \\
702 \mathrm{~m}\end{array}$ & $\begin{array}{l}696 \mathrm{~s} \\
671 \mathrm{~s}\end{array}$ & $\begin{array}{l}693 \mathrm{~m} \\
669 \mathrm{~s}\end{array}$ & \\
\hline & $608 \mathrm{~s}$ & $681 \mathrm{~s}$ & $663 \mathrm{~s}$ & & \\
\hline $620 \mathrm{mb}$ & $\ldots$ & $\begin{array}{l}661 \mathrm{~s} \\
628 \mathrm{~m}\end{array}$ & $\begin{array}{l}\text { 648ssh } \\
611 \mathrm{~m}\end{array}$ & & \\
\hline $955 \mathrm{mb}$ & $559 \mathrm{~s}$ & $\begin{array}{l}609 \mathrm{~s} \\
582 \mathrm{~s}\end{array}$ & $594 \mathrm{~m}$ & $601 \mathrm{svb}$ & \\
\hline $475 \mathrm{~s}$ & $\begin{array}{l}521 \mathrm{~m} \\
503 \mathrm{~m}\end{array}$ & $\begin{array}{l}567 \mathrm{msh} \\
560 \mathrm{msh}\end{array}$ & $553 \mathrm{~m}$ & $\begin{array}{l}552 \mathrm{sb} \\
524 \mathrm{~m}\end{array}$ & \\
\hline $437 \mathrm{~s}$ & - & $\begin{array}{l}509 \mathrm{~s} \\
476 \mathrm{~s}\end{array}$ & $\begin{array}{l}508 \mathrm{~s} \\
477 \mathrm{~s}\end{array}$ & $\begin{array}{l}493 \mathrm{sb} \\
458 \mathrm{~m}\end{array}$ & $\begin{array}{l}505 \mathrm{ssh} \\
460 \mathrm{sb}\end{array}$ \\
\hline $415 \mathrm{~s}$ & & $434 \mathrm{~s}$ & $439 \mathrm{ssh}$ & $443 \mathrm{~m}$ & - \\
\hline $377 \mathrm{vsb}$ & $\begin{array}{l}408 \mathrm{sb} \\
356 \mathrm{sb}\end{array}$ & $\begin{array}{l}418 \mathrm{~s} \\
409 \mathrm{~s}\end{array}$ & $433 \mathrm{~s}$ & $418 \mathrm{~m}$ & \\
\hline & & $\begin{array}{l}399 \mathrm{~s} \\
370 \mathrm{~s}\end{array}$ & $\begin{array}{l}397 \mathrm{~s} \\
375 \mathrm{~s}\end{array}$ & & - \\
\hline
\end{tabular}

\section{d. Borates Containing Only Tetrahedrally Coordinated Boron}

The three borate discussed in this section are known to contain boron only in $\mathrm{BO}_{4}$ groups and consist of the 1:1 compounds of $\mathrm{Ta}_{2} \mathrm{O}_{5}, \mathrm{As}_{2} \mathrm{O}_{5}$, and $\mathrm{P}_{2} \mathrm{O}_{5}$ with $\mathrm{B}_{2} \mathrm{O}_{3}$. The structures are known for all of these compounds which have the empirical formulae $\mathrm{ABO}_{4}$ with $\mathrm{A}$ representing $\mathrm{Ta}, \mathrm{P}$, or As. Both $\mathrm{PBO}_{4}$ and $\mathrm{AsBO}_{4}$ form crystals of space group $\mathrm{S}_{4}^{2} \equiv \mathrm{C}_{2}$ [46] and $\mathrm{TaBO}_{4}$, which is isostructural with zircon is of space group $\mathrm{D}_{\mathrm{h}}^{19}[58]$. The latter compound is expected to give a spectrum typical of tetrahedrally coordinated boron with all normal modes active. Coupling with the modes arising from Ta-O bonds is not expected to be important because of the relative weakness of these bonds and the large mass of the Ta atoms. It was determined experimentally that $\mathrm{Ta}_{2} \mathrm{O}_{5}$ showed no absorption in the frequency range used here. The compounds $\mathrm{PBO}_{4}$ and $\mathrm{AsBO}_{4}$ both contain two distinct types of tetrahedra, one of which is the $\mathrm{BO}_{4}$ unit, the other either $\mathrm{PO}_{4}$ or $\mathrm{AsO}_{4}$ tetrahedra. The two types of tetrahedra are connected at corners and each oxygen is therefore shared by boron and either phosphorous or arsenic. The $\mathrm{P}-\mathrm{O}$ and $\mathrm{As}-\mathrm{O}$ bonds are expected to be similar in strength to the $\mathrm{B}-\mathrm{O}$ bonds and the infrared spectrum will be expected to be representative of tightly coupled oscillators having at least some fundamentals nearly equal in frequency.

The spectra obtained on these compounds are shown in figure 19 and the observed absorption bands are tabulated in table 21. The spectrum of $\mathrm{Ta}_{2} \mathrm{O}_{5}$. $\mathrm{B}_{2} \mathrm{O}_{3}$ shows 3 strong bands at $840 \mathrm{~cm}^{-1}, 579 \mathrm{~cm}^{-1}$, and $490 \mathrm{~cm}^{-1}$, which have been assigned tentatively as corresponding to $\nu_{3}, \nu_{1}$, and $\nu_{4}$, respectively. The missing $\nu_{2}$ band may be located near $300 \mathrm{~cm}^{-1}$ and may correspond to the apparent absorption band observed in figure 19. However, the location of $\nu_{2}$ or its presence in the spectrum is not certain because of the low energy available near $300 \mathrm{~cm}^{-1}$. The assignments given are plausible and consistent with the expected strengths and complexities of the $\nu_{3}$ and $\nu_{4}$ bands. The assignments were not corroborated by isotopic substitution because of the difficulties involved in preparing the tantalum borate but it appears very probable that this spectrum should be characteristic of the isolated borate tetrahedral unit.

Although the spectra of $\mathrm{PBO}_{4}$ and $\mathrm{AsBO}_{4}$ are very simple in appearance their interpretation is not clear. First it should be noted that all bands in these compounds with one exception (the $858 \mathrm{~cm}^{-1}$ band) are very broad and the tabulated data are subject to considerable uncertainty. In addition it is possible that variations of index of refraction of the powdered specimens may produce artifacts in the observed spectra - the $858 \mathrm{~cm}^{-1}$ band is suspected in this connection. It should be noted that the normal frequencies of the isolated $\mathrm{PO}_{4}^{-3}$ ion are given as $\nu_{1} \approx 980 \mathrm{~cm}^{-1}, \quad \nu_{2} \approx 363 \mathrm{~cm}^{-1}, \quad \nu_{3} \approx 1082 \mathrm{~cm}^{-1}$, and $\nu_{4} \approx 515 \mathrm{~cm}^{-1}$. Comparing these values and those for $\mathrm{TaBO}_{4}$ in table 21 with the observed frequencies for $\mathrm{PBO}_{4}$ shows no clear correlation. The fact that 


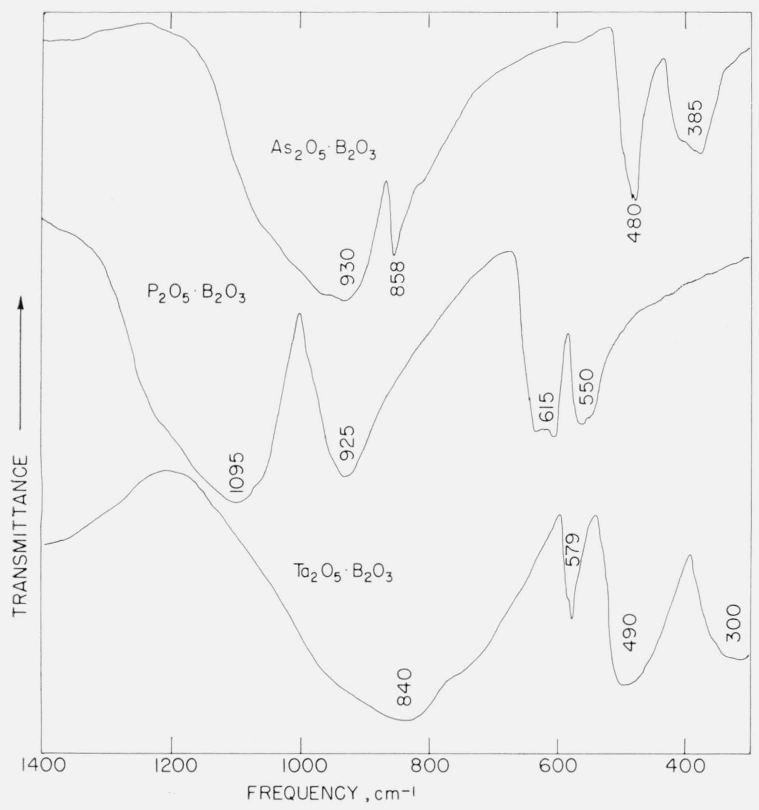

Figure 19. Absorption spectra of compounds containing tetrahedrally coordinated boron.

substitution of $\mathrm{As}$ for $\mathrm{P}$ in the structure produces strong shifts of all bands plus the fact that isotopic substitution of boron in a given compound results in shifts which appear to be in unexpected directions forces the conclusion that in a system of such tightly coupled oscillators, individual group frequencies cannot be recognized readily.

TABLE 21. Infrared absorption spectra of compounds containing only tetrahedrally coordinated boron

$\left(\mathrm{cm}^{-1}\right)$

\begin{tabular}{|c|c|c|c|c|}
\hline \multirow{2}{*}{$\mathrm{TaBO}_{4}$} & \multicolumn{3}{|c|}{$\mathrm{PBO}_{4}$} & \multirow{2}{*}{$\frac{\mathrm{AsBO}_{4}}{\mathrm{~B}^{11} \& \mathrm{~B}^{10}}$} \\
\hline & $\mathrm{B}^{11} \& \mathrm{~B}^{10}$ & $\mathrm{~B}^{10}$ & $\mathrm{~B}^{11}$ & \\
\hline $\begin{array}{l}840 \mathrm{vsvb}, \nu 3 \\
579 \mathrm{~s}, \nu_{1} \\
490 \mathrm{svb}, \nu_{4} \\
300 \mathrm{svb} ?, \nu_{2}\end{array}$ & $\begin{array}{c}1095 \mathrm{vsb} \\
925 \mathrm{vsb} \\
615 \mathrm{sb} \\
550 \mathrm{sb}\end{array}$ & $\begin{array}{c}1065 \mathrm{vsb} \\
925 \mathrm{vsb} \\
610 \mathrm{sb} \\
535 \mathrm{sb}\end{array}$ & $\begin{array}{c}1085 \mathrm{vsb} \\
923 \mathrm{vsb} \\
617 \mathrm{sb} \\
537 \mathrm{sb}\end{array}$ & $\begin{array}{l}930 \mathrm{vsb} \\
858 ? \mathrm{~s} \\
480 \mathrm{~s} \\
385 \mathrm{sb}\end{array}$ \\
\hline
\end{tabular}

\section{Spectroscopic Identification of Borate Anions}

From the studies described some generalizations on the character of the borate anion can be made on the basis of the observed spectrum. Under normal conditions the spectrum will be complicated by the presence of $\mathrm{B}^{10}$ and $\mathrm{B}^{11}$ isotopes in their natural abundance and recognition of the weaker, higher frequency bands arising from the $\mathrm{B}^{10}$ isotope is essential for purposes of identification.

As regards the problem of coordination of the boron, it can be concluded that the group frequency correlations may have certain validity in the spectra of the borates, regardless of the exact structure of the anion. Characteristic bands may shift by as much as $100 \mathrm{~cm}^{-1}$ or more depending on the structure so that conclusions must be made with caution particularly when very complex anions are involved.

With these reservations in mind, it can be concluded that boron in 3-fold coordination is characterized by the presence of strong, broad absorption in the region $1100 \mathrm{~cm}^{-1}$ to $1300 \mathrm{~cm}^{-1}$. This band (or more generally bands) is one of the strongest and most prominent features of the spectrum. In addition there is always absorption in the $700 \mathrm{~cm}^{-1}$ to $780 \mathrm{~cm}^{-1}$ region (derived from $\nu_{2}$ of the trigonal ion) which is strong, usually sharp, and frequently (but by no means always) consists of a single band. Both of these characteristic bands are strongly dependent on isotope mass and isotopic substitution can be used to differentiate the desired bands from others which occur in the same frequency region.

Boron in 4-fold coordination can be determined with much less certainty, particularly when boron in 3 -fold coordination is also present. Based on the present (and previous work) it may be concluded that the most characteristic feature is the presence of strong, broad absorption in the $800 \mathrm{~cm}^{-1}$ to 1100 $\mathrm{cm}^{-1}$ region. This band (or bands) is very strong and broad and its position is strongly sensitive to isotope mass. Absorption in the $600 \mathrm{~cm}^{-1}$ to 800 $\mathrm{cm}^{-1}$ region can be distinguished from the absorption of boron in 3 -fold coordination by the fact that it is relatively insensitive to isotopic mass. Caution must be exercised in this case to recognize overtones and combination bands which may be found in the region above $1100 \mathrm{~cm}^{-1}$ and be mistaken for fundamentals of trigonal borate groups. Overtones and combinations may be strongly dependent on isotope mass but may be differentiated from the fundamentals by their relative weakness compared to the fundamental bands. It appears to be characteristic of tetrahedral borates that reasonably strong absorption bands are found at much lower frequencies than in the trigonal borates (for example a band is generally observed near $470 \mathrm{~cm}^{-1}$ which may be derived from $\nu_{4}$ ) but this observation is of little diagnostic value. Complex borate anions give rise to a large number of low frequency modes so that the tetrahedral boron bands, if present, cannot be identified with assurance.

The identity of individual anions can be determined with assurance in a limited number of cases only. The best identification can be made in the case of the planar $\mathrm{BO}_{3}$ group. This spectrum is defined by the strong absorption above $1100 \mathrm{~cm}^{-1}$ which may be split into two bands, a strong band in the $700 \mathrm{~cm}^{-1}$ to $800 \mathrm{~cm}^{-1}$ region, and one or two weaker bands below $700 \mathrm{~cm}^{-1}$. A weak sharp band near $1000 \mathrm{~cm}^{-1}$ may appear (see figs. 1 and 2 ).

The pyroborate ion can probably be recognized from its spectrum. In this case the diagnostic region appears to be the $600 \mathrm{~cm}^{-1}$ to $800 \mathrm{~cm}^{-1}$ region which exhibits three strong bands (see fig. 10). Additional bands may appear slightly above 800 $\mathrm{cm}^{-1}$ but they are much weaker. A sharp moderately strong band will also appear near $1000 \mathrm{~cm}^{-1}$. Bands at still higher frequencies will occur but only 
the appearance of the strong 3 -fold coordination bands above $1100 \mathrm{~cm}^{-1}$ is of concern.

Compounds with infinite chains of triangles yield spectra very similar to those of the pyroborates. In the former, however, the bands appear to be broader, more complex in internal structure, and less easily resolved. The band near $1000 \mathrm{~cm}^{-1}$ is weak and may not be observed. The strong bands above $1100 \mathrm{~cm}^{-1}$ are also present but broader and less readily resolved than in the pyroborates.

Provided the spectrum obtained for $\mathrm{TaBO}_{4}$ is typical of an isolated tetrahedral $\mathrm{BO}_{4}$ group, the characteristics appear to be principally in the strong broad band near $840 \mathrm{~cm}^{-1}$ and the slightly weaker band near $490 \mathrm{~cm}^{-1}$. The bands near 579 $\mathrm{cm}^{-1}$ and $300 \mathrm{~cm}^{-1}$ are not considered to be diagnostic features because they may be inactive in many instances.

Any attempt to identify more complex borate anions solely on the basis of their infrared spectra does not appear possible at this time. Spectra containing large numbers of bands, particularly in the region below $600 \mathrm{~cm}^{-1}$ may be taken to be indicative of structurally complex anions of low symmetry. Further detailed interpretations can be made only as $\mathrm{x}$-ray structural data become available for more of the borates.

The authors are indebted to E. R. Lippincott for valuable suggestions.

\section{References}

[1] S. Anderson, R. Bohan, and D. Kimpton, J. Am. Ceram. Soc. 38, 370 (1955).

[2] H. Bauer, Z. anorg alleg. Chem. 320, 306 (1963).

[3] S. V. Berger, Acta Chem. Scan. 4, 1054 (1950).

[4] S. V. Berger, Acta Cryst. 5, 389 (1952).

[5] S. V. Berger, Acta Chem. Scan. 3, 660 (1949).

[6] S. Block, G. Burley, A. Perloff, and R. D. Mason, Jr., J. Research NBS 62, 95 (1959)

[7] S. Block, A. Perloff, and C. Weir, Acta Cryst. 17, 314 (1964).

[8] A. Buchler and E. P. Marram, J. Chem. Phys. 39, 292 (1963).

[9] E. T. Carlson, BS J. Res. 9, 825 (1932).

[10] H. M. Davis and M. A. Knight, J. Am. Ceram. Soc. 28, 97 (1945).

[11] J. C. Decius, J. Chem. Phys. 23, 1290 (1955).

[12] S. M. Fang, Z. Krist. 99, 1 (1938).

[13] R. F. Geller and E. N. Bunting, J. Research NBS 18, 585 (1937).

[14] J. Goubeau and D. Hummel, Z. Physik. Chem. 20, 15 (1959).

[15] J. Goubeau and H. Keller, Z anorg. alleg. Chem. 272, 303 (1953)

[16] W. D. Hand and J. Krogh-Moe, J. Am. Ceram. Soc. 45, 197 (1962).

[17] D. E. Harrison and F. A. Hummel, J. Electrochem. Soc. 103, 496 (1956).

[18] P. B. Hart and S. E. F. Smallwood, J. Inorg. Nucl. Chem. 24, 1047 (1962).

[19] G. Herzberg, Molecular Spectra and Molecular Structure, II, Infrared and Raman Spectra of Polyatomic Molecules (D. Van Nostrand Co., Inc., New York, N.Y. 1949).
[20] C. Hirayama and E. C. Subbarao, Phys. Chem. Glasses 3, 111 (1962)

[21] E. Hohne and L. Kutschabsky, Z. Chem. 1, 33 (1963).

[22] E. Ingerson, G. Morey, and O. F. Tuttle, Am. J. Sci. 246, 38 (1948).

[23] P. F. Konovalov, Dokl. Akad. Nauk. SSSR y0, 849 (1950).

[24] J. Krogh-Moe, Z. Krist. 11\%, 166 (1962).

[25] J. Krogh-Moe, Arkiv f. Kemi 12, 475 (1958).

[26] J. Krogh-Moe, Arkiv f. Kemi 12, 247 (1958).

[27] J. Krogh-Moe, Arkiv f. Kemi 14, 439 (1959).

[28] J. Krogh-Moe, Acta Cryst. 15, 190 (1962).

[29] J. Krogh-Moe, Acta Cryst. 13, 889 (1960).

[30] H. Lehmann and D. Tiess, Chem. Tech. 11, 260 (1959).

[31] E. M. Levin, R. S. Roth, and J. B. Martin, Am. Mineral. 46, 1030 (1961).

[32] E. M. Levin and C. L. McDaniel, J. Am. Ceram. Soc. 45, 355 (1962).

[33] E. M. Levin, C. R. Robbins, and J. L. Waring, J. Am. Ceram. Soc. 44, 87 (1961).

[34] E. M. Levin and H. F. McMurdie, J. Research NBS 42, 131 (1949).

[35] E. M. Levin and C. L. MeDaniel (private communication).

[36] M. Marezio, H. A. Plettinger, and W. H. Zachariasen, Acta Cryst. 16, 390 (1963).

[37] M. Marezio, H. A. Plettinger, and W. H. Zachariasen, Acta Cryst. 16, 594 (1963).

[38] C. Mazzetti and F. de Carli, Gazz. chim. ital. 56, 23 (1926).

[39] F. A. Miller and C. H. Wilkins, Anal. Chem. 24, 1253 (1952)

[40] G. W. Morey and H. E. Merwin, J. Am. Chem. Soc. 58, 2248 (1936)

[41] M. E. Mrose, Geol. Soc. Am., Program Annual Meetings 1961, p. 111

[42] A. Perloff and P. Shumate (private communication).

[43] P. J. Ring and P. J. Bray, Bull. Am. Phys. Soc. 9, 24 (1964).

[44] A. P. Rollet, Compt. Ren. 200, 1763 (1935).

[45] A. P. Rollet and R. Bouaziz, Compt. rend. 240, 2418 (1955).

[46] B. S. R. Sastry and F. A. Hummel, J. Am. Ceram. Soc. 41, 7 (1958).

[47] H. Scholze, Z. anorg. Chem. 284, 272 (1956).

[48] R. Schroeder, C. E. Weir, and E. R. Lippincott, J. Research NBS 66A, 407 (1962).

[49] G. E. R. Schulze, Z. Physik Chem. (B) 24, 215 (1934).

[50] P. Smith, S. Garcia-Blanco and L. Rivoir, Ann. Fisica Quim. 5\%A, 263 (1961).

[51] P. Smith, S. Garcia-Blanco and L. Rivoir, Z. Krist. 115, 460 (1961).

[52] W. C. Steele and J. C. Decius, J. Chem. Phys. 25, 1184 (1956).

[53] E. C. Subbarao and F. A. Hummel, J. Electrochem. Soc. 103, 29 (1956).

[54] Y. Takeuchi, Acta Cryst. 5, 574 (1952).

[55] Y. Takeuchi, Mineral. J. (Japan) 2, 245 (1958).

[56] C. E. Weir and A. Van Valkenburg, J. Research NBS 64A, 103 (1960).

[57] C. E. Weir and E. R. Lippincott, J. Research NBS 65A, 173 (1961).

[58] W. H. Zachariasen, Pro. Nat. Acad. Sci. 17, 617 (1931).

[59] W. H. Zachariasen and G. E. Ziegler, Z. Krist. 83, 354 (1932).

[60] W. H. Zachariasen, J. Chem. Phys. 5, 919 (1937).

[61] A. I. Zaspavskii and R. A. Zvinchuk, Doklad. Akad. Nauk. SSSR 90, 781 (1953). 